
\title{
$\mathrm{UNLV} \mid \underset{\text { LIBRARIES }}{\mathrm{UNIVRSTY}}$
}

UNLV Retrospective Theses \& Dissertations

$1-1-2004$

\section{Thermohydraulic and nuclear modeling of natural fission reactors}

Jason Charles Viggato

University of Nevada, Las Vegas

Follow this and additional works at: https://digitalscholarship.unlv.edu/rtds

\section{Repository Citation}

Viggato, Jason Charles, "Thermohydraulic and nuclear modeling of natural fission reactors" (2004). UNLV Retrospective Theses \& Dissertations. 2581.

http://dx.doi.org/10.25669/j64p-3nct

This Dissertation is protected by copyright and/or related rights. It has been brought to you by Digital Scholarship@UNLV with permission from the rights-holder(s). You are free to use this Dissertation in any way that is permitted by the copyright and related rights legislation that applies to your use. For other uses you need to obtain permission from the rights-holder(s) directly, unless additional rights are indicated by a Creative Commons license in the record and/or on the work itself.

This Dissertation has been accepted for inclusion in UNLV Retrospective Theses \& Dissertations by an authorized administrator of Digital Scholarship@UNLV. For more information, please contact digitalscholarship@unlv.edu. 


\title{
THERMOHYDRAULIC AND NUCLEAR MODELING OF NATURAL FISSION REACTORS
}

by

\author{
Jason Charles Viggato \\ Bachelor's Degree \\ State University of New York College at Buffalo \\ 1996 \\ Master of Science \\ University of Nevada, Las Vegas \\ 1998
}
Doctor of Philosophy Degree in Mechanical Engineering Department of Mechanical Engineering Howard R. Hughes College of Engineering

\author{
Graduate College \\ University of Nevada, Las Vegas
}
May 2004


UMI Number: 3143394

\title{
INFORMATION TO USERS
}

The quality of this reproduction is dependent upon the quality of the copy submitted. Broken or indistinct print, colored or poor quality illustrations and photographs, print bleed-through, substandard margins, and improper alignment can adversely affect reproduction.

In the unlikely event that the author did not send a complete manuscript and there are missing pages, these will be noted. Also, if unauthorized copyright material had to be removed, a note will indicate the deletion.

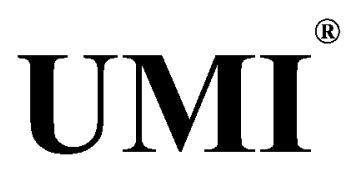

UMI Microform 3143394

Copyright 2004 by ProQuest Information and Learning Company.

All rights reserved. This microform edition is protected against unauthorized copying under Title 17, United States Code.

\author{
ProQuest Information and Learning Company \\ 300 North Zeeb Road \\ P.O. Box 1346 \\ Ann Arbor, MI 48106-1346
}


$\underline{\mathrm{UNLV}}$

\section{Thesis Approval}

The Graduate College

University of Nevada, Las Vegas

January 23 $20 \underline{04}$

The Thesis prepared by

Natachai Wongchavalidkul

\section{Entitled}

Aralysis of Factors Related to Pedestrian High Crash Locations

is approved in partial fulfillment of the requirements for the degree of

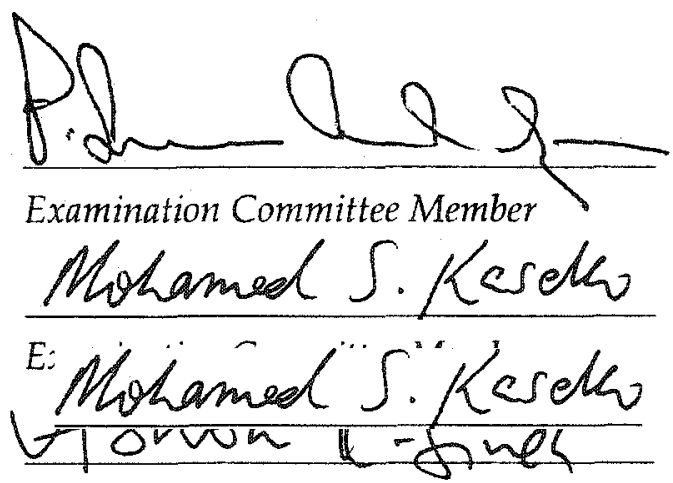

Graduate College Faculty Representative

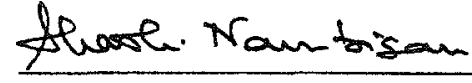

Examination Committee Chair

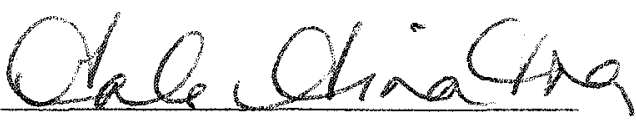

Dean of the Graduate College 


\title{
ABSTRACT \\ Thermohydraulic and Nuclear Modeling of Natural Fission Reactors
}

by

\author{
Jason C. Viggato \\ Dr. William Culbreth, Examination Committee Chair \\ Professor of Mechanical Engineering \\ University of Nevada, Las Vegas
}

Experimental verification of proposed nuclear waste storage schemes in geologic repositories is not possible, however, a natural analog exists in the form of ancient natural reactors that existed in uranium-rich ores. Two billion years ago, the enrichment of natural uranium was high enough to allow a sustained chain reaction in the presence of water as a moderator. Several natural reactors occurred in Gabon, Africa and were discovered in the early 1970 's. These reactors operated at low power levels for hundreds of thousands of years. Heated water generated from the reactors also leached uranium from the surrounding rock strata and deposited it in the reactor cores. This increased the concentration of uranium in the core over time and served to "refuel" the reactor. This has strong implications in the design of modern geologic repositories for spent nuclear fuel. The possibility of accidental fission events in man-made repositories exists and the geologic evidence from Oklo suggests how those events may progress and enhance local concentrations of uranium.

Based on a review of the literature, a comprehensive code was developed to model the thermohydraulic behavior and criticality conditions that may have existed in the Oklo 
reactor core. A two-dimensional numerical model that incorporates modeling of fluid flow, temperatures, and nuclear fission and subsequent heat generation was developed for the Oklo natural reactors.

The operating temperatures ranged from about $456 \mathrm{~K}$ to about $721 \mathrm{~K}$. Critical reactions were observed for a wide range of concentrations and porosity values ( 9 to 30 percent $\mathrm{UO}_{2}$ and 10 to 20 percent porosity). Periodic operation occurred in the computer model prediction with $\mathrm{UO}_{2}$ concentrations of 30 percent in the core and 5 percent in the surrounding material. For saturated conditions and 30 percent porosity, the model predicted temperature transients with a period of about 5 hours. Kuroda predicted 3 to 4 hour durations for temperature transients. The large instantaneous jumps in temperature could be an indication of the violent ejection of water that Kuroda predicted, resulting in ongoing geyser activity. The range of temperatures simulated by the computer model within the Oklo reactors agreed with evidence from the Oklo geology. 


\section{SYMBOLS}

\begin{tabular}{|c|c|}
\hline A & area $\left(\mathrm{m}^{2}\right)$ \\
\hline$A_{p}$ & area of pore $\left(\mathrm{m}^{2}\right)$ \\
\hline $\mathrm{A}_{V}$ & Avagadro's Number \\
\hline$A_{w}$ & Atomic weight $(\mathrm{u})$ \\
\hline B & buckling \\
\hline$c_{p}$ & specific heat $(\mathrm{kJ} / \mathrm{kg} \mathrm{K})$ \\
\hline $\mathrm{c}_{\mathrm{pf}}$ & specific heat of fluid ( $\mathrm{kJ} / \mathrm{kg} \mathrm{K}$ ) \\
\hline$c_{\mathrm{ps}}$ & specific heat of rock $(\mathrm{kJ} / \mathrm{kg} \mathrm{K})$ \\
\hline C.S. & control surface \\
\hline C.V. & control volume \\
\hline$D_{\mathrm{f}}$ & fast neutron diffusion (m) \\
\hline$D_{\text {th }}$ & thermal neutron diffusion $(\mathrm{m})$ \\
\hline $\mathrm{E}$ & energy $(J)$ \\
\hline$f$ & thermal utilization factor \\
\hline $\mathrm{g}$ & gravity constant $\left(\mathrm{m} / \mathrm{s}^{2}\right)$ \\
\hline G & fission constant ( $\mathrm{MeV} /$ fission) \\
\hline $\mathrm{i}$ & $\mathrm{x}$ coordinate \\
\hline j & y coordinate \\
\hline $\mathrm{k}_{\mathrm{a}}$ & apparent thermal conductivity $(\mathrm{W} / \mathrm{m} \mathrm{K})$ \\
\hline$k_{\text {eff }}$ & effective neutron multiplication factor \\
\hline
\end{tabular}


$k_{\mathrm{f}}$

$k_{\infty}$

$k_{s}$

1

$\mathbb{L}_{\mathrm{s}}$

$\mathrm{m}$

m

K

N

n

n

$\mathrm{p}$

P

$\mathrm{p}_{\mathrm{r}}$

$\mathrm{P}_{\mathrm{NL}}$

q"

$q_{s} "$

$Q$

r

S

$\mathfrak{t}$

$\mathrm{t}_{1 / 2}$

$\mathrm{T}$ thermal conductivity of fluid $(W / m \mathbb{K})$

infinite neutron multiplication factor

thermal conductivity of rock $(\mathrm{W} / \mathrm{m} \mathbb{K})$

effective neutron life (s)

slowing down length (m)

$\operatorname{mass}(\mathrm{kg})$

mass flow rate $\left(\mathrm{kg} / \mathrm{m}^{3}\right)$

permeability (darcy)

number density (atoms $/ \mathrm{kg}^{3}$ )

number of neutrons

normal vector

pressure (MPa)

power (W)

resonance escape probability

non-leakage probability

source generation per unit area $\left(\mathrm{W} / \mathrm{m}^{2}\right)$

source generation per unit volume $\left(\mathrm{W} / \mathrm{m}^{3}\right)$

heat (J)

relaxation factor

neutron source (neutrons $/ \mathrm{m}^{\wedge} 2$ )

time (s)

half-life (s)

temperature $(\mathbf{K})$ 


$\begin{array}{ll}\mathrm{T}_{\mathrm{r}} & \text { period of reactor }(\mathrm{s}) \\ \mathrm{u} & \mathrm{x} \text { velocity }(\mathrm{m} / \mathrm{s}) \\ \mathrm{U} & \text { internal energy }(\mathrm{kJ} / \mathrm{kg}) \\ \mathrm{v} & \mathrm{y} \text { velocity }(\mathrm{m} / \mathrm{s}) \\ \mathrm{V} & \text { velocity }(\mathrm{m} / \mathrm{s}) \\ \mathrm{W} & \text { thickness }(\mathrm{m}) \\ \dot{W} & \text { work }(\mathrm{J}) \\ \mathrm{X} & \text { element } \\ \mathrm{z} & \text { height }(\mathrm{m}) \\ \mathrm{Z} & \text { number of protons }\end{array}$

Greek Symbols

$\begin{array}{ll}\alpha & \text { angle (degrees) } \\ \nabla & \text { del operator } \\ \varepsilon & \text { fast fission factor } \\ \phi & \text { porosity } \\ \eta & \text { reproduction factor } \\ \lambda & \text { decay constant } \\ \mu_{\mathrm{f}} & \text { dynamic viscosity of fluid }(\mathrm{kg} / \mathrm{m} \mathrm{s}) \\ \pi & \text { pi } \\ \theta & \text { angle (degrees) } \\ \rho & \left.\text { density ( } \mathrm{kg} / \mathrm{m}^{3}\right) \\ \rho_{\mathrm{c}} & \text { reactivity (dollars) } \\ \rho_{\mathrm{f}} & \text { density of fluid }\left(\mathrm{kg} / \mathrm{m}^{3}\right)\end{array}$




\begin{tabular}{|c|c|}
\hline$\rho_{\mathrm{s}}$ & density of rock $\left(\mathrm{kg} / \mathrm{m}^{3}\right)$ \\
\hline$\sigma_{\mathfrak{a}}$ & absorption cross section $\left(\mathrm{m}^{2}\right)$ \\
\hline$\sigma_{\mathrm{s}}$ & scattering cross section $\left(\mathrm{m}^{2}\right)$ \\
\hline$\sigma_{\mathrm{se}}$ & elastic scattering cross section $\left(\mathrm{m}^{2}\right)$ \\
\hline$\sigma_{\mathrm{si}}$ & inelastic scattering cross section $\left(\mathrm{m}^{2}\right)$ \\
\hline$\sigma_{\mathrm{T}}$ & total absorption cross section $\left(\mathrm{m}^{2}\right)$ \\
\hline$\tau$ & volume $\left(\mathrm{kg} / \mathrm{m}^{3}\right)$ \\
\hline$\psi$ & stream function $\left(\mathrm{m}^{2} / \mathrm{s}\right)$ \\
\hline$\Phi$ & neutron flux (neutrons $/ \mathrm{m}^{2} \mathrm{~s}$ ) \\
\hline$\Phi_{\mathrm{f}}$ & neutron flux of fast neutrons (neutrons $/ \mathrm{m}^{2} \mathrm{~s}$ ) \\
\hline$\Phi_{\text {th }}$ & neutron flux of thermal neutrons (neutrons $/ \mathrm{m}^{2} \mathrm{~s}$ ) \\
\hline$\Sigma_{\mathrm{f}}$ & macroscopic fission cross section $\left(\mathrm{m}^{2} / \mathrm{m}^{3}\right)$ \\
\hline$\Sigma_{\mathrm{s}}$ & macroscopic scattering cross section $\left(\mathrm{m}^{2} / \mathrm{m}^{3}\right)$ \\
\hline$\Sigma_{\mathrm{T}}$ & total macroscopic cross section $\left(\mathrm{m}^{2} / \mathrm{m}^{3}\right)$ \\
\hline
\end{tabular}




\section{TABLE OF CONTENTS}

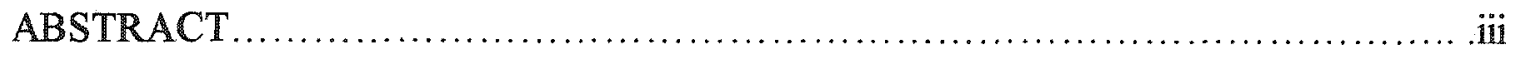

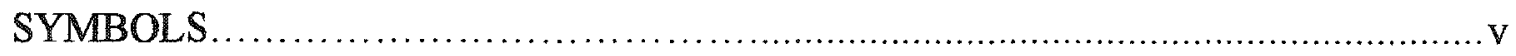

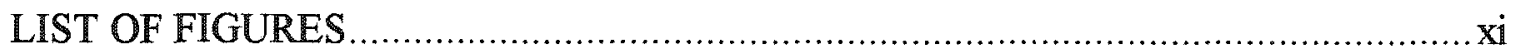

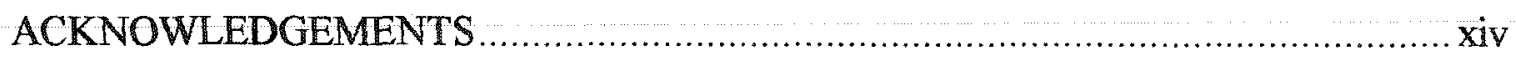

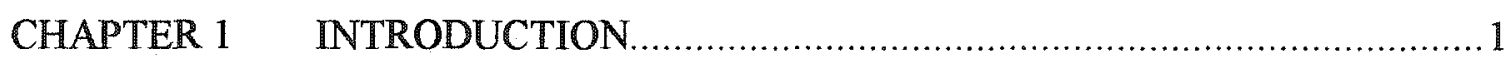

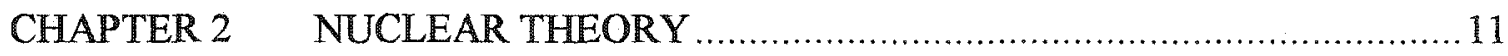

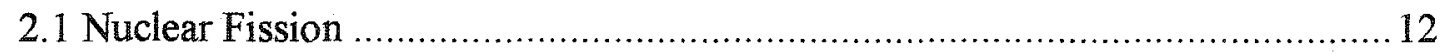

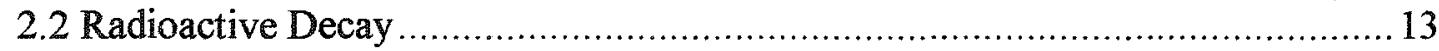

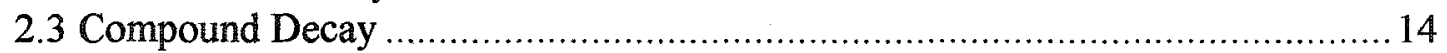

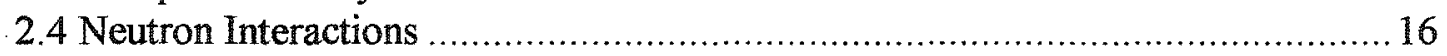

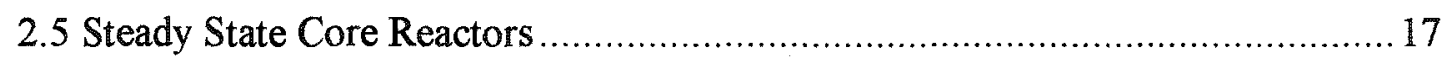

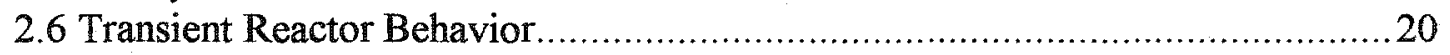

2.7 Analytical Solution of Transient Flux Distribution on a Flat Plate....................22

CHAPTER 3 CONSERVATION PRINCIPLES THEORY ......................................

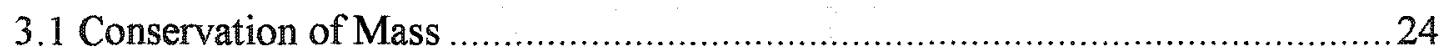

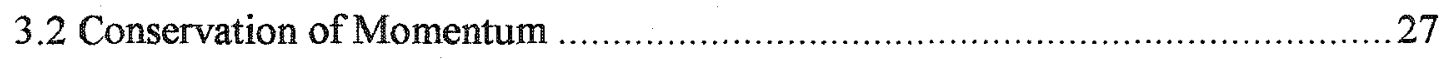

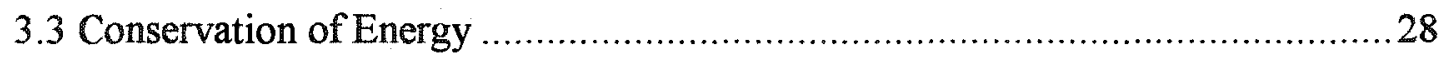

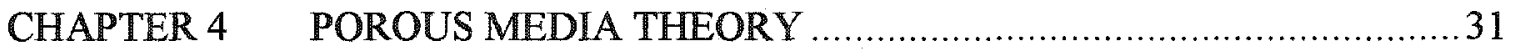

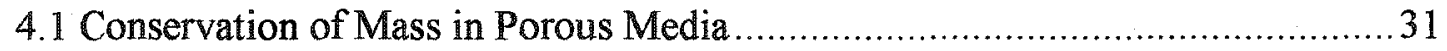

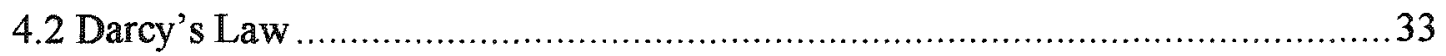

CHAPTER 5 HEAT TRANSFER AND FLUID FLOW THEORY .......................38

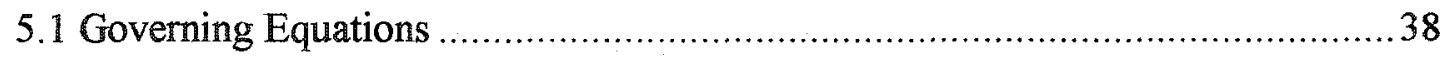

5.2 Analytical Solution of the Steady State Heat Transfer on a Two-dimensional

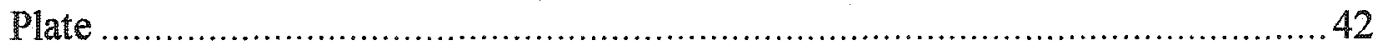

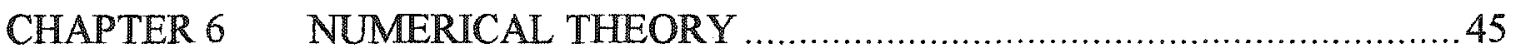

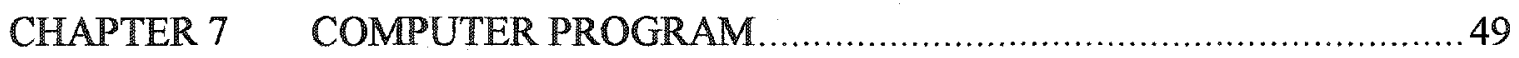

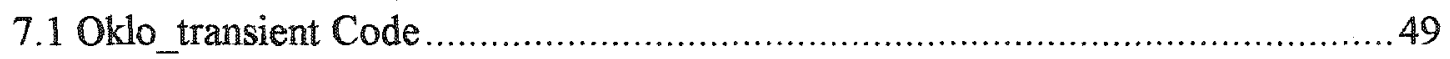

7.2 Verification of Transient Neutron Flux Diffusion on a Flat Plate .......................51

7.3 Verification of Steady State Heat Conduction on a Flat Plate ...........................55

ix 
7.4 Verification of Transient Mass Transfer on a Flat Plate .59

CHAPTER 8 DISCUSSION OF RESULTS ........................................... 61

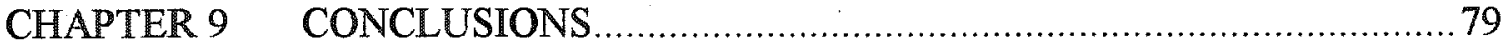

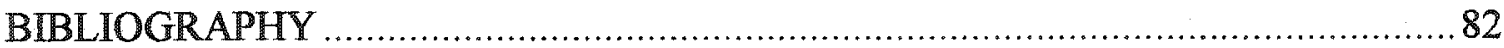

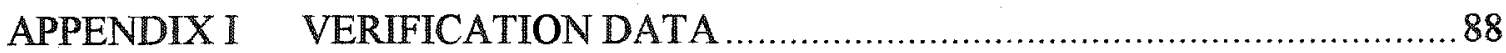

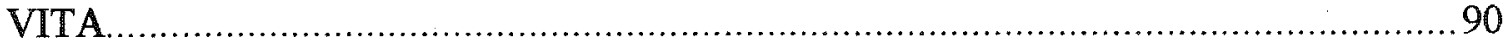




\section{LIST OF FIGURES}

Figure 1.1 Location of the Oklo Natural Fission Reactors (USGS) .......................4

Figure 2.1 ${ }^{235} \mathrm{U}$ Fission Resulting in ${ }^{90} \mathrm{Rb},{ }^{143} \mathrm{Cs}$ and Neutrons.......................... 13

Figure 2.2 TwoDimensional Transient Neutron Flux Distribution on

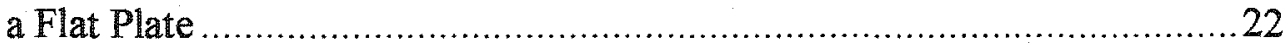

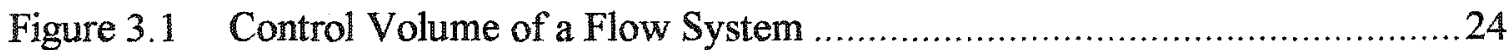

Figure 3.2 Continuity of Flow in a Control Volume ......................................... 26

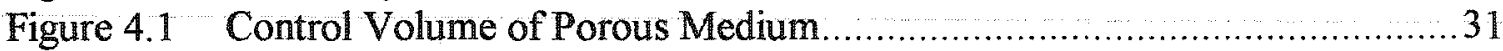

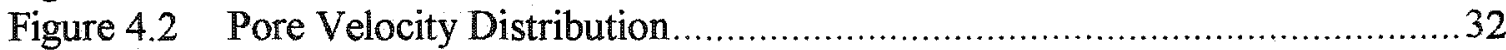

Figure 4.3 One-dimensional Flow in a Column of Porous Medium .............................34

Figure 4.4 One-dimensional Fluid Flow Through a Pore .........................................35

Figure 5.1 Two-dimensional Steady Heat Conduction on a Flat Plate........................42

Figure 6.1 Central Difference Scheme .........................................................45

Figure 7.1 Contour Plot of the Transient Neutron Flux for the Analytical

Solution on a Flat Plate at 10 seconds...............................................5. 52

Figure 7.2 Surface Plot of the Transient Neutron Flux Surface Plot for the Analytical Solution on a Flat Plate at 10 seconds ...............................52

Figure 7.3 Oklo transient Code - Transient Neutron Flux Contour Plot on a Flat Plate at 10 seconds............................................................5 53

Figure 7.4 Oklo_transient Code - Transient Neutron Flux Surface Plot on a Flat Plate at 10 seconds.........................................................5 53

Figure 7.5. Percent Error of Oklo transient Neutron Flux vs. Analytical Solution Surface Plot Across the Flat Plate

Figure 7.6 Error in Neutron Flux between Oklo transient and the Analytical Solution

Figure 7.7 Contour Plot for the Steady State Temperature Distribution for the Analytical Solution of Conduction on a Flat Plate .56

Figure 7.8 Surface Plot of the Steady State Temperature Distribution for the Analytical Solution of Conduction on a Flat Plate ......................56

Figure 7.9 Oklo_transient Code-Contour Plot of the Steady State Temperature Distribution for Conduction on a Flat Plate

Figure 7.10 Oklo transient Code-Surface Plot of the Steady State Temperature Distribution for Conduction on a Flat Plate

Figure 7.11 Contour Plot Percent Error of Oklo transient vs. Analytical

Solution Contours Across the Flat Plate.

Figure 7.12 Percent Error of Oklo_transient vs. Analytical Solution

Surface Plot Across the Flat Plate. 58

Figure 8.1 Control Volume Representation of the Oklo Reactor ............................61

Figure 8.2 Verification of Spatial and Time Dependence for Temperatures at the Center of the Reactor. 
Figure 8.3 Temperatures for 9 Percent Concentration at the core and 5

Percent in Surrounding Areas of $\mathrm{UO}_{2}$ for varying Sandstone

Porosity for the Center of the Reactor.

Figure 8.4 Temperatures for 15 Percent Concentration at the core and 5

Percent in Surrounding Areas of $\mathrm{UO}_{2}$ for varying Sandstone

Porosity for the Center of the Reactor.

Figure 8.5 Temperatures for 30 Percent Concentration at the core and 5

Percent in Surrounding Areas of $\mathrm{UO}_{2}$ for varying Sandstone

Porosity for the Center of the Reactor.

Figure 8.6 Stream Function Surface Plot for 20,000 seconds $15 \% \mathrm{UO}_{2}$

- core, $5 \% \mathrm{UO}_{2}$ - surrounding and $20 \%$ porosity.

Figure 8.7 Stream Function Surface Plot for 40,000 seconds $15 \% \mathrm{UO}_{2}$

- core, $5 \% \mathrm{UO}_{2}$ - surrounding and $20 \%$ porosity

Figure 8.8 Stream Function Surface Plot for 60,000 seconds $15 \%$ UO2

- core, $5 \%$ UO2 - surrounding and $20 \%$ porosity

Figure 8.9 Stream Function Surface Plot for 80,000 seconds $15 \% \mathrm{UO}_{2}$

- core, $5 \% \mathrm{UO}_{2}$ - surrounding and $20 \%$ porosity ....

Figure 8.10 Stream Function Surface Plot for 100,000 seconds $15 \% \mathrm{UO}_{2}$

- core, $5 \% \mathrm{UO}_{2}$ - surrounding and $20 \%$ porosity

Figure 8.11 Temperature Surface Plot for 20,000 seconds $15 \%$ UO2

- core, $5 \%$ UO2 - surrounding and $20 \%$ porosity

Figure 8.12 Temperature Surface Plot for 40,000 seconds $15 \%$ UO2 - core, $5 \%$ UO2 - surrounding and $20 \%$ porosity

Figure 8.13 Temperature Surface Plot for 60,000 seconds $15 \%$ UO2

- core, $5 \%$ UO2 - surrounding and $20 \%$ porosity

Figure 8.14 Temperature Surface Plot for 80,000 seconds $15 \%$ UO2

- core, $5 \%$ UO2 - surrounding and $20 \%$ porosity

Figure 8.15 Temperature Surface Plot for 100,000 seconds $15 \%$ UO2

- core, $5 \%$ UO2 - surrounding and $20 \%$ porosity

Figure 8.16 Neutron Flux Surface Plot for 20,000 seconds $15 \%$ UO2

- core, $5 \%$ UO2 - surrounding and $20 \%$ porosity

Figure 8.17 Neutron Flux Surface Plot for 40,000 seconds $15 \%$ UO2

- core, $5 \%$ UO2 - surrounding and $20 \%$ porosity

Figure 8.18 Neutron Flux Surface Plot for 60,000 seconds $15 \%$ UO2

- core, $5 \%$ UO2 - surrounding and $20 \%$ porosity ............................. 74

Figure 8.19 Neutron Flux Surface Plot for 80,000 seconds $15 \%$ UO2

- core, $5 \%$ UO2 - surrounding and $20 \%$ porosity

Figure 8.20 Neutron Flux Surface Plot for 100,000 seconds $15 \%$ UO2

- core, $5 \%$ UO2 - surrounding and $20 \%$ porosity ....

Figure 8.21 Pressure Surface Plot for 20,000 seconds $15 \%$ UO2 - core,

$5 \%$ UO2 - surrounding and $20 \%$ porosity

Figure 8.22 Pressure Surface Plot for 40,000 seconds $15 \%$ UO2 - core,

$5 \% \mathrm{UO} 2$ - surrounding and $20 \%$ porosity

Figure 8.23 Pressure Surface Plot for 60,000 seconds $15 \%$ UO2 - core,

$5 \%$ UO2 - surrounding and $20 \%$ porosity

Figure 8.24 Pressure Surface Plot for 80,000 seconds $15 \%$ UO2 - core, 
$5 \%$ UO2 - surrounding and $20 \%$ porosity

Figure 8.25 Pressure Surface Plot for 100,000 seconds $15 \%$ UO2 - core,

$5 \%$ UO2 - surrounding and $20 \%$ porosity

Figure 9.1 Operating Temperature Range Comparison to Previous Studies 


\section{ACKNOWLEDGEMENTS}

I would like to take the time once again to thank my entire family, especially my motherGail Viggato, father- Charles Viggato and brother- Jeff Viggato for the continued support needed to accomplish the requirements for the Doctor of Philosophy degree. I would like to also thank my advisor William Culbreth, Ph.D. for the many hours of time, guidance and advice throughout the entire course of study and research. I would like to thank the late Paul "Doc" Culkowski, Ph.D. for his guidance and help during some trying times as an undergraduate. It is largely due to him that I am still pursuing Mechanical Engineering. 


\section{CHAPTER 1}

\section{INTRODUCTION}

Since the discovery and use of atomic energy, there has been an enormous problem with the disposition of waste products produced by radioactive material. Over the last five decades, the use of radioactive material for both military purposes and the peaceful use for power generation, has generated large amounts of radioactive waste. Unfortunately, these by-products have extremely long half-lives, and can remain dangerous for thousands of years. One purposed way to deal with this waste is through use of a permanent, long-term underground storage facility known as a "geologic repository".

Extensive research has been done over the years to find a location suitable to safely store high level radioactive waste. For a potential site to be considered, many factors must be examined. Some of the factors in deciding the suitability of a site are the geologic characteristics, such as faults, fissures or volcanic areas, level of the water table in the area, and the climate to name a few.

Since a geologic repository for high-level waste has never been constructed, there is no previous experimental data for the repository as a whole. This leads to many uncertainties, such as the effects that water infiltration will have, how the nuclear waste will behave after canister degradation, and the manner in which radioactive species will 
migrate. This lack of experimental data leads to the use of natural analogs to provide answers.

In 1956, J. P. Kuroda, a radiochemist at the University of Arkansas, predicted that the natural enrichment of uranium in the earth's distant past would have been sufficient to sustain a nuclear chain reaction (fission) to occur in water-saturated uranium ores. Kuroda indicated that sites rich in uranium around the world could be investigated to determine whether nuclear fission had occurred in the earth's geologic past.

Natural uranium is composed primarily of two isotopes, fissionable ${ }^{235} \mathrm{U}$ and nonfissionable ${ }^{238} \mathrm{U}$. Worldwide, the enrichment, or relative abundance, of naturallyoccurring uranium is $0.714 \%$. To manufacture commercial reactor fuel, uranium must be "enriched" to bring this ratio up to about $3 \%$ in order to sustain a fission chain reaction in the presence of water. Due to the relative short half-life of ${ }^{235} \mathrm{U}$, Kuroda was able to predict that 2 billion years ago, the natural enrichment of uranium on the earth was about $3 \%$. This corresponds closely to the enrichment of modern pressurized water reactor fuel.

On June 7, 1972, H. Bouzigne, R.J.M. Boyer, C. Seyve, and P. Teulieres at the French Atomic Energy Establishment at Pierrelatte witnessed an anomaly in the abundance of the fissionable isotope $U^{235}$ in a uranium sample from the Oklo mine in the Republic of Gabon, Africa. The abundance of ${ }^{235} \mathrm{U}$ in this sample was 0.7171 atompercent, as opposed to the normal value of $0.7202 \pm 0.0010$ in naturally occurring uranium.

Between December 1970 and May 1972, samples of uranium ore that were extracted from the Oklo site were lower in total ${ }^{235} \mathrm{U}$ by $200 \mathrm{~kg}$. These samples of uranium also 
contained an extremely low abundance of ${ }^{235} \mathrm{U}(0.440$ percent $)$ and oddly contained the fission products neodymium and samarium indicating that nuclear fission had occurred in the ore at sometime in the earth's past.

Using the facts listed above, it was determined that a self-sustaining nuclear reactor occurred at the Oklo site approximately two billion years ago. These natural nuclear reactors contained layers of very rich uranium ore "sandwiched" between layers of nearly impermeable clay on the top and bottom. The reactors, contained more than 500 tons of uranium, and may have released as much as $10^{11}$ kilowatt-hours of energy. Neutron flux at various points in the reactor may have exceeded $1.5 \times 10^{21}$ neutrons $/ \mathrm{cm}^{2}$ sec. Samples have also been found that contained a concentration of ${ }^{235} \mathrm{U}$ as low as 0.29 percent, as compared with the standard 0.72 percent concentration found in natural uranium.

Further studies had concluded that Kuroda's earlier theory that natural reactors existed was not only correct, but operated for a period as long as 600 thousand to 1.5 million years. The reactor had uranium with enrichments exceeding 3 percent, and remained critical with the presence of water as a moderator, until the enrichment decreased below 1.5 percent. 


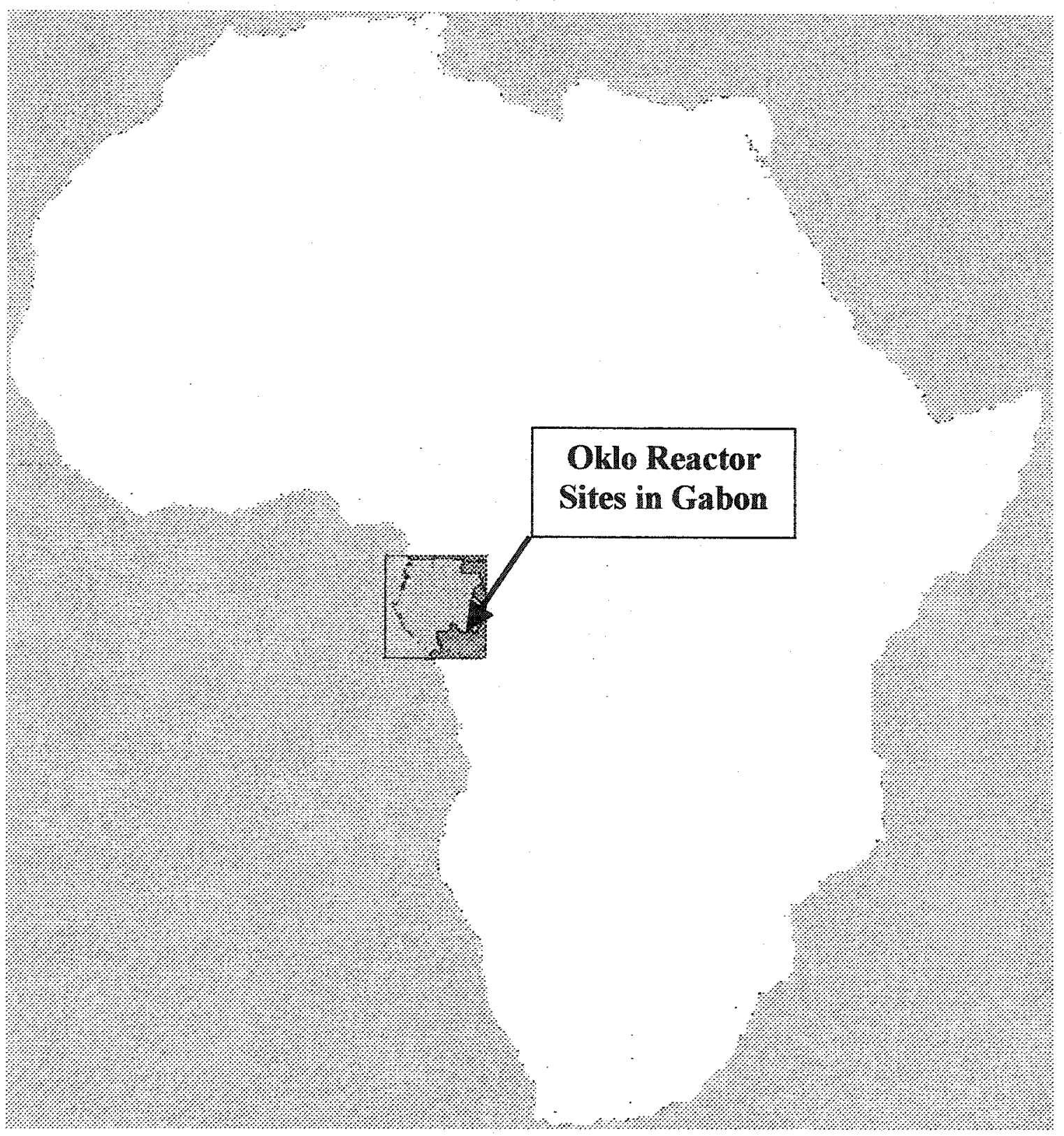

Figure 1.1 Location of the Oklo Natural Fission Reactors 
Naudet (1976) demonstrated that spontaneous criticality can occur in high-grade sandstone ore when the uranium concentration is about $10 \%$ for a layer two meters thick. These ores are rare, but did exist in the Oklo natural reactor zone. "Therefore, fission reactions can begin in small volumes with the resulting heat-inducing convective circulation which causes desilicification and argillization of sandstones." (Naudet, 1976) The extremely hot fluid circulation may have resulted in leaching of uranium from the surrounding area as well as uranium migration, resulting in an increase of the concentration of fissionable material in the reactor zone. Areas that were depleted in uranium and that contained no fission products were discovered around the reactor zone. This is evidence that uranium migration occurred and that the result was a concentrated zone of uranium rich ore at the center of the reactor. "Thus, hydrothermal processes resulting from fission reactions produce an increase in uranium and support the on-going nuclear reactions." (Naudet, 1976)

Curtis and Gancarz (1983) studied radiolysis in nature, through use of the Oklo reactor geologic data. The natural reactor operating temperatures were found to be between $450^{\circ} \mathrm{C}$ and $600^{\circ} \mathrm{C}$. It was noted that the thermal effects of the reaction extended outward, producing lower temperatures out to a few meters. Curtis studied the transport of the fission products ruthenium and technetium, and concluded that they migrated out of the reactor core a few thousand years after the reactor stopped operating. He concluded that the fission products in the reactor must have been transported at temperatures between $100^{\circ} \mathrm{C}$ and $425^{\circ} \mathrm{C}$. Fluid inclusions in the reactor zone were used to study the pressures that occurred during time of the ongoing nuclear criticality. These inclusions revealed reactor operating pressures between 800 and 1070 bars. 
In a study performed by LaFaye-Gauthier and Weber (1989), the various isotopes and the processes of operation that occurred in the natural fission reactors of Oklo were investigated. "The main factors initializing the nuclear fission reactions are (1) a high uranium concentration, (2) a low content of poison elements (neutron-capturing nuclei such as boron and rare earth elements), (3) the presence of light nuclei (neutron moderators) such as hydrogen in water, and (4) a high concentration of fissionable nuclei in the uranium." Condition number (4) refers to the ratio of ${ }^{235} \mathrm{U}$ to ${ }^{238} \mathrm{U}$.

Analyses of the chemical composition in the reactor zones showed that the amounts of magnesium and uranium greatly exceeded the values in normal ore. These excessive amounts may have been increased by convective circulation during the reaction. An increase in the amount of uranium provides additional fissionable material, thus prolonging the life of the nuclear reaction. The occurrence of the nuclear reaction implies that high concentrations of uranium existed in zones prior to the convective circulation.

Brookins (1990) studied the radionuclide behavior of Oklo and some of the possible applications to radioactive waste management programs. Brookins found that noble gases $\mathrm{Kr}$ and $\mathrm{Xe}$, along with the alkali elements $\mathrm{Rb}$ and $\mathrm{Cs}$ also migrated from the host $\mathrm{UO}_{2}$. The mass spectrometer data suggests large amounts of the elements are fixed in the surrounding minerals.

Actinides such as $\mathrm{Th}, \mathrm{U}, \mathrm{Np}, \mathrm{Pu}$, and probably Am have not migrated from their original sites. A minor redistribution of $U$ was seen. All of the individual element migrations were consistent with predictions that could be made from Eh-pH diagrams an/or from crystal chemical and other theoretical interpretations. After two billion years 
most of the radionuclides and/or their decay products at Oklo have not migrated or have only migrated a few meters. Due to the temperature range observed (several hundred degrees $\mathrm{C}$ ), using Oklo as a natural analog to man-made radioactive waste management was logical.

Kuroda (1990) discussed the transient mode of operation for the natural reactor, which periodically shut down and then restarted. He suggests that the reactor operating temperature was in the range between the boiling point of iodine $\left(183^{\circ} \mathrm{C}\right)$ and the melting point of tellurium $\left(452^{\circ} \mathrm{C}\right)$. Xenon data obtained by Shukolyukov et al., was used to calculate the time interval in which the reactor operated within and then shutdown. This data yielded values of the period to be between about 3 to 4 hours. Kuroda notes the similarity of these values to the duration of the eruption (181 minutes) of the Big Geyser at the Naruko Hot Springs in Japan. These results indicate the natural reactors at Oklo may have behaved in a manner similar to that of modern geysers.

Cramer (1995) investigated another natural analogue in Northern Saskatchewan that possessed striking similarities to the Oklo natural reactors. The Cigar Lake deposit contained a high concentration of uranium ore situated between thick clay layers of clay, about 430 meters below the surface. The dominant uranium mineral in the deposit was natural $\mathrm{UO}_{2}$ (uraninite) which was similar in structure to the $\mathrm{UO}_{2}$ used in commercial reactor fuel.

The clay was shown to provide an effective barrier against the flow of ground water by sealing fissures and fractures, and only allowed diffusion across the interface. Observation of the Cigar Lake deposit shows that the large uranium rich layer (approximately 148,000 tons) has been well preserved for an extremely long time. This 
indicated that the clay barriers severely retard the migration of radionuclides from within the reactor zone. The Cigar Lake deposit, which was formed about 1.3 billion years ago, has withstood major geologic events such as earthquakes, erosion and glaciers for more than a billion years. The Cigar Lake natural reactor, like Oklo, has great implications in the behavior and possible migration of fission products from the core of the reactor to the surrounding areas.

Culbreth and Viggato (2000) conducted a study to determine the depth and pressure at which the Oklo natural reactors occurred. A nuclear criticality code was developed to replicate the conditions at Oklo. From the program, $k_{\infty}$, the infinite neutron multiplication factor was computed as a function of temperature and pressure. The functions were then curve-fitted and analyzed for the conditions that would have led to the minimum and maximum temperatures suggested by Kuroda and Holliger.

It was observed that reactor performance was heavily dependent on water density. As the temperature inside the reactor rose above $710^{\circ} \mathrm{K}$, superheated water would expand and the $k_{\infty}$ value would decrease. The decrease in the infinite neutron multiplication factor lead to a lower power output and cooling of the water inside the reactor. The minimum deviation occurred at values of $48.4 \mathrm{MPa}$ and $44 \mathrm{MPa}$ based on Kuroda and Holliger's data. This corresponds to two sets of depths depending on whether hydrostatic or lithostatic pressures occurred at reactor depth during operation. Curvefits showed that in order for a geologic reactor to operate between the geologic temperature and the upper temperature range, the pressures must have been hydrostatic corresponding to a depth of 4.5 to $4.8 \mathrm{~km}$. 
A computer model of Oklo has been developed to conduct parametric studies of the conditions that led to sustained fission. In this model, uranium concentrations, porosity, pore saturation, temperature and pressure within the core have been predicted based on the transient behavior. Transient behavior is extremely important in the operation of the reactor. After a study of the relative concentrations of radionuclides with the cores at Oklo, Kuroda indicated that the reactors operated with a periodic output. It was suggested that this may have resulted in the forceful ejection of superheated water from the reactors in the form of geysers. This water would have also contained fission products. If degradation of waste packages in a repository occurred and similar conditions existed, this could lead to the possible transport of radionuclides into the outside environment.

The theory used to compose the computer model has been taken from the areas of heat transfer and fluid flow within porous media. In addition to the flow in porous media, equations for nuclear criticality and thermodynamic properties of water at various temperatures of water have been used. A finite difference approach was used to model flow in and around the reactor. The equations for neutron flux, temperature, and fluid flow within the reactor zone were iteratively solved on a mesh of nodes.

The equations for conservation of mass, Darcy Flow, neutron generation and diffusion, and the energy equation were combined in the program to predict the long-term behavior of the Oklo reactors. Based on recent calculations of pressure within the critical reactors, water existed in a single phase as superheated steam. Geologic records have been studied and documented in the Oklo reactor, and through use of this data, a natural 
analogue for geologic repositories is proposed. The results of this work and the possible implications for the design of a geologic repository are presented. 


\section{CHAPTER 2}

\section{NUCLEAR THEORY}

The structure of an atom consists of protons, electrons and neutrons. The protons and neutrons reside at the center of the atom in the nucleus, while electrons orbit the nucleus in the surrounding shells. Protons are positively charged, electrons are negatively charged and neutrons posses no charge. Electrons have the smallest mass, while neutrons are slightly more massive than protons. The masses for a proton, neutron and an electron are $1.007276 \mathrm{u}, 1.008665 \mathrm{u}$, and $5.48580 \times 10^{-4} \mathrm{u}$ respectively. The unit for mass is one atomic mass unit $(\mathrm{u})$, which is equal to $1.660438 \times 10^{-27} \mathrm{~kg}$. An element's atomic number is given by the total number of protons in the nucleus. Atomic weight of an element is given by:

$$
A_{w}=n+Z
$$

where $\mathrm{n}$ is the number of neutrons and $\mathrm{Z}$ is the number of protons. Different elements may have different values of mass numbers, while still containing the same amount of protons. The differing atoms of the same element are known as isotopes. Natural uranium is an example of this, which has different isotopes listed below

$$
\begin{array}{ccc}
{ }_{92}^{234} U & 0.006 \% & \text { abundance } \\
{ }_{92}^{235} U & 0.714 \% & \text { abundance } \\
{ }_{92}^{238} U & 99.28 \% & \text { abundance }
\end{array}
$$




\subsection{Nuclear Fission}

"Abundance" is defined as the atom percentage of each isotope present in a naturally occurring mixture. The 234,235 and 238 listed above before the symbol for uranium (U) are the atomic weights of the various isotopes of uranium. It is shown that each isotope has the same number of protons (92 - atomic number) as stated previously in the definition of an isotope. Enrichment is defined as the artificial increasing of the abundance of an isotope. For example, the enrichment of uranium indicates the

percentage of ${ }^{235} \mathrm{U}$ present in a mixture of uranium isotopes. ${ }^{235} \mathrm{U}$ is the fissionable isotope and easily absorbs a slow neutron (thermal neutrons), which may then start a fission reaction. The 238 isotope of uranium is non-fissile, and therefore cannot sustain a fission reaction. The number density $(\mathrm{N})$, or number of atoms present of an individual element is

$$
N=\frac{\rho A_{v}}{A_{w}}
$$

where $\rho$ is the density of the material, and $A_{v}$ is Avagadro's number $\left(6.02252 \times 10^{26}\right.$ atoms per kilogram mole). (Foster and Wright, 1983)

A fission reaction occurs when a neutron strikes a fissionable nucleus and is captured. Fission, as shown in figure 2.1 , results in the emission of two or more neutrons, two large fission fragments, other subatomic particles, and significant energy. The fission products follow a statistical distribution that varies by fissionable isotope. Fission produces gamma radiation and kinetic energy that may be converted into heat to run a steam cycle to produce electricity. 


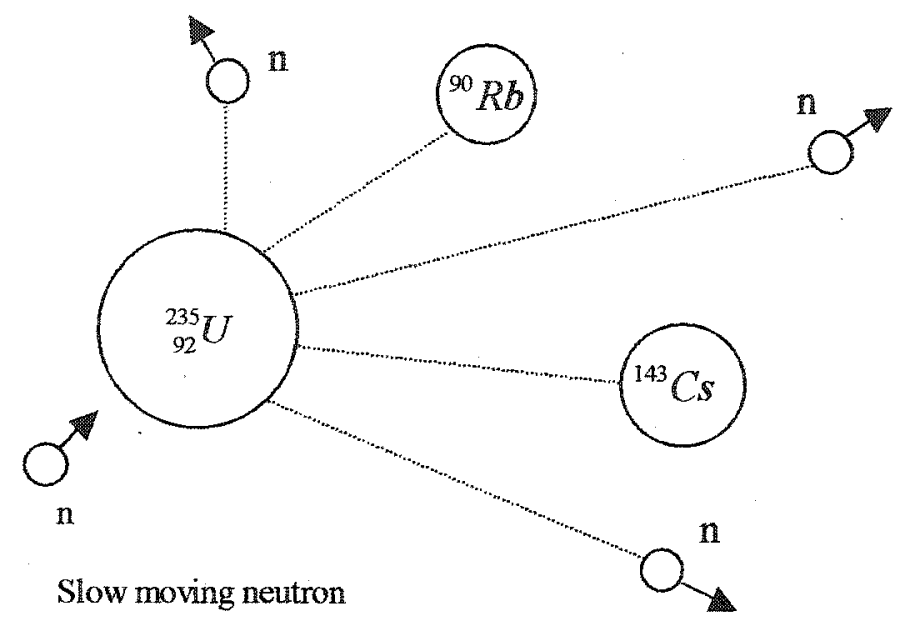

Figure $2.1{ }^{235} \mathrm{U}$ Fission Resulting in ${ }^{90} \mathrm{Rb},{ }^{143} \mathrm{Cs}$ and Neutrons

\subsection{Radioactive Decay}

Radioactivity is produced from the decay of unstable nuclei. Depending on the element, half-lives can be on the order of seconds or up to hundreds of millions of years. The lighter elements that result from the radioactive decay are known as daughter products. Decay of radioisotopes occurs in a random manner with a half-life that is specific to each isotope. $\lambda$, also known as the decay constant, is used to describe the probability that a certain fraction of the unstable nuclei will decay in a given time interval. The rate of decay is defined by the following differential equation

$$
\frac{d N}{d t}=-\lambda N
$$

where $N$ is the number of unstable nuclei present. This first order differential equation can be solved using separation of variables.

$$
\int_{N_{0}}^{N} \frac{d N}{N}=-\lambda \int_{0}^{t} d t
$$


$N_{0}$ represents the original number of unstable nuclei present at time zero and $\mathrm{N}$ is the number of unstable nuclei present at some time t. Integration of equation 2.4 yields

$$
\ln \left(\frac{N}{N_{0}}\right)=-\lambda t
$$

The equation for the for the amount of nuclei present at time $t$ is then solved for by taking the anti-log of both sides.

$$
N=N_{0} e^{-\lambda t}
$$

The half-life of a radioisotope is given by

$$
t_{1 / 2}=\frac{0.693}{\lambda}
$$

(Foster and Wright, 1983)

\subsection{Compound Decay}

Daughter products of a radioisotope are many times unstable, and decay to produce a third nuclide, which may also be unstable. To illustrate this phenomena, the case of an element decaying to an unstable daughter and then to a third stable isotope, is used to derive an expression to show the number of nuclei present for each element at some time

t. $N_{10}$ represents the number of nuclei of the parent element present at time zero and $N_{1}$ is the number of parent atoms with a decay constant $\lambda_{1}$ at any time $t$, then

$$
N_{1}=N_{10} e^{-\hat{\lambda} t}
$$

The rate of change of the parent nuclei is

$$
\frac{d N_{1}}{d t}=-N_{10} \lambda_{1} e^{-\lambda_{1} t}
$$


The rate of change of the daughter atoms, $\mathrm{dN}_{2} / \mathrm{dt}$ is defined as the number of parent atoms change with respect to time minus the decay of the daughter, which has it's own decay constant, $\lambda_{2}$.

$$
\begin{aligned}
\frac{d N_{2}}{d t} & =-\frac{d N_{1}}{d t}-\lambda_{2} N_{2} \\
& =\lambda_{1} N_{10} e^{-\lambda_{1} t}-\lambda_{2} N_{2}
\end{aligned}
$$

Rearranging leads to

$$
\frac{d N_{2}}{d t}+\lambda_{2} N_{2}=\lambda_{1} N_{10} e^{-\lambda_{1} t}
$$

which is an equation in the form of

$$
\frac{d y}{d x}+a_{1}(x) y=h(x)
$$

This first order ordinary differential equation can be solved through use of the integrating factor, $\mathrm{p}$.

$$
p=e^{\int a_{1}(x) d x}
$$

The solution to equation (2.12) is

$$
y=\frac{1}{p} \int p h(x) d x+\frac{C}{p}
$$

where $\mathrm{C}$ is a constant of integration. Substituting values into equation (2.11)

$$
\begin{aligned}
N_{2} & =\frac{1}{e^{\lambda_{2} t}} \int e^{\lambda_{2} t} \lambda_{1} N_{10} e^{-\lambda_{1} t} d t+\frac{C}{e^{\lambda_{2} t}} \\
& =\frac{\lambda_{1}}{\lambda_{2}-\lambda_{1}} N_{10} e^{-\lambda_{1} t}+C e^{-\lambda_{2} t}
\end{aligned}
$$

The constant of integration $C$, can to obtained with the initial condition of $\mathrm{N}_{2}=0$.

$$
C=\frac{-\lambda_{1} N_{10}}{\lambda_{2}-\lambda_{1}}
$$


The number of daughter atoms is then

$$
N_{2}=\frac{\lambda_{1} N_{10}}{\lambda_{2}-\lambda_{1}}\left(e^{-\lambda_{1} t}-e^{-\lambda_{2} t}\right)
$$

With the granddaughter element stable, the number of atoms of this element is

$$
N_{3}=N_{10}-N_{1}-N_{2}
$$

\subsection{Neutron Interactions}

Neutrons produced by fission interact with the reactor core materials in two ways, they are either absorbed or scattered. The average energy produced by fission is about 2 $\mathrm{MeV}\left(1 \mathrm{eV}=1.60210 \times 10^{-19}\right.$ joules $)$. Neutrons produced by fission processes may either create more fissions, be scattered and reduced to thermal neutron speed, or be destroyed through absorption by parasitic materials.

The probability of scattering, absorption, or fission interactions between neutrons and nuclei is given by an "interaction rate":

$$
R=\sigma N \phi
$$

where $\sigma$ is the microscopic cross section in barns $\left(1 \mathrm{barn}=10^{-24} \mathrm{~cm}^{2} /\right.$ nucleus $)$ and $\phi$ is the neutron flux in (neutrons $/ \mathrm{cm}^{2} \mathrm{~s}$ ).

The macroscopic cross section, $\Sigma$, is equal to $N \sigma$, where $N$ is the number density of target atoms in nuclei $/ \mathrm{cm}^{3}$. Macroscopic cross sections represent the effective target area per unit volume of material. The mean free path is the average distance traveled by a neutron before it interacts with another neutron or nucleus. A value for the mean free path, $\lambda_{\text {mean }}$ is then obtained by taking the reciprocal of the macroscopic cross section ( $1 /$ $\Sigma$ ). Since the cross sections represent probabilities of interaction, the individual properties may be added together to get the total cross section 


$$
\sigma_{T}=\sigma_{a}+\sigma_{s}
$$

where $\sigma_{\mathrm{a}}$ is the absorption cross-section and $\sigma_{\mathrm{s}}$ is the scattering cross section. For a fissionable nucleus, the absorption cross-section is the sum of the fission and capture cross sections.

$$
\sigma_{a}=\sigma_{f}+\sigma_{a}
$$

The scattering cross section is composed of the elastic and inelastic values.

$$
\sigma_{s}=\sigma_{s e}+\sigma_{s i}
$$

Macroscopic cross sections are also additive giving

$$
\Sigma_{T}=\Sigma_{f}+\Sigma_{c}+\Sigma_{s}
$$

For thermal neutrons in most materials, the absorption cross section varies inversely with neutron velocity. Thus, the absorption cross section will vary inversely with the square root of both the kinetic energy and the absolute temperature. The average neutron velocity is larger than the most probable neutron velocity by a factor of $2 / \pi^{1 / 2}$. The absorption cross sections at these velocities vary as the inverse of this ratio. The corrected neutron cross section at temperature $\mathrm{T}$ is

$$
\bar{\sigma}_{a}^{\prime}=\sigma_{a 293} \frac{\sqrt{\pi}}{2} \sqrt{\frac{293}{T}}
$$

In equation (2.23), $\sigma_{a 293}$ is the absorption cross section of the material at $293 \mathrm{~K}$, which can be found in appropriate tables.

\subsection{Steady State Core Reactors}

Fast neutrons are generated inside the thermal reactor core. The fast neutrons eventually slow to thermal neutrons through collisions with moderating nuclei. Some remaining neutrons are then absorbed by fissionable nuclei and then produce a new 
generation of neutrons through fission. The ratio of the new generation of neutrons to the previous is known as the multiplication factor. In an infinitely large reactor, no neutrons leak out and the infinite multiplication factor is defined as:

$$
k_{\infty}=\frac{n^{\prime}}{n}
$$

where " $n$ " neutrons in one generation lead to the production of $n$ ' neutrons in the next generation by fission. Neutrons transport in an actual reactor consists of the migration from the reactor core outward to the physical boundaries. At the boundaries, neutrons may leak out. Neutron leakage is accounted for by using a non-leakage probability $\left(\mathbb{P}_{N L}\right)$, in the equation for the effective multiplication factor.

$$
k_{e f f}=k_{\infty} P_{N L}
$$

The value of the effective multiplication factor must be 1.0 for a reactor to operate under stable critical conditions with a sustained chain reaction. For a $\mathrm{k}_{\mathrm{eff}}$ value greater than 1.0 , supercritical conditions exist in the reactor, and the power increases exponentially. A $\mathrm{k}_{\mathrm{eff}}$ value of less than 1.0 indicates that subcritical conditions exist. During subcritical conditions, the reactor power decreases along with the number of neutrons present in the reactor. The four-factor equation is a variation of equation 2.25 for the infinite multiplication factor.

$$
k_{\infty}=\varepsilon p f \eta
$$

Equation (2.27) contains the fast fission factor $(\varepsilon)$, the resonance escape probability $(p)$, the thermal utilization factor $(\mathfrak{f})$, and the reproduction factor $(\eta)$.

The fast fission factor is defined as the ratio of the total number of fission neutrons produced by both fast and thermal neutrons to that produced by thermal fission alone. 
The probability that a fission neutron is not absorbed by any resonance such as a thermal or fast neutron is the resonance escape probability. To obtain the thermal utilization factor, the ratio of the number or neutrons absorbed in the fuel to the total number of absorptions in the fuel, cladding and other reactor material is investigated. Lastly, the number of fast neutrons produced per thermal neutron absorbed in the fuel is the fast fission factor. Values for the fast fission factor are usually equal to one. The resonance escape probability may be calculated through use of the following equation:

$$
p=\exp \left(-\frac{N_{238}}{\xi \Sigma_{s}} I_{e f f}\right)
$$

$\mathrm{N}_{238}$ is the number density of ${ }^{238} \mathrm{U}, \xi$ is the logarithmic energy decrement, $\Sigma_{\mathrm{s}}$ is the macroscopic scattering cross-section and $I_{e f f}$ is the effective resonance integral. The energy loss of a neutron due to collision is quantified through use of the logarithmic energy decrement and is represented by:

$$
\xi=\frac{2}{A_{w}+\frac{2}{3}}
$$

The effective resonance integral is:

$$
I_{e f f}=3.9\left(\frac{\Sigma_{s}}{N_{238}}\right)^{0.415}
$$

A value for the thermal utilization factor is found by using:

$$
f=\frac{\Sigma_{a b s}^{f}}{\Sigma_{a b s}^{f}+\Sigma_{a b s}^{m}+\Sigma_{a b s}^{c}}
$$

where $\Sigma$ is the macroscopic absorption cross-sections and $f$ indicates the fission material, $m$ the moderating material, and $c$ the fuel cladding. The value of the reproduction factor is: 


$$
\eta=v \frac{\Sigma_{f}}{\Sigma_{a}}
$$

where $v$ is the number of neutrons produced in each fission. For thermal fission in ${ }^{235} \mathrm{U}$, 2.43 neutrons are produced per fission.

\subsection{Transient Reactor Behavior}

A deviation in a steady state neutron population is known as a reactivity change. The total lifetime of a neutron is equal to the time it takes to thermalize plus the amount of time it survives as a thermal neutron. The thermalizing time is the period it takes for a fast neutron slow down through multiple collisions with nuclei in the reactor and to reach the speed of neutrons influenced only by the temperature of the reactor material. Neutron generation time is very short, and may be taken as equal to the thermal life. Neutron effective life is defined in equation 2.33 .

$$
l \approx \frac{1}{\sum_{a} \bar{v}\left(1+B^{2} L^{2}\right)}
$$

The reactivity is the ratio of the effective multiplication factor minus 1.0 (the value for critical conditions) to the effective multiplication factor, and may be seen in equation 2.34

$$
\rho_{c}=\frac{k_{e f f}-1}{k_{e f f}}
$$

The reactor period is defined as:

$$
T_{r}=\frac{1}{\Delta k_{e f f}}
$$

and the neutron flux as a function of time may then be solved.

$$
\Phi=\Phi_{0} e^{t / T_{r}}
$$


Bilanovic and Harms (1985) have conducted a study of the nonlinear dynamics of the Oklo reactors. In their study, nonlinear continuous differential and nonlinear discrete iterative formulations are established. Power oscillations were obtained, as well as nonlinear mappings for nuclear simulations. The results indicated that the power output of the reactor oscillated between two values with the period between 2.3 and 2.5 seconds.

In their study, as power increased, the temperature inside the reactor also increased, resulting in the water contained in the reactor to be brought above the boiling point. As more steam was produced in the core, the density of the water acting as a moderator decreased thus causing the number of fissions to decrease as well. The decrease in fission reduced the temperature in the core and allowed the water to be condensed and to reenter the reactor core. This influx of water back into the core acted as a moderator and allowed the reaction to again, once more raising the power output. The cycle repeated itself in the manner previously described until enough fuel had been consumed to prevent any significant power surges.

Neutrons produced directly by fission are referred to as "prompt" neutrons and comprise the majority of neutrons found in a reactor. Radioactive decay of fission products also produces "delayed" neutrons at time intervals dictated by the half-life of each decaying radioisotope. Prompt and delayed neutrons follow in seven different groups organized by half-life. The neutron diffusion equation describing the transient neutron flux distribution, $\Phi$, in a reactor is shown below:

$$
\frac{1}{v} \frac{\partial \Phi}{\partial t}=D \nabla^{2} \Phi-\Phi \Sigma_{a}+S
$$

where $S$ is source of neutrons for the next fission, $D$ is the diffusion coefficient and $v$ is the average velocity neutrons. The neutron source due to fission is defined as: 


$$
S=k_{\infty} \Sigma_{a} \Phi
$$

The power generation of the core can then be obtained through use of

$$
P=\Phi \Sigma_{f} G d x d y
$$

where $\Sigma_{f}$ is the macroscopic cross section of fission and $G$ is a constant of 191 (MeV/fission) that describes the recoverable energy produced per fission.

2.7 Analytical Solution of Transient Flux Distribution on a Flat Plate

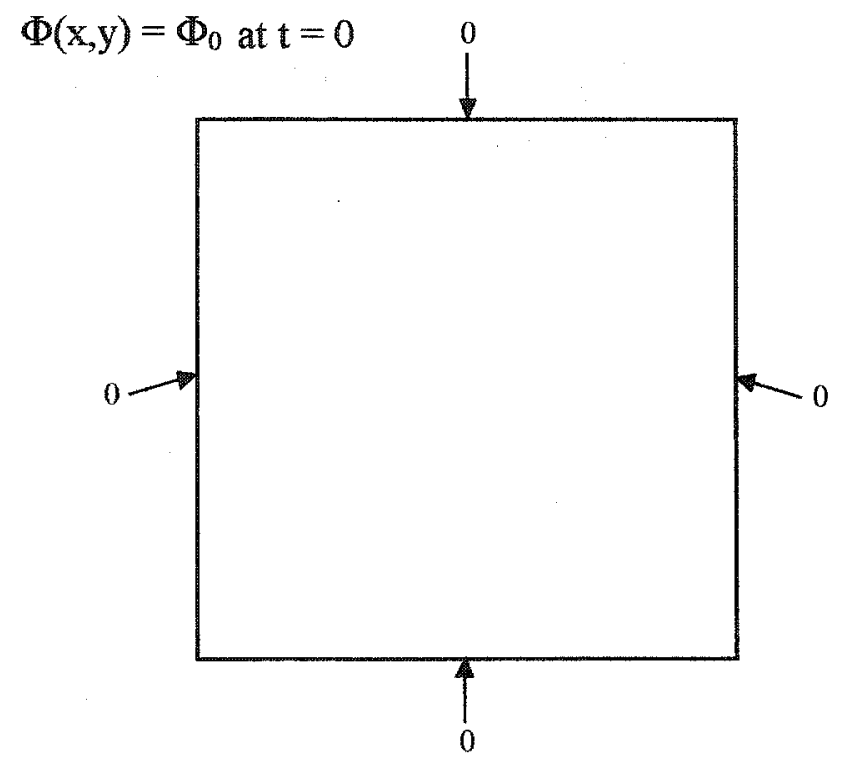

Figure 2.2 Two-dimensional Transient Neutron Flux Distribution on a Flat Plate

For a two-dimensional flat plate the diffusion equation is written as:

$$
\frac{1}{v} \frac{\partial \Phi}{\partial t}=D\left(\frac{\partial^{2} \Phi}{\partial x^{2}}+\frac{\partial^{2} \Phi}{\partial y^{2}}\right)-\Sigma_{a} \Phi+S
$$

An analytical solution to the problem shown in Figure 2.2, with no source and no absorption terms can be solved through the use of equation $(2.40)$ by separation of variables. 
Therefore

$$
\Phi(x, y, t)=X(x) Y(y) T(t)=X Y T
$$

Using $X, Y$ and $T$ equal to equation $(2.42 a, b, c)$ respectively,

$$
X=B \sin \left(\frac{n \pi x}{a}\right) \quad Y=D \sin \left(\frac{m \pi y}{b}\right) \quad T=e^{-D_{n}\left(p^{2}+q^{2}\right) t}
$$

where $a$ is the total length in the $\mathrm{x}$ direction, $\mathrm{b}$ is the length in the $\mathrm{y}$ direction and $\mathrm{t}$ is the time, $D_{n}$ is the neutron diffusion coefficient and $p$ and $q$ are equal to terms in equation $(2.42 a, b)$.

$$
p=\left(\frac{n \pi}{a}\right) \quad q=\left(\frac{m \pi}{b}\right)
$$

Substitution of equation $(2.42 a, b, c)$ into equation (2.41) yields:

$$
\begin{aligned}
& \Phi=B \sin \left(\frac{n \pi x}{a}\right) D \sin \left(\frac{m \pi y}{b}\right) e^{-D_{n} \pi^{2}\left(\frac{n^{2}}{a^{2}}+\frac{m^{2}}{b^{2}}\right) t}
\end{aligned}
$$

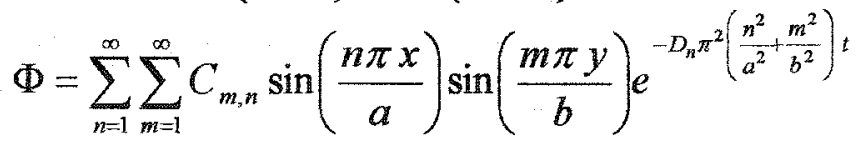

Application of the boundary conditions and the initial conditions for $t=0$ shown in

Figure 2.2, gives the equation for the flux distribution as a function of position.

$$
\Phi_{0}=\sum_{n=1}^{\infty} \sum_{m=1}^{\infty} C_{m, n} \sin \left(\frac{n \pi x}{a}\right) \sin \left(\frac{m \pi y}{b}\right)
$$

Integrating over the entire area gives $C_{m, n}$.

$$
C_{m, n}=\frac{2 \Phi_{0}}{a b}\left(\frac{a-a \cos (n \pi)}{n \pi}\right)\left(\frac{b-b \cos (m \pi)}{m \pi}\right)
$$

The analytical solution for the two-dimensional transient flux then becomes:

$$
\Phi(x, y, t)=\sum_{n=1}^{\infty} \sum_{m=1}^{\infty} \frac{2 \Phi_{0}}{a b}\left(\frac{a-a \cos (n \pi)}{n \pi}\right)\left(\frac{b-b \cos (m \pi)}{m \pi}\right) \sin \left(\frac{n \pi x}{a}\right) \sin \left(\frac{m \pi y}{b}\right) e^{-D_{n} \pi^{2}\left(\frac{n^{2}}{a^{2}}+\frac{m^{2}}{b^{2}}\right) t}
$$




\section{CHAPTER 3}

\section{CONSERVATION PRINCIPLES THEORY}

In modeling the heat transfer and fluid flow, two basic principles were used. These include conservation of mass, momentum and energy. Derivations of both principles are given in the following sections (Hughes, 1991).

\subsection{Conservation of Mass}

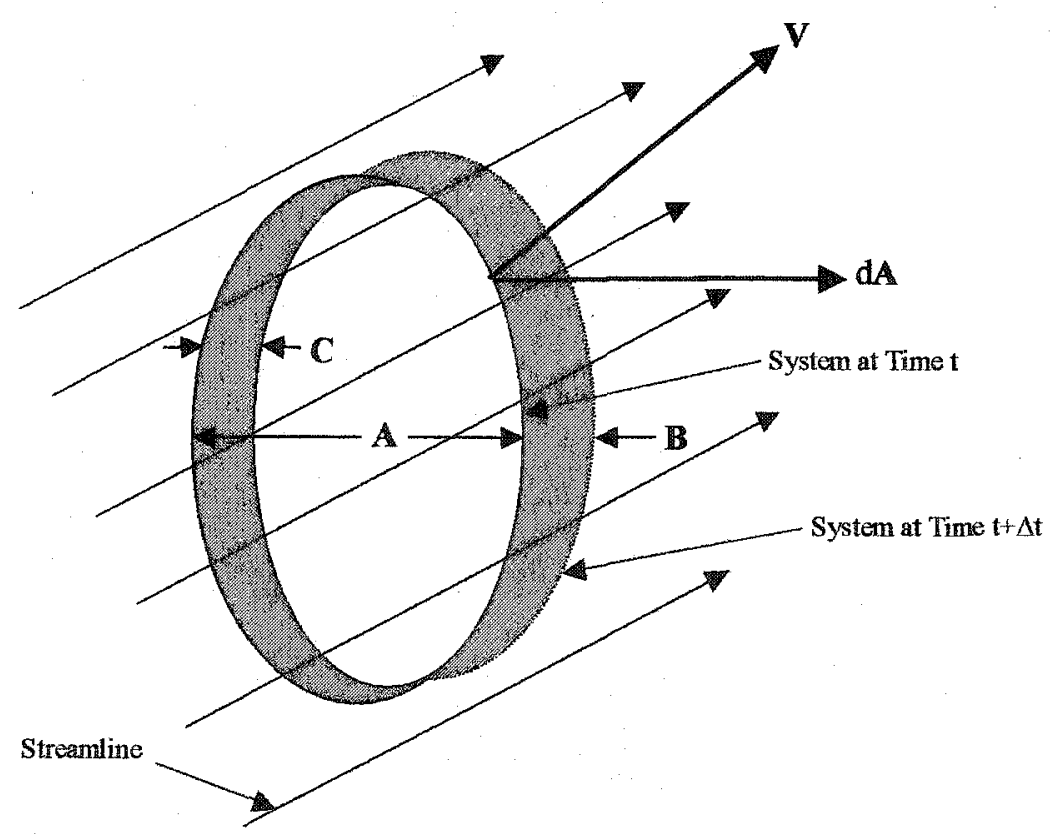

Figure 3.1 Control Volume of a Flow System 
A control volume may be established which contains any amount of a substance, which in this case is water. Water properties are held constant in the control volume. A second control volume may be drawn around the first, and the boundary of this new volume is considered to enclose the same mass of fluid at the next time step, $(t+\Delta t)$. The chosen control volumes are depicted in Figure 3.1 showing the fluid in zone $A$ at time $t$ and the fluid in zone $C$ at time $(t+\Delta t)$. The amount of mass, $m$, in the various zones at a given time may then be solved with the following derivation.

$$
m_{1}(t)=m_{1}(t+\Delta t)-m_{3}(t+\Delta t)+m_{2}(t+\Delta t)
$$

Reordering terms and dividing by $\Delta \mathrm{t}$,

$$
\frac{m_{1}(t+\Delta t)-m_{1}(t)}{\Delta t}=\frac{m_{3}(t+\Delta t)-m_{2}(t+\Delta t)}{\Delta t}
$$

The limit as $\Delta \mathrm{t} \rightarrow 0$ is then applied and the equation becomes:

$$
\lim _{\Delta t \rightarrow 0} \frac{m_{1}(t+\Delta t)-m_{1}(t)}{\Delta t}=\frac{\partial}{\partial t} \int_{C . V .} \rho d \tau
$$

where $\rho$ is the density of the water, $\tau$ is the volume, and C.V. is the control volume. With

$$
\lim _{\Delta t \rightarrow 0}\left\{\frac{m_{3}(t+\Delta t)}{\Delta t}-\frac{m_{2}(t+\Delta t)}{\Delta t}\right\}=\dot{m}_{\text {in }}-\dot{m}_{\text {out }}
$$

then

$$
\dot{m}_{\text {in }}-\dot{m}_{\text {out }}=\int_{A_{i t}} \rho V \cos \alpha d A-\int_{A_{\text {out }}} \rho V \cos \alpha d A=-\int_{C . S} \rho \vec{V} \cdot d \vec{A}
$$


where $\dot{m}_{\text {in }}$ and $\dot{m}_{\text {out }}$ are the mass flow rates in and out of the control volume, $\alpha$ is the angle between the velocity vector and the normal, and $\vec{V}$ is the velocity vector. The continuity equation for the control volume is:

$$
\int_{C . S .} \rho \vec{V} \cdot d \vec{A}=-\frac{\partial}{\partial t} \int_{C . V} \rho d \tau
$$

Equation (3.6) is the continuity equation in integral form and demonstrates that the rate of mass flow out of the control surface is equal to the decrease inside the control volume with respect to time. For a steady flow $(\partial \rho / \partial t=0)$ and since the control volume is fixed, equation 3.7 results.

$$
\int_{C . S .} \rho \vec{V} \cdot d \vec{A}=0
$$

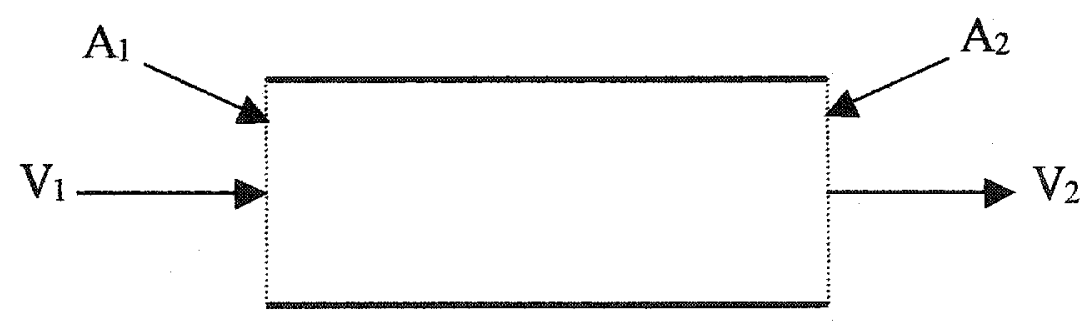

Figure 3.2 Continuity of Flow in a Control Volume

For the flow entering and leaving the control volume pictured in Figure 3.2, the equation is

$$
\int_{A_{2}} \rho_{2} V_{2} \cdot d A-\int_{A_{1}} \rho_{1} V_{1} \cdot d A=0
$$

After integration equation 3.8 reduces to:

$$
\rho_{1} V_{1} A_{1}=\rho_{2} V_{2} A_{2}
$$


If the flow is incompressible ( $\rho$ is constant) $\rho_{1}=\rho_{2}$, the flow rate $Q_{\text {out }}$ is equal $Q_{\text {in }}$ $(\mathrm{Q}=\mathrm{AV})$ due to conservation of mass as seen in equation 3.9 .

\subsection{Conservation of Momentum}

The force acting on a particle is given by Newton's second law of motion.

$$
\vec{F}=\frac{d \vec{M}}{d t}
$$

The force, $\mathrm{F}$ is given by the change in linear momentum, $\vec{M}$ with respect to the change in time, $t$. With a constant force, the momentum equation may then be written as follows:

$$
\Delta \vec{M}=\vec{F} \Delta t
$$

Using the control volume setup in Figure 3.1, $\Delta \vec{M}$ may be then expressed as:

$$
\Delta \vec{M}=\vec{M}_{A}(t+\Delta t)-\vec{M}_{C}(t+\Delta t)+\vec{M}_{B}(t+\Delta t)-\vec{M}_{A}(t)
$$

After rearranging equation 3.12 , and dividing the entire equation by $t$ :

$$
\frac{\Delta \vec{M}}{\Delta t}=\frac{\vec{M}_{A}(t+\Delta t)-\vec{M}_{A}(t)}{\Delta t}+\frac{\vec{M}_{B}(t+\Delta t)-\vec{M}_{C}(t+\Delta t)}{\Delta t}
$$

Taking the limit as $\Delta t$ goes to zero, the first term on the right side becomes

$$
\lim _{\Delta t \rightarrow 0} \frac{\vec{M}_{A}(t+\Delta t)-\vec{M}_{A}(t)}{\Delta t}=\frac{\partial}{\partial t}(\vec{M})_{C . V .}=\frac{\partial}{\partial t} \int_{C V .} \rho \vec{V} d \tau
$$

Then taking the limit as $\Delta t$ goes to zero for the second term:

$$
\lim _{\Delta t \rightarrow 0}\left[\frac{\vec{M}_{B}(t+\Delta t)-\vec{M}_{C}(t+\Delta t)}{\Delta t}\right]=\int_{c . s .} \vec{V} \rho \vec{V} \cdot d \vec{A}
$$


Equation 3.11 becomes:

$$
\vec{F}=\frac{\partial}{\partial t} \int_{C . V .} \vec{V} \rho d \tau+\int_{C . S .} \vec{V} \rho \vec{V} \cdot d \vec{A}
$$

The momentum equation including a body force and shear force is then given in equation 3.17.

$$
\vec{F}_{s}+\int_{C . V .} \vec{B} d \tau=\frac{\partial}{\partial t} \int_{C . V .} \vec{V} \rho d \tau+\int_{C . S .} \vec{V} \rho \vec{V} \cdot d \vec{A}
$$

\subsection{Conservation of Energy}

A derivation of the conservation of energy equation for a given control volume is achieved through use of the first law of thermodynamics. The first law is:

$$
Q-W=\Delta E
$$

where $\mathrm{Q}$ is the heat added, $\mathrm{W}$ is the work done and $\triangle \mathrm{E}$ is the change in energy within the control volume. The total energy seen in the first law is given by the sum of the internal energy, kinetic energy and potential energy. The amount of the energy within the volume is:

$$
E=U+\frac{1}{2} m V^{2}+m g z
$$

In equation (3.19), $\mathrm{U}$ is the internal energy, $\mathrm{m}$ is the mass, $\mathrm{g}$ is the gravitational acceleration, and $z$ is the change in height. The second component of equation 3.19 is the kinetic energy $\left(1 / 2 \mathrm{mV}^{2}\right)$ and the third is the potential energy (mgz).

Using the volume depicted in Figure 3.1, the energy equation at time $t$ is:

$$
Q-W=E_{f}-E_{i}
$$

where $E_{\mathrm{f}}$ is the final energy of the volume and $\mathrm{E}_{\mathrm{i}}$ is the initial energy. Dividing by $\Delta t$, 


$$
\frac{Q}{\Delta t}-\frac{W}{\Delta t}=\frac{E_{f}-E_{i}}{\Delta t}
$$

The right hand side of equation (3.21) is evaluated as follows:

$$
\frac{E_{f}-E_{i}}{\Delta t}=\frac{E_{1}(t+\Delta t)-E_{3}(t+\Delta t)+E_{2}(t+\Delta t)-E_{1}(t)}{\Delta t}
$$

Applying the limit as $\Delta t \rightarrow 0$,

$$
\begin{array}{r}
\lim _{\Delta t \rightarrow 0} \frac{E_{1}(t+\Delta t)-E_{1}(t)}{\Delta t}=\frac{\partial}{\partial t} \int_{C . V .} e \rho d \tau \\
\lim _{\Delta t \rightarrow 0} \frac{E_{f}-E_{i}}{\Delta t}=\frac{\partial}{\partial t} \int_{C . V .} e \rho d \tau+\int_{C . S .} e \rho \vec{V} \cdot d \vec{A}
\end{array}
$$

The work done at the boundary of the volume is the hydrostatic pressure. The work done by the flow for both inflow and outflow is given in equation 3.25 .

$$
\begin{aligned}
\left(\frac{d W}{d t}\right)_{\text {flow_work }} & =\lim _{\Delta t \rightarrow 0}\left[\frac{\left.\sum(p / \rho)(\Delta m)_{2}\right|_{t+\Delta t}}{\Delta t}-\frac{\left.\sum(p / \rho)(\Delta m)_{3}\right|_{t+\Delta t}}{\Delta t}\right] \\
& =\int_{C . S .}(p / \rho) \rho \vec{V} \cdot d \vec{A}
\end{aligned}
$$

The energy equation then becomes:

$$
\frac{d Q}{d t}-\frac{d W}{d t}=\frac{\partial}{\partial t} \int_{C . V .} e \rho d \tau+\int_{C . S .}(e+p / \rho) \rho \vec{V} \cdot d \vec{A}
$$

where

$$
e=u+\frac{1}{2} V^{2}+g z
$$

Equation (3.26) states that the heat transfer rate minus the work production rate in the control volume is equal to the change of energy stored in the control volume with respect 
to time plus the net rate of stored energy and flow work moving out of the control volume. 


\section{CHAPTER 4}

\section{POROUS MEDIA THEORY}

\subsection{Conservation of Mass in Porous Media}

A finite control volume with the dimensions $\Delta x, \Delta y$ and $W$, with $W$ much larger than $\Delta \mathrm{x}$ or $\Delta \mathrm{y}$, may be established. Since $\mathrm{W}$ is much larger than the $\mathrm{x}$ and $\mathrm{y}$ dimensions, the mass-flow analysis may be done in the $\mathrm{x}$ and $\mathrm{y}$ directions alone. Figure 4.1 shows a twodimensional control volume of a porous medium. This control volume can be used to show the two-dimensional conservation of mass in porous media, as seen later. (Bejan, 1995).

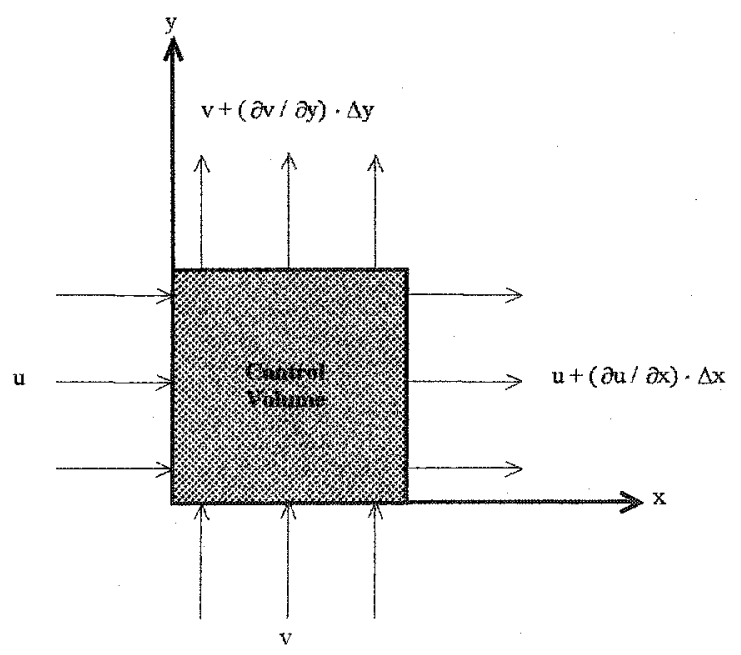

Figure 4.1 Control Volume of Porous Medium 


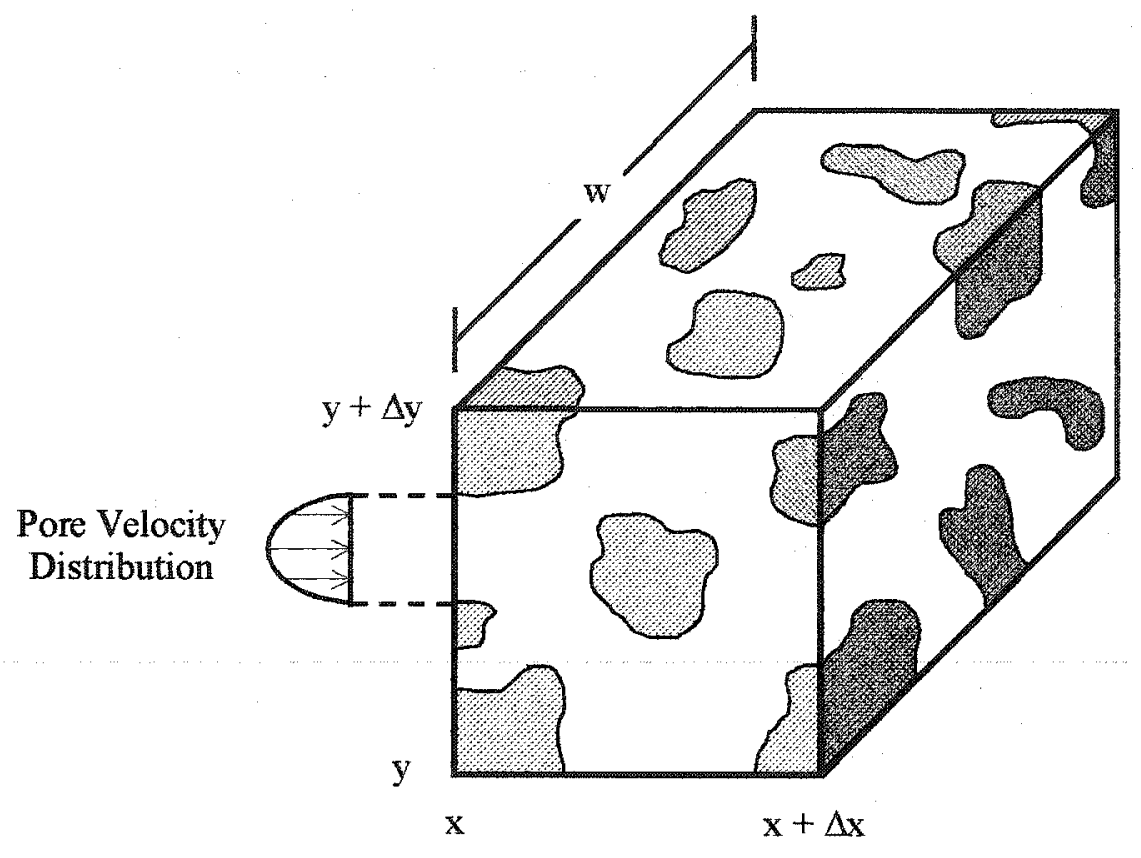

Figure 4.2 Pore Velocity Distribution

The mass flow rate entering the volume depicted in Figure 4.2 from the left in the $\mathrm{x}$ direction is defined by equation 4.1 ,

$$
\dot{m}_{x}=\rho \int_{y}^{y+\Delta y} \int_{0}^{W} u_{\text {pore }} d z \cdot d y
$$

where $u_{\text {pore }}$ (pore velocity distribution) is the velocity distribution over the void in the $x$ direction. Selecting the control surface size WAy to be significantly larger than that of the pore surface, the velocity in the $\mathrm{x}$ direction is

$$
u=\frac{1}{W \Delta y} \int_{y}^{y+\Delta y} \int_{0}^{W} u_{p o r e}(y, z) d z \cdot d y
$$

The mass flow rate in the $\mathrm{x}$ direction is then reduced to the following form

$$
\dot{m}_{x}=\rho u(W \Delta y)
$$

The velocity in the $y$ direction is computed in the same way as shown for the $x$ direction. 


$$
v=\frac{1}{W \Delta x} \int_{x}^{(x+\Delta x)} \int_{0}^{W} v_{\text {pore }}(x, z) d z \cdot d x
$$

The mass flow rate in the $y$ direction is

$$
\dot{m}_{y}=\rho v(W \Delta x)
$$

Using the conservation of mass equation

$$
\frac{\partial M_{c y}}{\partial t}=\sum_{\text {inlet }} \dot{m}-\sum_{\text {outlet }} \dot{m}
$$

then

$$
\frac{\partial}{\partial t}(\rho \phi W \Delta x \Delta y)+\frac{\partial \dot{m}_{x}}{\partial x} \Delta x+\frac{\partial \dot{m}_{y}}{\partial y} \Delta y=0
$$

where $\phi$ is the porosity of the medium. By combining equations (4.3), (4.5), and (4.7) the following results,

$$
\phi \frac{\partial \rho}{\partial t}+\frac{\partial(\rho u)}{\partial x} \Delta x+\frac{\partial(\rho v)}{\partial y} \Delta y=0
$$

The simplified form of the mass conservation for the average flow is then acquired and shown in equation 4.9 ,

$$
\phi \frac{\partial \rho}{\partial t}+\vec{\nabla} \cdot(\rho \vec{V})=0
$$

where $\vec{V}$ is the volume averaged velocity vector $(\mathrm{u}, \mathrm{v}, \mathrm{w})$.

\subsection{Darcy's Law}

Darcy's Law summarizes the flow, the momentum equations and force balances for a porous media. Darcy discovered that the velocity for the fluid through a column of porous medium is directly related to the pressure drop across the column. Subsequent 
experiments indicated an inverse relationship between the velocity and the viscosity of the fluid flowing through the porous medium.

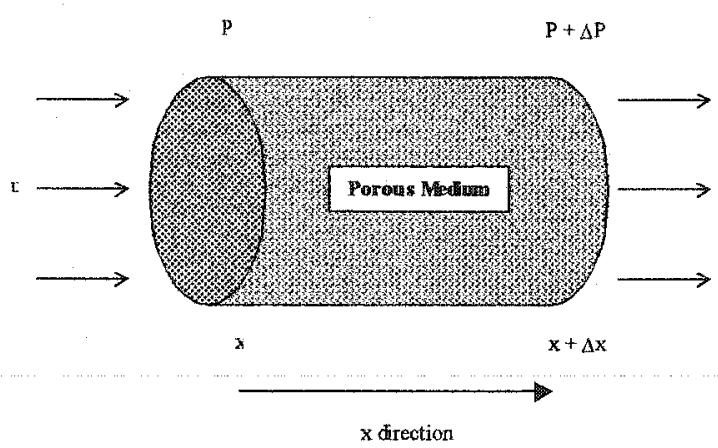

Figure 4.3 One-dimensional Flow in a Column of Porous Medium

Figure 4.3 shows a forced flow through a one-dimensional column filled with a porous medium. From this geometry, Darcy's observations lead to the conclusion that the velocity may be represented by

$$
u=\frac{K}{\mu}\left(-\frac{d p}{d x}\right)
$$

where $\mathrm{K}$ is the permeability, $\mathrm{p}$ is the pressure and $\mu$ is the dynamic viscosity.

The permeability in Equation (4.10) is analogous to the thermal conductivity in Fourier's Law of heat conduction. Taking into account a body force, Darcy's Law becomes

$$
u=\frac{K}{\mu}\left(-\frac{\partial p}{\partial x}+\rho g_{x}\right)
$$

The three-dimensional representation of equation (4.11) then becomes 


$$
\vec{V}=\frac{K}{\mu}(-\vec{\nabla} p+\rho \vec{g})
$$

\subsection{Conservation of Energy in Porous Media}

To derive the conservation of energy for a porous medium, heat and fluid flow are considered in one dimension only as shown in Figure 4.4 (Bejan, 1995)

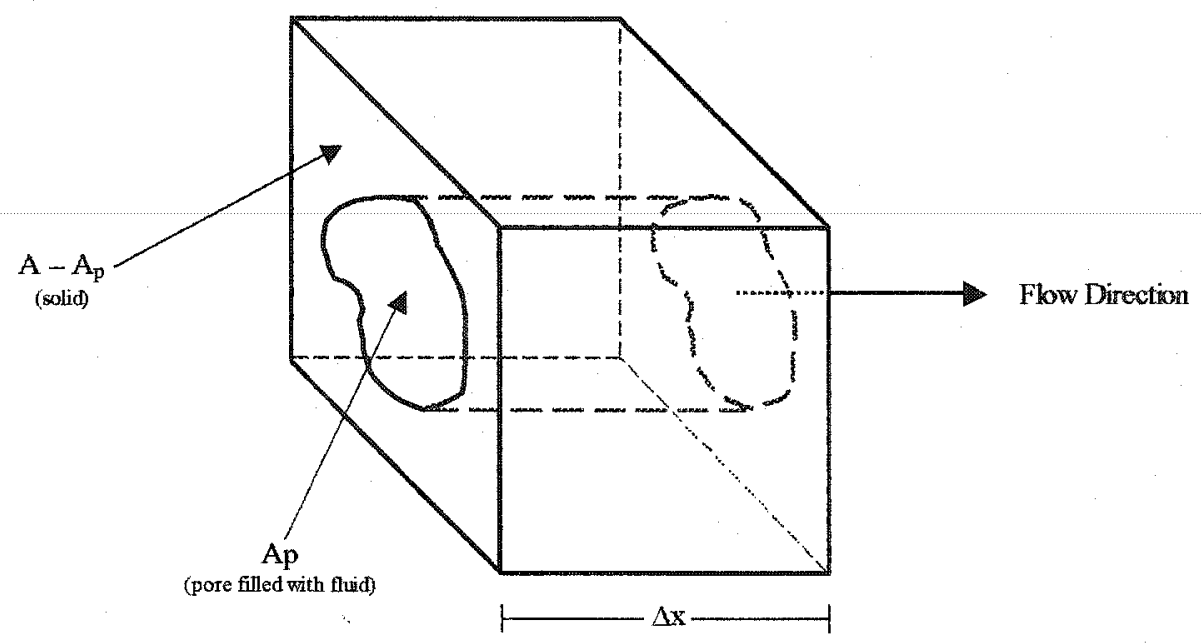

Figure 4.4 One-dimensional Fluid Flow Through a Pore

The void in Figure 4.4 is defined such that $\left(A_{p} \Delta x\right) /(A \Delta x)$ is equal to the porosity.

$$
\phi=\frac{A_{p} \Delta x}{A \Delta x}
$$

Through out the derivation of the energy equation, a homogenous medium is considered to make up the porous medium. The finite volume $\mathrm{A} \Delta \mathrm{x}$ is selected when analyzing the fluid and solid phase in the energy equation. Temperature in the solid phase is represented by the equation given by

$$
\rho_{s} c_{p_{s}} \frac{\partial T}{\partial t}=k_{s} \frac{\partial^{2} T}{\partial x^{2}}+\dot{q}_{s}{ }^{\prime \prime}
$$


where $\rho_{\mathrm{s}}$ is the density of the solid, $c_{\mathrm{ps}}$ is the specific heat of the solid, $\mathrm{k}_{\mathrm{s}}$ is the thermal conductivity of the solid and $\dot{q}_{s}^{\prime \prime}$ is the heat source generation per unit volume and per unit time within the solid material. Using the assumption of homogenity, the temperature does not vary in the solid and thus equation (4.14) may be written as

$$
\Delta x\left(A-A_{p}\right) \rho_{s} c_{p_{s}} \frac{\partial T}{\partial t}=\Delta x\left(A-A_{p}\right) k_{s} \frac{\partial^{2} T}{\partial x^{2}}+\Delta x\left(A-A_{p}\right) \dot{q}_{s}^{\prime \prime}
$$

The energy conservation within the fluid at any point in the fully saturated void is

$$
\rho_{f} c_{p_{f}}\left(\frac{\partial T}{\partial t}+u_{p} \frac{\partial T}{\partial x}\right)=k_{f} \frac{\partial^{2} T}{\partial x^{2}}+\mu \phi
$$

where $\left(\rho, c_{p}, k\right)_{f}$ are the properties of the fluid. Integrating over the pore volume results in equation 4.17 .

$$
\Delta x A_{p} \rho_{f} \mathcal{C}_{p_{f}} \frac{\partial T}{\partial t}+\Delta x A \rho_{f} \mathcal{c}_{p_{f}} u \frac{\partial T}{\partial x}=\Delta x A_{p} k_{f} \frac{\partial^{2} T}{\partial x^{2}}+\Delta x \mu \iint_{A_{p}} \phi d A_{p}
$$

Using equation 4.2 , the average velocity may be substituted into the second term giving

$$
A u=\iint_{A_{p}} u_{p} d A_{p}
$$

Internal heating with viscous dissipation is taken account for in the last term on the right hand side of equation (4.17). The dissipation term is the work necessary to force the flow through the pore. This work term is equal to the mass flow rate times the pressure drop divided by the density of the fluid, thus giving 


$$
\Delta x \mu \iint_{A_{p}} \phi d A_{p}=A u\left(-\frac{\partial p}{\partial x}+\rho_{f} g_{x}\right) \Delta x
$$

Equation 4.19 holds true for any pore geometry. To acquire the volumetric average of the energy equation, equations (4.15) and (4.17) are added together and the divided by the volume $(A \triangle x)$ of the porous void. The porous void is once again considered to be a homogeneous medium.

$$
\begin{aligned}
{\left[\phi \rho_{f} c_{p s}+(1-\phi) \rho_{s} c_{p_{s}}\right] \frac{\partial T}{\partial t}+\rho_{f} c_{p s} u \frac{\partial T}{\partial x} } & =\left[\phi k_{f}+(1-\phi) k_{s}\right] \frac{\partial^{2} T}{\partial x^{2}}+(1-\phi) q_{s} " \\
& +u\left(-\frac{\partial p}{\partial x}+\rho_{f} g_{x}\right)
\end{aligned}
$$

The apparent thermal conductivity of the porous medium, $\mathrm{k}_{\mathrm{a}}$, is defined below as the combination of the fluid and the solid conductivities through use of the porosity as shown in equation 4.21 .

$$
k_{a}=\phi k_{f}+(1-\phi) k_{s}
$$

The one-dimensional energy equation becomes

$$
\rho_{f} \mathcal{c}_{p f}\left(u \frac{\partial T}{\partial x}\right)=k \frac{\partial^{2} T}{\partial x^{2}}+q^{\prime \prime}
$$

The three-dimensional form of equation (4.23) is

$$
\rho_{f} \mathcal{C}_{p f}(\vec{V} \cdot \vec{\nabla} T)=k \nabla^{2} T+q^{\prime \prime \prime}
$$

where $V$ is the volume average velocity vector $(u, v, w)$. 


\section{CHAPTER 5}

\section{HEAT TRANSFER AND FLUID FLOW THEORY}

\subsection{Governing Equations}

The heat transfer and fluid portions of the computer model were developed based on a two-dimensional transient convection transport model. (Oosthuizen, and Naylor, 1999) The Darcy flow model and the Boussinesq approximation convection model were used to develop the governing equations. In this study, since conditions are saturated, superheated water, the air values inside the porous media were neglected. The equations were used to represent continuity, momentum in the $\mathrm{x}$ and $\mathrm{y}$ directions and energy, respectively. Continuity for two-dimensional, incompressible flow is given by:

$$
\frac{d u}{d x}+\frac{d v}{d y}=0
$$

The continuity equation is written to show conservation of mass, stating that the total amount of mass in the system is equal to the total amount in minus the total amount out in both the $\mathrm{x}$ and $\mathrm{y}$ directions. For the case of natural convection in two dimensions, the Boussinesq approximation may be used to represent the pressures and temperatures in both directions. The Boussinesq approximation is:

$$
u \frac{\partial u}{\partial x}+v \frac{\partial u}{\partial y}=-\frac{1}{\rho} \frac{\partial p}{\partial x}+v\left(\frac{\partial^{2} u}{\partial x^{2}}+\frac{\partial^{2} u}{\partial y^{2}}\right)+\beta g\left(T-T_{o}\right)
$$


The variables in equation (5.2) are as follows:

$u$ is the velocity in the $x$ direction

$\rho$ is the density of the fluid

$v$ is the kinematic viscosity of the fluid

$\mathrm{g}$ is the gravitational constant

$\mathrm{T}$ is the temperature

$\beta$ is the expansion coefficient of the fluid where:

$$
\beta=\frac{1}{T}
$$

Using the Darcy Flow equations along with Boussinesq approximation, the momentum equations in the $\mathrm{x}$ and $\mathrm{y}$ directions are written as follows:

$$
\begin{aligned}
& \frac{\mu_{f} u}{K}=-\frac{\partial p}{\partial x}+\beta g \rho_{f}\left(T-T_{o}\right) \cos \theta \\
& \frac{\mu_{f} v}{K}=-\frac{\partial p}{\partial y}+\beta g \rho_{f}\left(T-T_{0}\right) \sin \theta
\end{aligned}
$$

where $\mu_{\mathrm{f}}$ is the dynamic velocity of the fluid, which in this case is water, $K$ is the permeability of the surrounding rock (sandstone), and $p$ is the pressure. The symbol $\beta$ represents the expansion coefficient, $g$ is the gravitational constant of $9.81 \mathrm{~m} / \mathrm{s}^{2}, \rho_{\mathrm{f}}$ is the density of water, $T$ is the temperature, $T_{0}$ is the neighboring temperature, and $\theta$ is the angle of inclination of the system. The velocity in the $\mathrm{x}$ direction is represented by $u$ and the velocity in the $y$ direction is given by $v$. The energy equation is the final equation written to govern the heat transfer in the system.

$$
u \frac{\partial T}{\partial x}+v \frac{\partial T}{\partial y}=\left(\frac{k_{a}}{\partial c_{p}}\right)\left(\frac{\partial^{2} T}{\partial x^{2}}+\frac{\partial^{2} T}{\partial y^{2}}+\frac{\dot{q}^{\prime \prime}}{k}\right)
$$

In the energy equation, $k_{a}$ is the apparent thermal conductivity, $c_{p}$ is the specific heat of water and rock combined and $q^{\prime \prime \prime}$ is the heat generation per unit volume. To obtain an 
apparent thermal conductivity, the following equation was used, where $\phi$ is the porosity and $\mathbf{k}_{\mathrm{s}}$ is the thermal conductivity of the rock, which is that of sandstone.

$$
k_{a}=\phi k_{f}+(1-\phi) k_{s}
$$

Implementing the use of the stream function, $\psi$, the continuity equation is then satisfied by defining $\psi$ in terms of $u$ and $v$ in the following manner.

$$
\begin{aligned}
& u=\frac{\partial \psi}{d y} \\
& v=-\frac{\partial \psi}{\partial x}
\end{aligned}
$$

The continuity in terms of the stream function is then

$$
\frac{\partial^{2} \psi}{\partial x^{2}}+\frac{\partial^{2} \psi}{\partial y^{2}}=0
$$

After taking the derivative for the $\mathrm{x}$ component of equation $5.4 \mathrm{a}$ and the derivative of the $y$ component of $5.4 \mathrm{~b}$, and then subtracting the two results, the pressures are eliminated, resulting in one equation for the momentum.

$$
\frac{\mu_{f}}{K}\left(\frac{\partial u}{\partial y}-\frac{\partial v}{\partial x}\right)=\beta g \rho_{f}\left(\frac{\partial T}{\partial y} \cos \theta-\frac{\partial T}{\partial x} \sin \theta\right)
$$

The previous definitions of the stream function in equation $5.7 \mathrm{a}$ and $5.7 \mathrm{~b}$ are then implemented so the steady state equation for momentum is given as:

$$
\frac{\partial^{2} \psi}{\partial x^{2}}+\frac{\partial^{2} \psi}{\partial y^{2}}=\frac{\beta g \rho_{f} K}{\mu_{f}}\left(\frac{\partial T}{\partial y} \cos \theta-\frac{\partial T}{\partial x} \sin \theta\right)
$$

Similarly, the velocity terms in the energy equation are replaced by the streamfunction representation: 


$$
\frac{\partial \psi}{\partial y} \frac{\partial T}{\partial x}-\frac{\partial \psi}{\partial x} \frac{\partial T}{\partial y}=\left(\frac{k_{a}}{\rho c_{p}}\right)\left(\frac{\partial^{2} T}{\partial x^{2}}+\frac{\partial^{2} T}{\partial y^{2}}+\frac{q^{\prime \prime \prime}}{k}\right)
$$

The convective components for the equation above are represented by the terms on the left hand side and those on the right hand side are the conductive components along with a heat generation term supplied by nuclear fission in the reactor. Adding the change in temperature with time results in the transient form of the energy equation.

$$
\frac{\partial T}{\partial t}=\left(\frac{k_{a}}{\rho c_{p}}\right)\left(\frac{\partial^{2} T}{\partial x^{2}}+\frac{\partial^{2} T}{\partial y^{2}}+\frac{\dot{q}^{\prime \prime}}{k}\right)-\frac{\partial \psi}{\partial y} \frac{\partial T}{\partial x}+\frac{\partial \psi}{\partial x} \frac{\partial T}{\partial y}
$$

Application of the appropriate boundary conditions and initial conditions must then be carried out. For the natural reactor, the boundary conditions at all walls (edges of reactor) are constant temperature and the initial conditions are constant temperature. Both the boundary condition and initial condition temperatures are calculated from the geothermal gradient that results as depth increases. Natural convection is induced through input of heat sources throughout the reactor mesh. Heat generation is the result of the fission processes discussed in Chapter 2. Values of velocities may then be "backed" out of the calculated stream functions. Once the velocities are known, pressures may be obtained by using Darcy's Law, which is stated below.

$$
\begin{aligned}
& u=-\frac{K}{\mu_{f}} \frac{\partial p}{\partial x} \\
& v=-\frac{K}{\mu_{f}} \frac{\partial p}{\partial y}
\end{aligned}
$$


5.2 Analytical Solution of the Steady State Heat Transfer on a Two-dimensional Plate

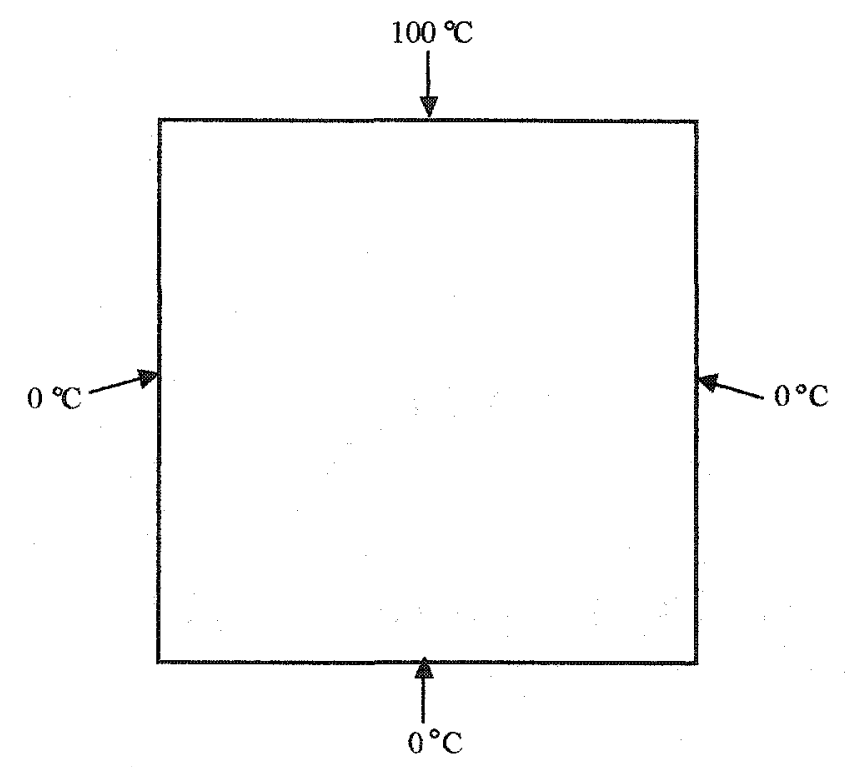

Figure 5.1 Two-dimensional Steady Heat Conduction on a Flat Plate

A transient conduction problem will eventually come to a steady state solution for the temperature distribution at every point on a plate. This is a good verification of the validity of results obtained through the relaxation numerical solution. A two-dimensional flat plate initially with zero temperature at the interior nodes and with isothermal boundary conditions as shown in Figure 5.1, is governed by the Equation 5.5, with the convection terms (left side) equal to zero. This is known as the Laplace equation and may be solved through separation of variables since the boundary conditions are homogeneous. The first step is the assumption of a product solution shown in equation 5.14 .

$$
T(x, y)=X(x) \cdot Y(y)
$$


Using this assumption the equation with constant thermal conductivity, density, and specific heat becomes, the heat conduction equation becomes:

$$
X \frac{\partial^{2} X}{\partial x^{2}}+Y \frac{\partial^{2} Y}{\partial y^{2}}=0
$$

Both variables are set equal to a constant value, $\gamma$ :

$$
X \frac{\partial^{2} X}{\partial x^{2}}=-Y \frac{\partial^{2} Y}{\partial y^{2}}=\gamma
$$

and the two equations may be written to derive $\mathrm{X}$ and $\mathrm{Y}$.

$$
\begin{aligned}
& \frac{d^{2} X}{d x^{2}}+X(x) \cdot y=0 \\
& \frac{d^{2} Y}{d y^{2}}-Y(y) \cdot y=0
\end{aligned}
$$

The only non-trivial solution is obtained when $\gamma$ not equal to 0 . The solutions for $\mathrm{x}$ and $\mathrm{y}$ using $\gamma=\lambda^{2}$ are then:

$$
\begin{aligned}
& X(x)=A \sin \lambda x+B \cos \lambda x \\
& Y(y)=C \sinh \lambda y+D \cosh \lambda y
\end{aligned}
$$

Equations for $\mathrm{X}(\mathrm{x})$ and $\mathrm{Y}(\mathrm{y})$ are substituted back into equation (5.14) to yield the steady state temperature distribution as a function of $\mathrm{x}$ and $\mathrm{y}$.

$$
T(x, y)=(A \sin \lambda x+B \cos \lambda x) \cdot(C \sinh \lambda x+D \cosh \lambda x)
$$

Constants A, B, C and D are solved for by using the appropriate boundary conditions. After application of boundary conditions (shown in Figure 5.1) to the Sturm-Liouville equation and use of the Fourier sine expansion, the following equation is obtained for temperature as a function of the $\mathrm{x}$ and $\mathrm{y}$ positions. 


$$
T(x, y)=\frac{2 T_{0}}{\pi} \sum_{n=1}^{\infty} \frac{1-(-1)^{n}}{n} \frac{\sin \left(\frac{n \pi}{a}\right) x \sinh \left(\frac{n \pi}{a}\right) y}{\sinh \left(\frac{n \pi}{a}\right) b}
$$




\section{CHAPTER 6}

\section{NUMERICAL THEORY}

The numerical approximation of the governing equations listed in the previous section is achieved easily through use of a central differencing technique. The central differencing form of the finite difference equations consists of taking the values at the next node in the positive direction subtracting the previous node, and then dividing the difference by twice the distance.

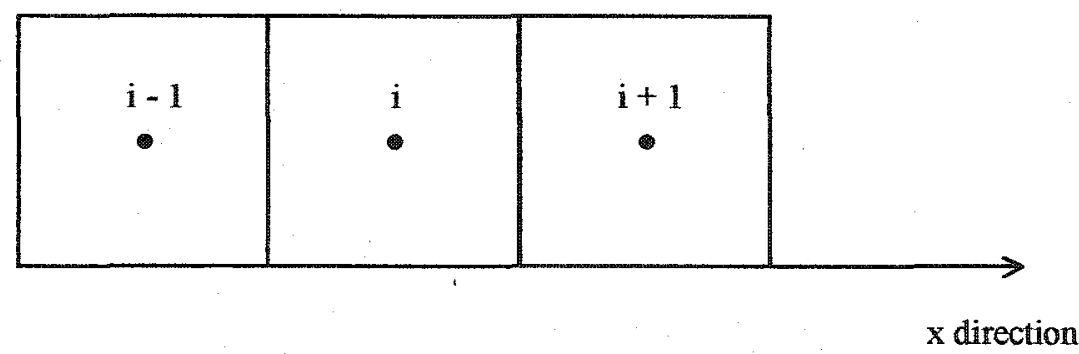

Figure 6.1 Central Difference Scheme

For example in Figure 6.1, to find the derivative of neutron flux with respect to $x$, the equation with central differencing would look like:

$$
\frac{d \Phi}{d x}=\frac{\Phi_{i+1}-\Phi_{i-1}}{2 \Delta x}
$$

where $\Delta \mathrm{x}$ is the distance between each node. The second derivative is then as follows:

$$
\frac{d^{2} \Phi}{d x^{2}}=\frac{\Phi_{i+1}-\Phi_{i-1}-2 \Phi_{i}}{(\Delta x)^{2}}
$$


If the difference is taken in the second direction $y$, a j subscript is included in addition to that of the $i$. The neutron diffusion equation is then:

$$
\frac{1}{v} \frac{\Phi_{i, j}^{t+1}-\phi_{i, j}^{t}}{\Delta}=D\left(\frac{\Phi_{i+1, j}^{t+1}+\Phi_{i-1, j}^{t+1}-2 \Phi_{i, j}^{t+1}}{(\Delta x)^{2}}+\frac{\Phi_{i, j+1}^{t+1}+\Phi_{i, j-1}^{t+1}-2 \Phi_{i, j}^{t+1}}{(\Delta y)^{2}}\right)-\Sigma_{a} \phi_{i, j}+S
$$

where $t$ is the old time step and $t+1$ is the new time step.

$$
\Phi_{i, j}^{t+1}=\left(\frac{\Phi_{i, j}^{t}}{v \Delta t}+D\left(\frac{\Phi_{i+1, j}^{t+1}+\Phi_{i-1, j}^{t+1}}{(\Delta x)^{2}}+\frac{\Phi_{i, j+1}^{t+1}+\Phi_{i, j-1}^{t+1}}{(\Delta y)^{2}}\right)+S\right) \times \frac{1}{\left(\frac{1}{v \Delta t}+\frac{2 D \Delta t}{(\Delta x)^{2}}+\frac{2 D \Delta t}{(\Delta y)^{2}}+\Sigma_{a}\right)}
$$

Applying the central difference to the momentum equation results in the following finite difference solution for the stream function at the new time step for each node:

$$
\begin{aligned}
& \frac{\psi_{i+1, j}^{t+1}+\psi_{i-1, j}^{t+1}-2 \psi_{i, j}^{t+1}}{(\Delta x)^{2}}+\frac{\psi_{i, j+1}^{t+1}+\psi_{i, j-1}^{t+1}-2 \psi_{i, j}^{t+1}}{(\Delta y)^{2}}=\frac{\beta g \rho_{f} K}{\mu_{f}}\left(\begin{array}{c}
\frac{T_{i, j+1}{ }^{t+1}-T_{i, j-1}{ }^{t+1}}{2 \Delta y} \cos \theta \\
-\frac{T_{i+1, j}{ }^{t+1}-T_{i-1, j}{ }^{t+1}}{2 \Delta x} \sin \theta
\end{array}\right) \\
& \psi_{i, j}^{t+1}=\left(\frac{\psi_{i+1, j}^{t+1}+\psi_{i-1, j}^{t+1}}{(\Delta x)^{2}}+\frac{\psi_{i, j+1}^{t+1}+\psi_{i, j-1}^{t+1}}{(\Delta y)^{2}}-\frac{\beta g \rho_{f} K}{\mu_{f}}\left(\begin{array}{c}
\frac{T_{i, j+1}{ }^{t+1}-T_{i, j-1}{ }^{t+1}}{2 \Delta y} \cos \theta \\
-\frac{T_{i+1, j}{ }^{t+1}-T_{i-1, j}{ }^{t+1}}{2 \Delta x} \sin \theta
\end{array}\right)\right) \\
& \quad \times \frac{1}{\left(\frac{2}{(\Delta x)^{2}}+\frac{2}{(\Delta y)^{2}}\right)}
\end{aligned}
$$


The stream function is treated as quasi-steady, meaning the steady state solution is solved at each time step, thus there is no transient term in the equation. The transient energy equation is obtained by solving for temperature values at each node:

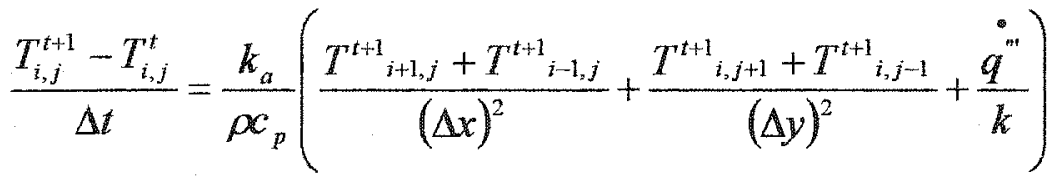

$$
\begin{aligned}
& -\frac{\psi^{i}{ }_{i, j+1}-\psi^{t}{ }_{i, j-1}}{2 \Delta y} \frac{T^{t+1}{ }_{i+1, j}-T^{t+1}{ }_{i-1, j}}{2 \Delta x}+\frac{\psi^{t}{ }_{i+1, j}-\psi^{t}{ }_{i-1, j}}{2 \Delta x} \frac{T^{t+1}{ }_{i, j+1}-T^{t+1}{ }_{i, j-1}}{2 \Delta y}
\end{aligned}
$$

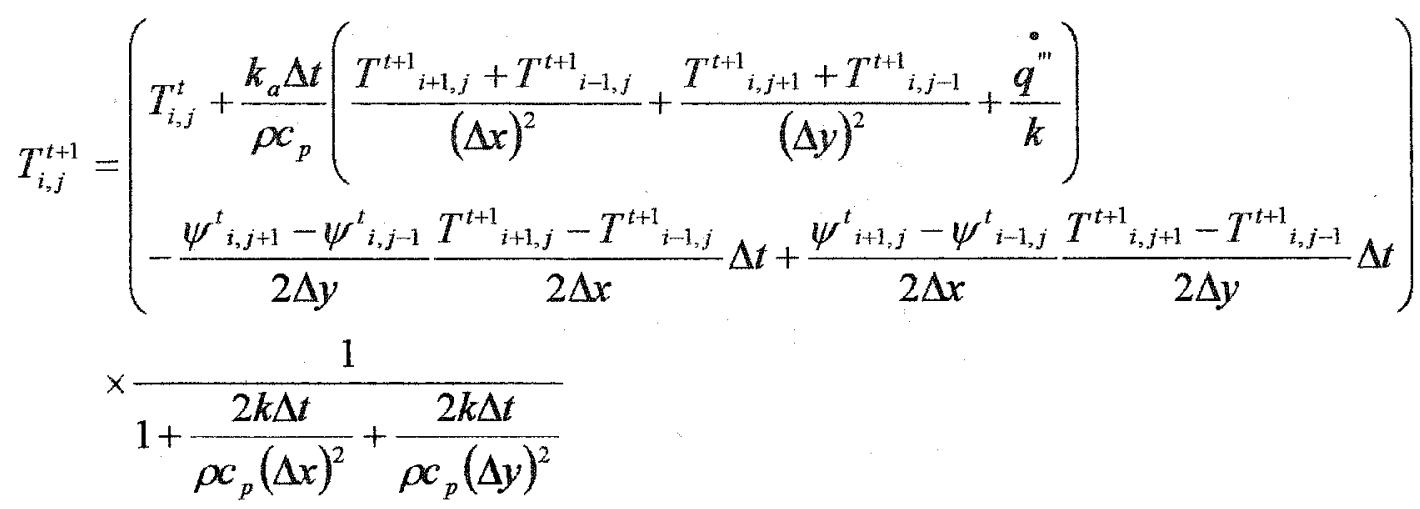

Using the neutron diffusion, momentum and energy equations coupled together, an iterative procedure may be used to iteratively solve for neutron flux, streamfunction and temperature at every node. The updated values are then acquired through the governing equations and then repeated until convergence is attained. A relaxation numerical method is used so the updated value of $\phi_{\mathrm{i}, \mathrm{j}}$ is given by:

$$
\phi_{i, j}^{t+1}=\phi_{i, j}^{t}+r\left(\phi_{i, j}^{c a t e}-\phi_{i, j}^{t}\right)
$$

in which $\phi_{i, j}^{\text {calc }}$ is the value computed from equation $6.3 \mathrm{~b}, \phi_{i, j}^{t}$ is the value from the previous iteration and $\mathrm{r}$ is the relaxation factor. For under-relaxation the value for $\mathrm{r}$ is less than 1.0, and for over-relaxation the value for $\mathrm{r}$ is greater than 1.0. The same 47 
procedure is used to calculate values of the stream function at every node in which $\psi_{i, j}^{\text {calc }}$ and $T_{i, j}^{c a l c}$ are acquired through use of equations $6.4 \mathrm{~b}$ and $6.5 \mathrm{~b}$.

$$
\begin{aligned}
& \psi_{i, j}^{t+1}=\psi_{i, j}^{t}+r\left(\psi_{i, j}^{\text {calc }}-\psi_{i, j}^{t}\right) \\
& T_{i, j}^{t+1}=T_{i, j}^{t}+r\left(T_{i, j}^{\text {calc }}-T_{i, j}^{t}\right)
\end{aligned}
$$

The values for neutron flux, streamfunction and temperature are solved implicitly through use of the equations discussed previously. Convergence is based on the tolerance values given for each variable and the limit on the maximum number of iterations specified. 


\section{CHAPTER 7}

\section{COMPUTER PROGRAM}

\subsection{Oklo transient Code}

The computer program developed consists of one-group neutron theory, twodimensional fluid flow and heat transfer in a porous medium, and thermodynamic properties of water. Since all fission reactions are due to thermal neutrons (slow neutrons), fast neutron groups have been neglected for the preliminary version of the program. All of the program, subroutines and functions are written in Fortran 90 source code. The main program Oklo_transient calis the various subroutines, which then calculate streamfunctions, temperatures, velocities and pressures, check for convergence and carry out the appropriate number of iterations. During calculation of quantities that involve thermodynamic properties of water, the appropriate function for the property needed is called by passing the pressure, temperature and any other variables required. The functions compute dynamic viscosity, thermal conductivity, specific heat, density, and the compressibility factor for water. The functions are valid within a temperature range up to $1450^{\circ} \mathrm{C}$ and pressures up to $100 \mathrm{MPa}$, extending beyond the range of operation of the Oklo reactors. All properties of the rock are considered to be that of sandstone $\left(\mathrm{SiO}_{2}\right)$, with five percent concentrations of $\mathrm{Al}_{2} \mathrm{O}_{3}$ and $\mathrm{Fe}_{2} \mathrm{O}_{3}$ within each volume. The porosity of sandstone may be varied, however, the pores at this depth were considered to be fully saturated. First the program reads the defined constant information 
such as the number of nodes in each direction, initial pressures and temperatures, rock properties, and the angle of inclination of the reactor. After reading the input data, the cross-sections for absorption, fission and scattering are defined. The program enters a loop for incrementing time and the various iteration cycles for each variable are encountered.

Neutron flux is calculated first by calculating the number densities of each element, macroscopic cross-sections corrected for temperature, individual factors of the four-factor equation, logarithmic energy decrement and finally the diffusion coefficient. Hydrogen is a moderator, and the fission process depends upon the number density of hydrogen, as well as other elements and their isotopes, present in the system. The only hydrogen found in the reactor is found in the form of water, and the density changes with temperature. As the density goes down, so does the number density of hydrogen. Temperature and pressure are passed into the function for the density of water during each iteration, and for each time step until convergence is achieved. The various values of the four-factor equation along with the diffusion coefficient are then calculated. The neutron diffusion equation is then solved and checked for convergence. This cycle is repeated until the convergence criterion for the neutron flux is met. At each new time step, the source of neutrons is calculated and then introduced into the neutron diffusion equation.

The temperature iteration is then started and is then carried out until the convergence criterion is accomplished. The value of the heat generation rate produced by fission is then calculated. Heat generation is based on the converged neutron flux. The temperature distribution is next computed based on the streamfunction and heat 
generation through the energy equation. The streamfunction affects the overall temperature through convective dissipation. Functions for specific heat, density and the compressibility factor for water are called along with the volume-averaged thermal conductivity in each iteration for each time step.

As the temperature increases, changes in the density of water within the reactor also change, leading to movement of water due to natural convection. The streamfunction computation is carried out in the same manner as both the neutron flux and temperature iterations.

7.2 Verification of Transient Neutron Flux Diffusion on a Flat Plate

To verify that the computer code properly models the transient neutron flux within a reactor, an analytical transient solution is used. First, the analytical solution of the neutron flux distribution as shown in Chapter 2, is used to solve for the distribution over the geometry with the boundary conditions shown in Figure 2.2. With an initial flux of 100 neutrons $/ \mathrm{m}^{2} \mathrm{sec}$ and a diffusion coefficient of $0.001 \mathrm{~m}^{2} / \mathrm{sec}$, the flux distribution at a time of 10 seconds is found. Figures 7.1 and 7.2 show the analytical values calculated for a one meter by one meter plate with a $\Delta x$ and $\Delta y$ equal to 0.1 meters and the conditions shown in Figure 2.2. Figures 7.3 and 7.4 show the values obtained from the Oklo_transient code with identical boundary and initial conditions. Table 7.1 shows values of the error between the code predictions and the analytical solution over the entire plate. Figures 7.5 and 7.6 show plots of the percent error as a function of $x$ and $y$ over the surface of the plate. Figures $7.1,7.2,7.3$ and 7.4 are in good agreement with each other, indicating very little difference between the analytical solution and that of the Oklo code. The results were compared at different points in time, although only the solution at 
10 seconds is shown in the figures. Table 7.1 shows a maximum error of 7.9 percent when compared to the analytical solution. This occurs at the comers of the plate, where a higher error would be expected, and shows good agreement between the code and theory.

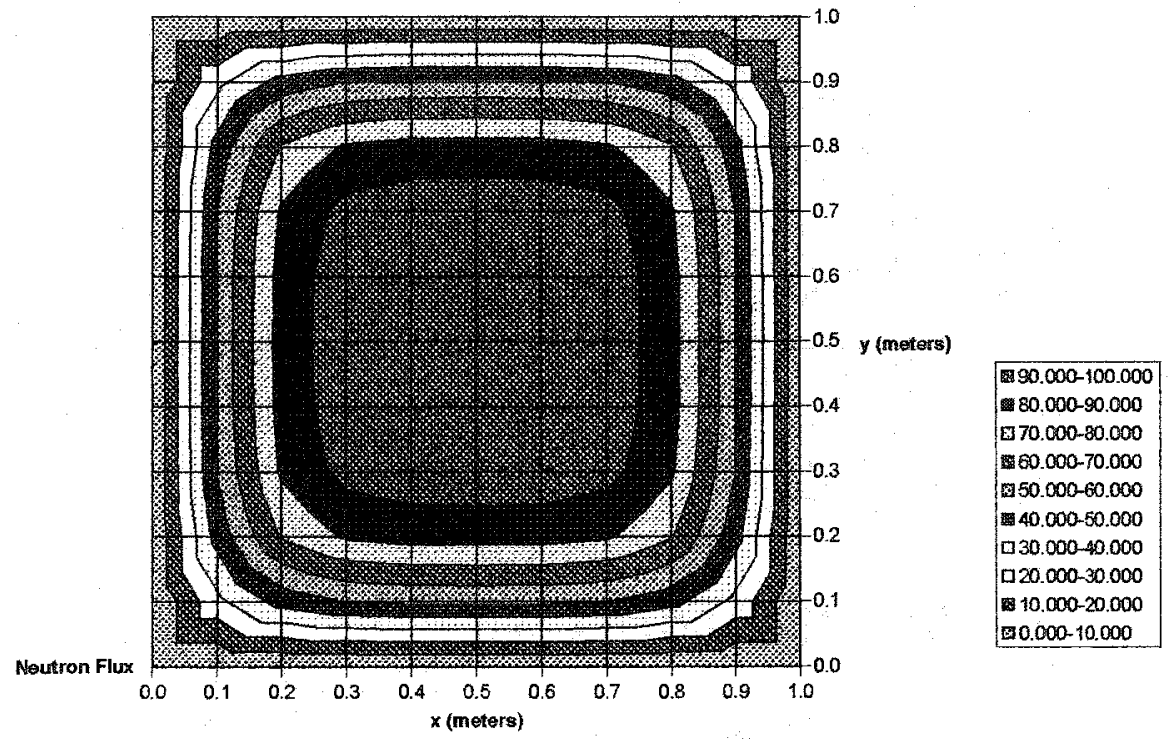

Figure 7.1 Contour Plot of the Transient Neutron Flux for the Analytical Solution on a Flat Plate at 10 seconds

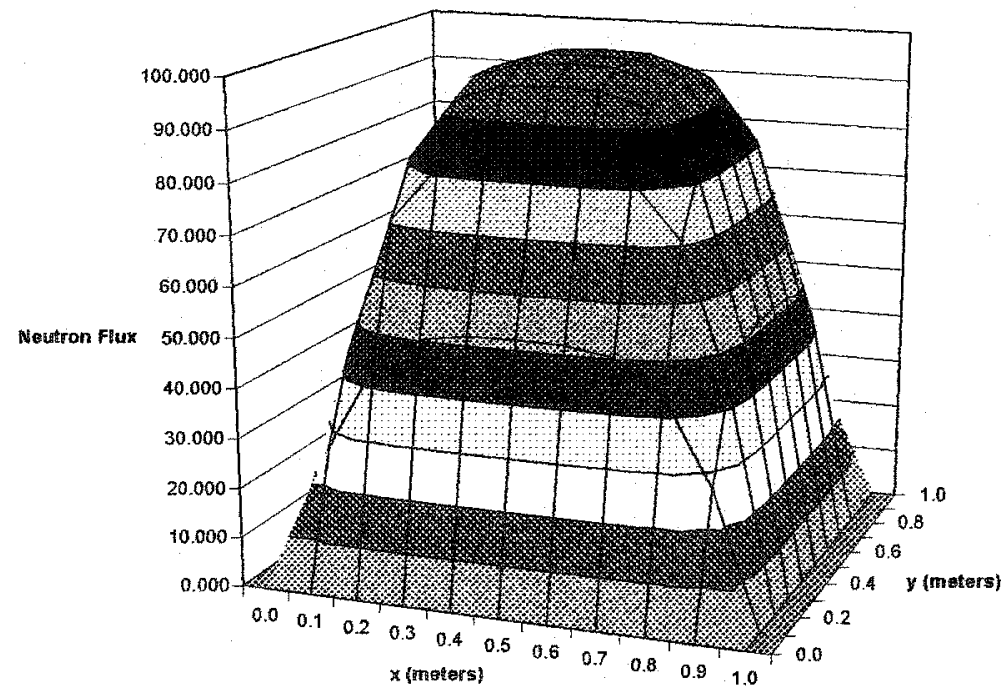

Figure 7.2 Surface Plot of the Transient Neutron Flux Surface Plot for the Analytical Solution on a Flat Plate at 10 seconds 


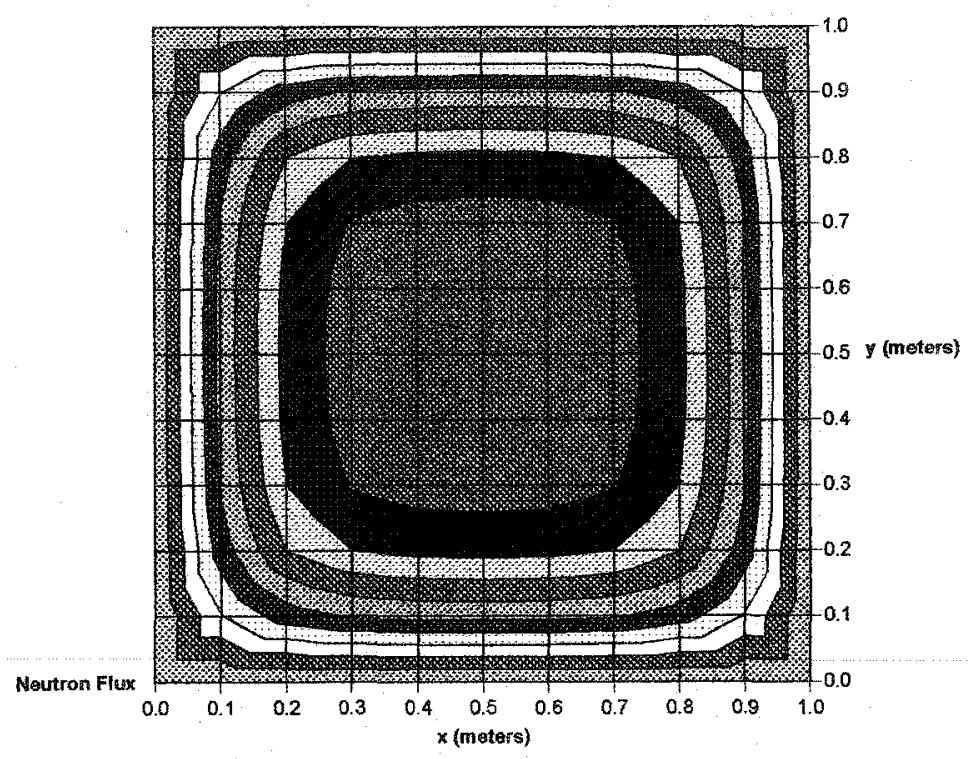

$900.000-100.000$

$80.000-90.000$

$\square 70.000-80.000$

$600.000-70.000$

\$50.000-60.000

$40.000-50.000$

$030.000-40.000$

口20.000-30.000

$10.000-20.000$

a $0.000-10.000$

Figure 7.3 Oklo_transient Code - Transient Neutron Flux Contour Plot on a Flat Plate at 10 seconds
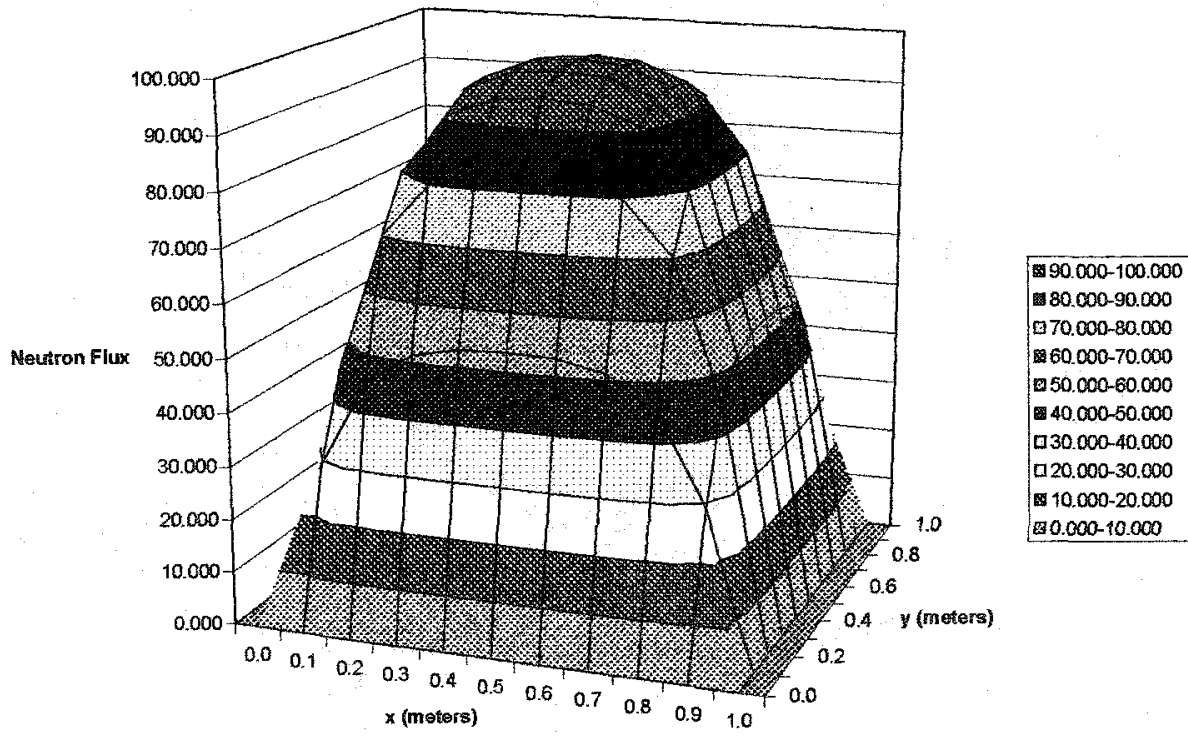

Figure 7.4 Oklo_transient Code - Transient Neutron Flux Surface Plot on a Flat Plate at 10 seconds 


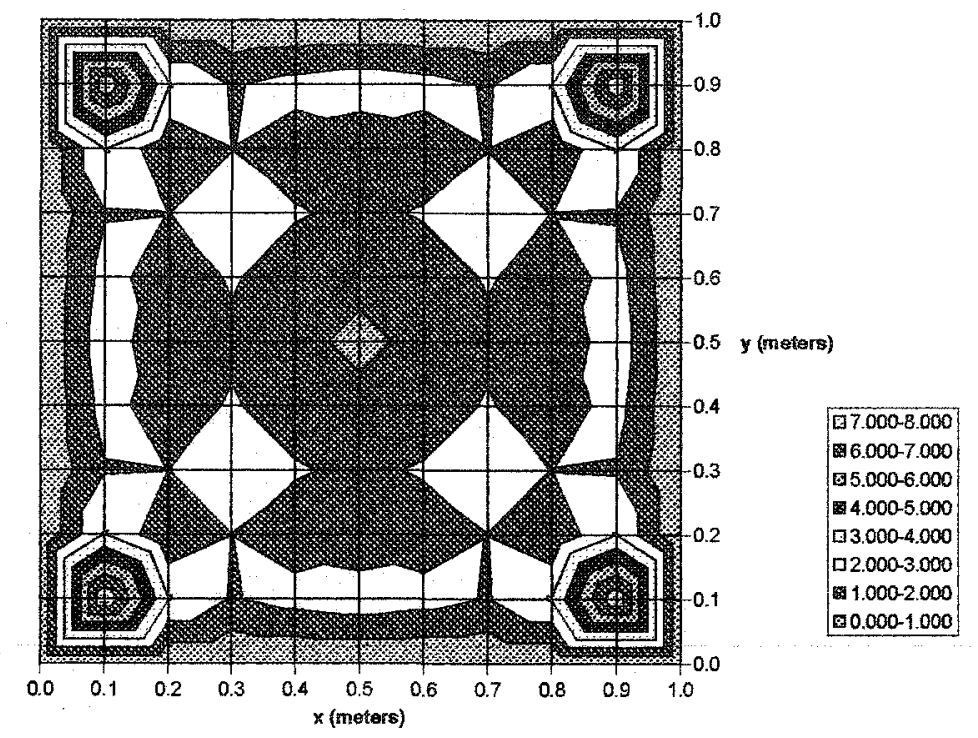

Figure 7.5. Percent Error of Oklo_transient Neutron Flux vs. Analytical Solution Surface Plot Across the Flat Plate

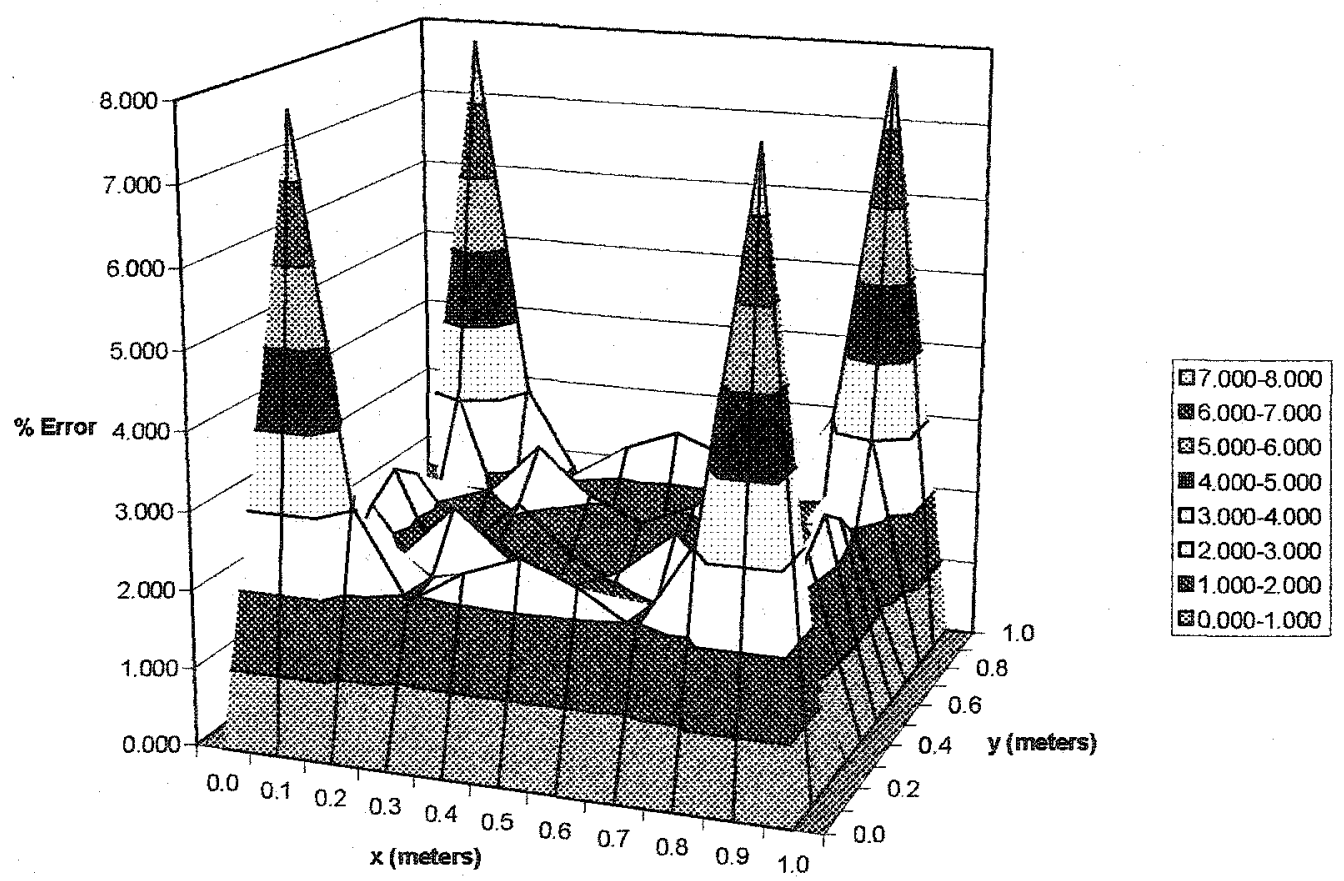

Figure 7.6 Error in Neutron Flux between Oklo_transient and the Analytical Solution 
Table 7.1. Percent Error of Neutron Flux Across the Flat Plate

\begin{tabular}{|c|c|c|c|c|c|c|c|c|c|c|c|}
\hline & 0.0 & 0.1 & 0.2 & 0.3 & 0.4 & 0.5 & 0.6 & 0.7 & 0.8 & 0.9 & 1.0 \\
\hline 0.0 & 0.000 & 0.000 & 0.000 & 0.000 & 0.000 & 0.000 & 0.000 & 0.000 & 0.000 & 0.000 & 0.000 \\
\hline 0.1 & 0.000 & 7.856 & 3.064 & 1.925 & 2.363 & 2.637 & 2.368 & 1.933 & 3.064 & 7.830 & 0.000 \\
\hline 0.2 & 0.000 & 3.064 & 1.130 & 1.990 & 1.468 & 1.177 & 1.462 & 1.981 & 1.126 & 3.048 & 0.000 \\
\hline 0.3 & 0.000 & 1.925 & 1.990 & 2.690 & 2.104 & 1.798 & 2.098 & 2.679 & 1.982 & 1.916 & 0.000 \\
\hline 0.4 & 0.000 & 2.363 & 1.468 & 2.104 & 1.484 & 1.167 & 1.477 & 2.092 & 1.458 & 2.358 & 0.000 \\
\hline 0.5 & 0.000 & 2.637 & 1.177 & 1.798 & 1.167 & 0.846 & 1.160 & 1.786 & 1.166 & 2.632 & 0.000 \\
\hline 0.6 & 0.000 & 2.368 & 1.462 & 2.098 & 1.477 & 1.160 & 1.470 & 2.086 & 1.453 & 2.362 & 0.000 \\
\hline 0.7 & 0.000 & 1.933 & 1.981 & 2.679 & 2.092 & 1.786 & 2.086 & 2.669 & 1.974 & 1.922 & 0.000 \\
\hline 0.8 & 0.000 & 3.064 & 1.126 & 1.982 & 1.458 & 1.166 & 1.453 & 1.974 & 1.124 & 3.046 & 0.000 \\
\hline 0.9 & 0.000 & 7.830 & 3.048 & 1.916 & 2.358 & 2.632 & 2.362 & 1.922 & 3.046 & 7.806 & 0.000 \\
\hline 1.0 & 0.000 & 0.000 & 0.000 & 0.000 & 0.000 & 0.000 & 0.000 & 0.000 & 0.000 & 0.000 & 0.000 \\
\hline
\end{tabular}

\subsection{Verification of Steady State Heat Conduction on a Flat Plate}

Results from the numerical code were also compared to an analytical solution to verify that the code could accurately predict the conduction of heat within the Oklo reactor. A one meter by one meter plate with $\Delta x$ and $\Delta y$ equal to 0.1 meter was analyzed with the conditions shown in Figure 5.1. The values from the analytical solution for temperature are plotted in Figure 7.7 and Figure 7.8. Values from the Oklo_transient code are shown in Figure 7.9 and Figure 7.10. Table 7.2 lists the error between the Oklo_transient values and the analytical solution. Figures 7.11 and Figure 7.12 show plots of the error over the entire plate. A maximum percent error value of 2.5 percent was found at the comers of the reactor model. The plots of Figure 7.7, 7.8, 7.9 and 7.10 are almost identical and a maximum value of 2.5 percent error shows excellent agreement between the analytical solutions and those produced by the code. These values also showed that the code performed in the proper manner due to the fact that the correct steady state solution was reached. If the code were not performing correctly, a steady 
state temperature distribution similar to that of the analytical solution would not be achieved through the use of a transient analysis.

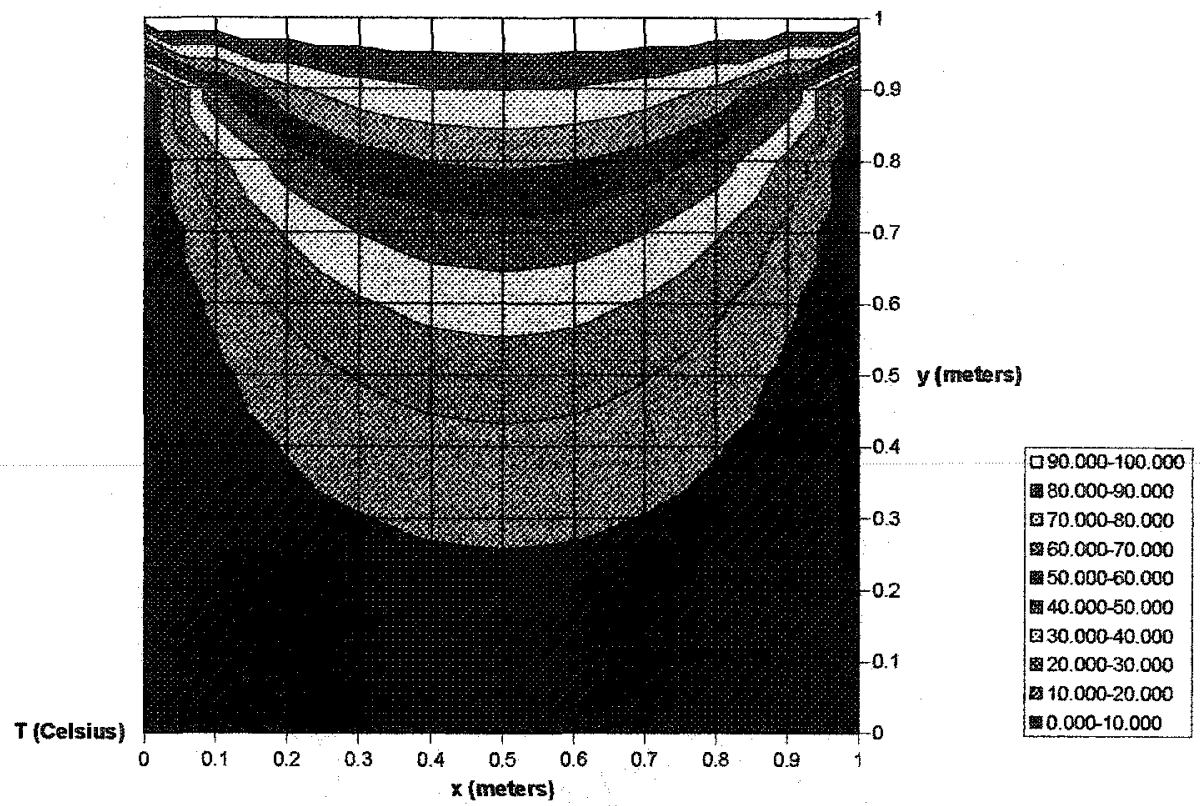

Figure 7.7 Contour Plot for the Steady State Temperature Distribution for the Analytical Solution of Conduction on a Flat Plate

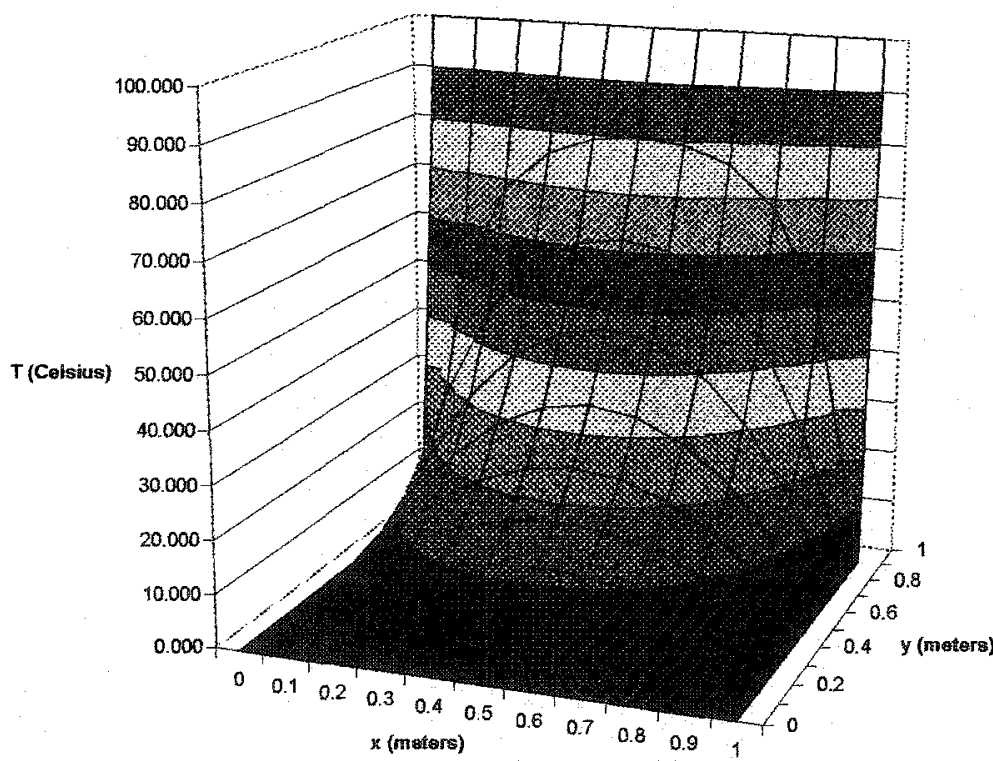

Figure 7.8 Surface Plot of the Steady State Temperature Distribution for the Analytical Solution of Conduction on a Flat Plate 

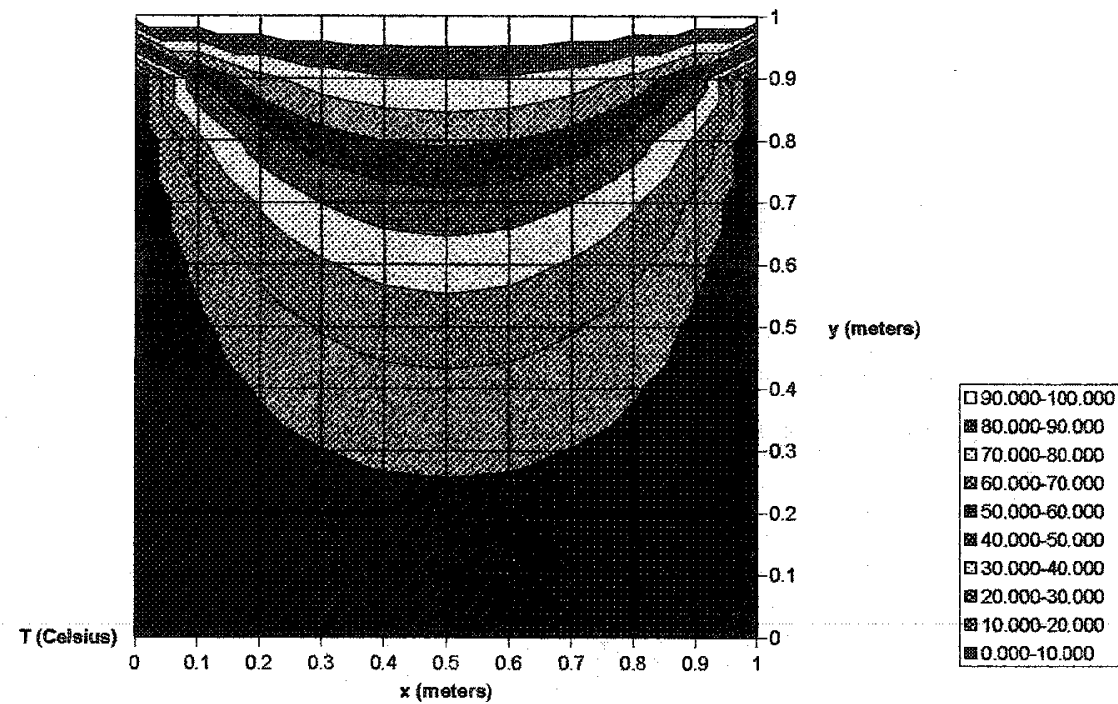

Figure 7.9 Oklo_transient Code-Contour Plot of the Steady State Temperature Distribution for Conduction on a Flat Plate

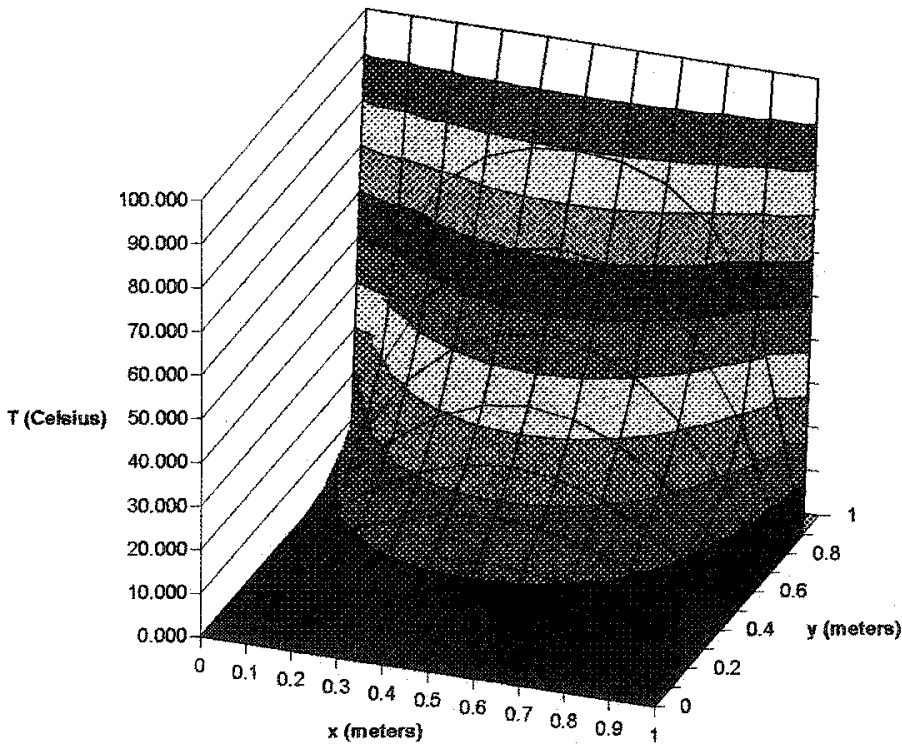

Figure 7.10 Oklo_transient Code-Surface Plot of the Steady State Temperature Distribution for Conduction on a Flat Plate 


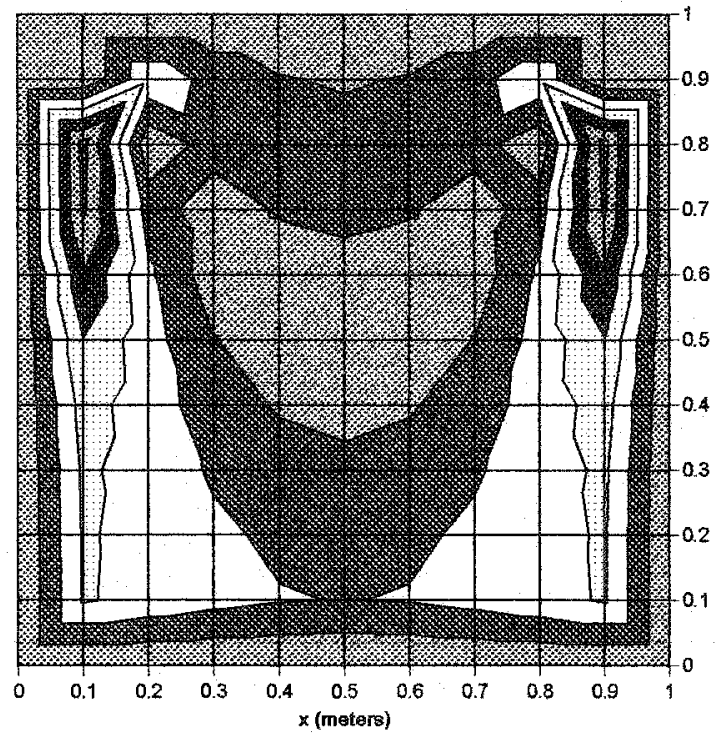

$y$ (meters)

240-2.80

$2.00-2.40$

$1.60-2.00$

$01.20-1.60$

D0.80-1.20

$0.00-0.40$

Figure 7.11 Contour Plot Percent Error of Oklo transient vs. Analytical Solution Contours Across the Flat Plate

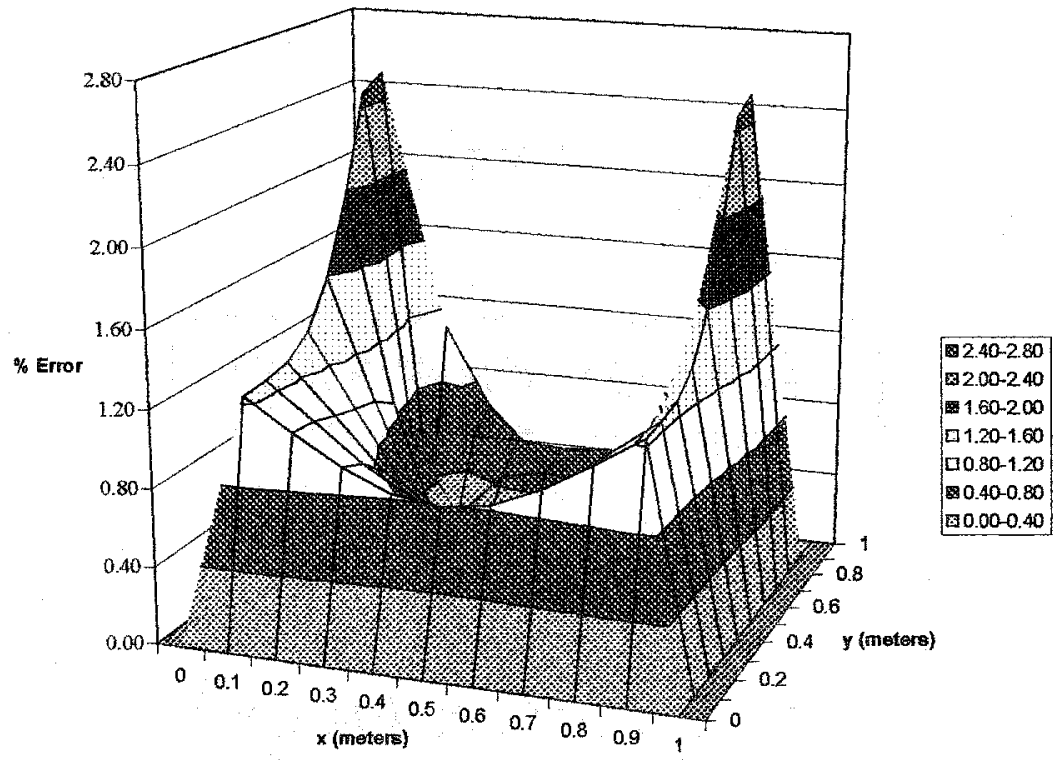

Figure 7.12 Percent Error of Oklo_transient vs. Analytical Solution Surface Plot Across the Flat Plate 
Table 7.2. Percent Error of Steady State Temperature Across the Flat Plate

\begin{tabular}{|c|c|c|c|c|c|c|c|c|c|c|c|c|}
\hline & & & & & & $y(\mathrm{~m})$ & & & & & & \\
\hline & & 0.0 & 0.1 & 0.2 & 0.3 & 0.4 & 0.5 & 0.6 & 0.7 & 0.8 & 0.9 & 1.0 \\
\hline & 0.0 & 0.00 & 0.00 & 0.00 & 0.00 & 0.00 & 0.00 & 0.00 & 0.00 & 0.00 & 0.00 & 0.00 \\
\hline & 0.1 & 0.00 & 1.23 & 1.25 & 1.27 & 1.37 & 1.59 & 1.97 & 2.47 & 2.54 & 0.03 & 0.00 \\
\hline & 0.2 & 0.00 & 1.08 & 1.06 & 1.02 & 0.98 & 0.95 & 0.87 & 0.61 & 0.10 & 1.09 & 0.00 \\
\hline & 0.3 & 0.00 & 0.93 & 0.87 & 0.76 & 0.61 & 0.42 & 0.16 & 0.18 & 0.56 & 0.67 & 0.00 \\
\hline$x(\mathrm{~m})$ & 0.4 & 0.00 & 0.82 & 0.73 & 0.56 & 0.36 & 0.10 & 0.18 & 0.44 & 0.57 & 0.43 & 0.00 \\
\hline & 0.5 & 0.00 & 0.79 & 0.67 & 0.50 & 0.27 & 0.00 & 0.28 & 0.49 & 0.55 & 0.36 & 0.00 \\
\hline & 0.6 & 0.00 & 0.82 & 0.73 & 0.56 & 0.36 & 0.10 & 0.18 & 0.44 & 0.57 & 0.43 & 0.00 \\
\hline & 0.7 & 0.00 & 0.93 & 0.87 & 0.76 & 0.61 & 0.42 & 0.16 & 0.18 & 0.56 & 0.67 & 0.00 \\
\hline & 0.8 & 0.00 & 1.08 & 1.06 & 1.02 & 0.98 & 0.95 & 0.87 & 0.61 & 0.10 & 1.09 & 0.00 \\
\hline & 0.9 & 0.00 & 1.23 & 1.25 & 1.27 & 1.37 & 1.59 & 1.97 & 2.47 & 2.54 & 0.03 & 0.00 \\
\hline & 1.0 & 0.00 & 0.00 & 0.00 & 0.00 & 0.00 & 0.00 & 0.00 & 0.00 & 0.00 & 0.00 & 0.00 \\
\hline
\end{tabular}

\subsection{Verification of Transient Mass Transfer on a Flat Plate}

The final case studied was that of the convective flow and mass transfer of a fluid in the cavity with the boundary conditions shown in Figure 7.13. Due to heat generation, fluid flow would be present in the pore water of the reactor due to natural convection. A simple check of the streamfunction was conducted for a time equal to 20,000 seconds after commencing operation of the reactor. The simulation was carried out for a $\mathrm{UO}_{2}$ concentration of 15 percent in the reactor core and 5 percent in the surrounding areas and with a porosity of 20 percent as seen in Figure 8.5. The fluid flow induced by the difference in the buoyancy of the fluid at various locations caused natural or free convection. In the case studied, the flow in the reactor would be representative of that of a fluid flow in a closed rectangular box heated from below. Flow in such a system would be expected to have a bifurcating flow pattern. The streamfunctions in Figure 8.6 contained two distinct cells, consistent with the expected flow pattern. Pressures and velocities can be calculated from these values for the streamfunction. The flows shown 
in Figures 8.6 through 8.10 show good agreement with the expected bifurcating flow at $20,000,40,000,60,000,80,000$, and 100,000 seconds after reactor operation commenced. 


\section{CHAPTER 8}

\section{DISCUSSION OF RESULTS}

The Oklo transient code was pursued in the interest of developing a computer model to replicate conditions and behavior found to occur in core samples at the Oklo reactor site, as well as those hypothesized by previous researchers. The focus of this investigation was to determine reactor operating conditions such as the temperature range over time, pressure variation, flow patterns and the possibility of periodic fluctuations during critical operation.

\begin{tabular}{|l|l|l|l|l|l|l|l|}
\hline & & & & & & & \\
\hline & & & & & & & \\
\hline & & & & & & & \\
\hline & & & & & & & \\
\hline & & & & & & & \\
\hline & & & & & & & \\
\hline & & & & & & & \\
\hline
\end{tabular}

Figure 8.1 Control Volume Representation of the Oklo Reactor

There were a series of over 19 sites in Gabon, Africa where small lens-like natural reactors operated over 2 billion years ago. A representative Oklo reactor has been modeled numerically using finite differences and the geometry shown in Figure 8.1. The Oklo reactor model was approximately $6 \mathrm{~m}$ long by $1 \mathrm{~m}$ high represented by the two 
filled squares in Figure 8.1. An impermeable layer of clay below the reactor prevented the flow of water and another impermeable layer of clay capped the uranium-rich sandstone shown at the top of the figure.

The two-dimensional reactor geometry represented a semi-infinite extending in the $z^{-}$ direction. Three cases of $\mathrm{UO}_{2}$ concentrations in the reactor core were investigated; 9,15 and 30 percent in the shaded area for the geometry shown Figure 8.1. The reactor core was placed at the bottom of this model to represent a confined wall where the reactor was above a clay substrate. This type of configuration was witnessed in the geological remains of the Oklo and Cigar Lake deposits.

The core of the Oklo reactor contained the highest concentration of uranium. The surrounding sandstone contained 5 percent $\mathrm{UO}_{2}$ concentration. Core uranium concentration of 9 percent was chosen as the lower limit because it was the lowest concentration that would allow criticality to occur. This percentage also coincided with Naudet's work which predicted minimum concentration levels of 10 percent within uranium-rich sandstone. Throughout all runs, ${ }^{235} \mathrm{U}$ enrichment values of 3.5 percent were used, as this is the approximate calculated natural abundance of ${ }^{235} \mathrm{U}$ two billion years ago. The porosity of the sandstone was also varied to investigate the effect that water content had on the behavior of the reactor. Porosity values used were 10, 20, and 30 percent for the sandstone in which the reactor resided. Limits of $1750 \mathrm{~K}$ for the temperature and $1 \times 10^{17}$ neutrons $/ \mathrm{m}^{2} \mathrm{sec}$ for the neutron flux were applied to maintain reasonable neutron flux and temperature values during power excursions.

Isothermal conditions were used at the reactor walls for temperature, pressure, streamfunction and neutron flux. A temperature of $400 \mathrm{~K}$ was used to represent the 
geothermal temperature and a pressure of $40 \mathrm{MPa}$ corresponding to a depth of about 4.5 $\mathrm{km}$. Streamfunction and neutron flux values of zero were used at the boundaries, a condition which allowed no fluid or neutron transfer across the reactor walls.

Cases were first run to verify the independence of results with varying time step and for a variable number of nodes in the $\mathrm{x}$ and $\mathrm{y}$ directions. The first case used a time step of 0.0001 seconds corresponding to the mean prompt neutron lifetime in the reactor. A 9 by 9 volume grid was used in the preliminary model. The runtime for this case was approximately 7 days on a $2.66 \mathrm{GHz}$ Pentium 4 processor.

Another run was then conducted using the same time step, but with a 19 by 19 grid. Figure 8.2 shows the temperatures versus time for the center of the reactor for each of the three cases described above. The curve located in the center of Figure 8.2 represents the 9 by 9 grid with a time step of $1 \times 10^{-4}$ seconds. The curve below represents the 9 by 9 with a time step of $5 \times 10^{-5}$ seconds and the curve above shows the 19 by 19 case with a time step of $1 \times 10^{-4}$ seconds.

The three curves are very similar and show that increasing the number of nodes or decreasing the time step changes the accuracy of the solution very little. Of course, the finer the time step and grid, the more precise the solution becomes with a significantly greater computation time. All subsequent cases were run with the standard time step of 0.0001 seconds and with a $9 \times 9$ grid. Results included time-dependent values of the neutron flux, temperature, streamfunction, heat generation and pressure at every node. The fluid properties must be updated during every iteration, thus producing run times of up to several weeks or more depending on grid size and time step. 


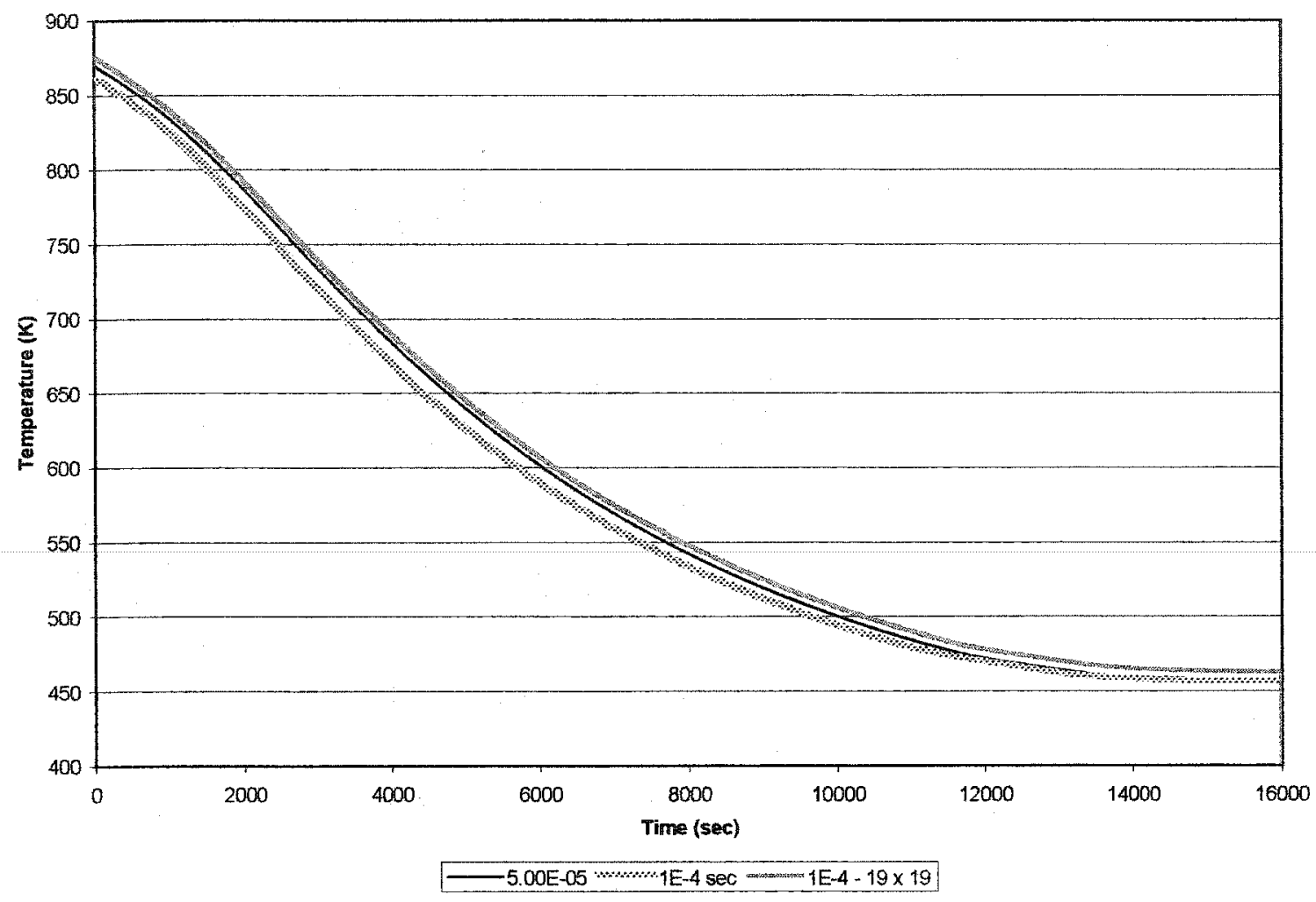

Figure 8.2 Verification of Spatial and Time Dependence for Temperatures at the Center of the Reactor

Figure 8.3 shows temperature profiles for 9 percent concentration in the reactor core and 5 percent for the surrounding area of $\mathrm{UO}_{2}$ and porosity ranging from 10 to 30 percent. Temperatures in Figure 8.3 show two main differences between the various values of porosity; initial peak temperature and the steady state temperature. As the porosity increases, the initial temperature and steady state temperatures increase.

Figure 8.4 gives the temperature plots for concentrations at the reactor core of 15 percent with varying porosity. Once again the initial peaks are higher with higher porosity, however the steady state temperature for 30 percent porosity is slightly lower than that of the 20 percent case. All the curves have similar profiles to those observed in Figure 8.2. 
The last set of cases for 30 percent concentration for temperatures at the center of the reactor are given in Figure 8.5. The temperature behavior for 10 and 20 percent behavior exhibit similar trends as those seen in the 9 and 15 percent concentration cases. A noticeable difference is observed in the 30 percent porosity case. The initial spike occurred and decayed normally. Instead of the decay to steady state temperature as seen in other runs, a second transient occurred and then decayed to a steady state temperature. The presence of a second transient indicates the possibility of periodic operation of the reactor as Kuroda states. The first and second peak to trough temperature change occurs over about 5 hours. These times are only slight greater than the 3 hour period concluded the reactor operated in by examining xenon concentrations. The periodicity is directly affected by the thermohydraulics and thermophysical properties of water.

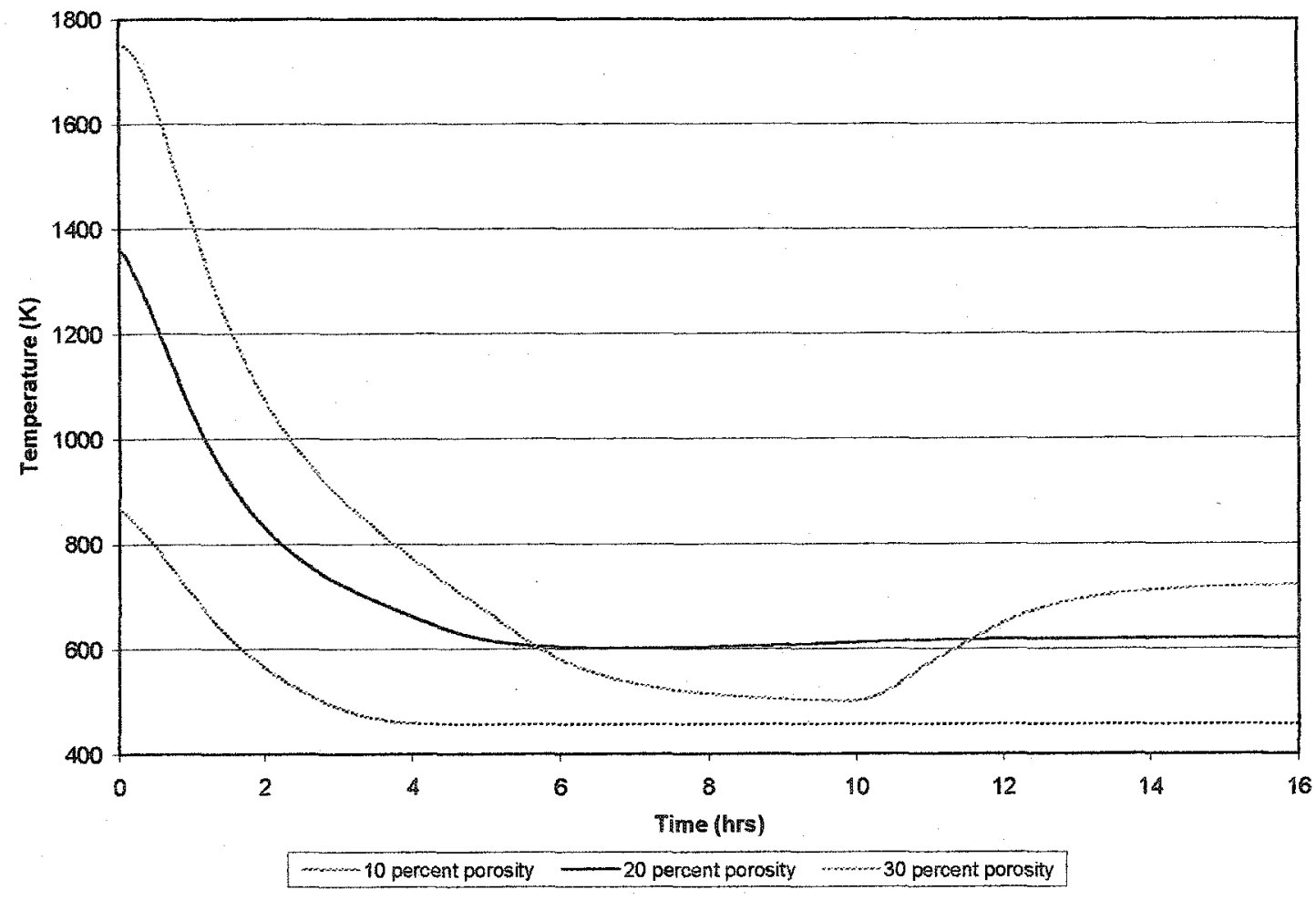

Figure 8.3 Temperatures for 9 Percent Concentration at the core and 5 Percent in Surrounding Areas of $\mathrm{UO}_{2}$ for varying Sandstone Porosity for the Center of the Reactor 


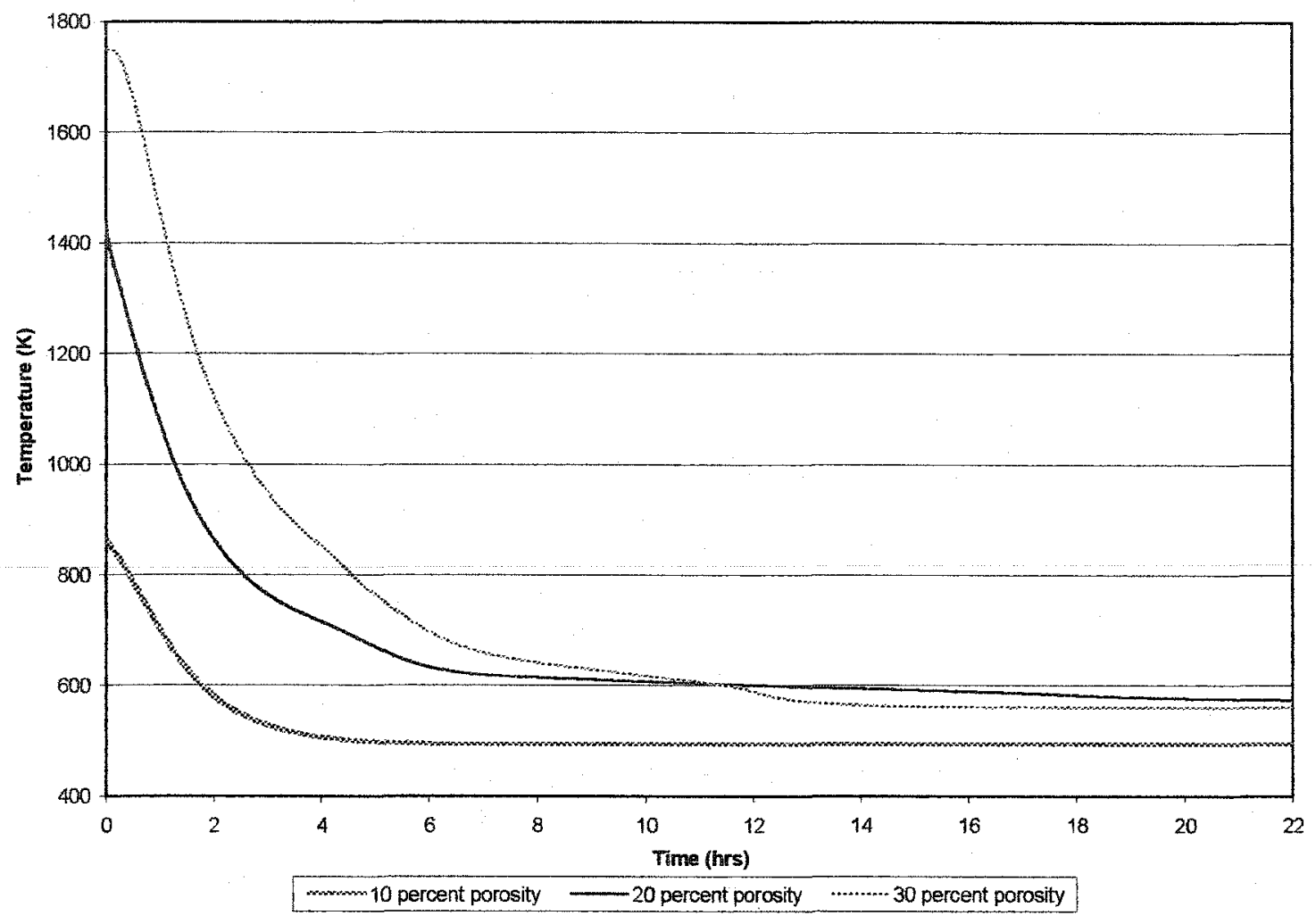

Figure 8.4 Temperatures for 15 Percent Concentration at the core and 5 Percent in Surrounding Areas of $\mathrm{UO}_{2}$ for varying Sandstone Porosity for the Center of the Reactor 


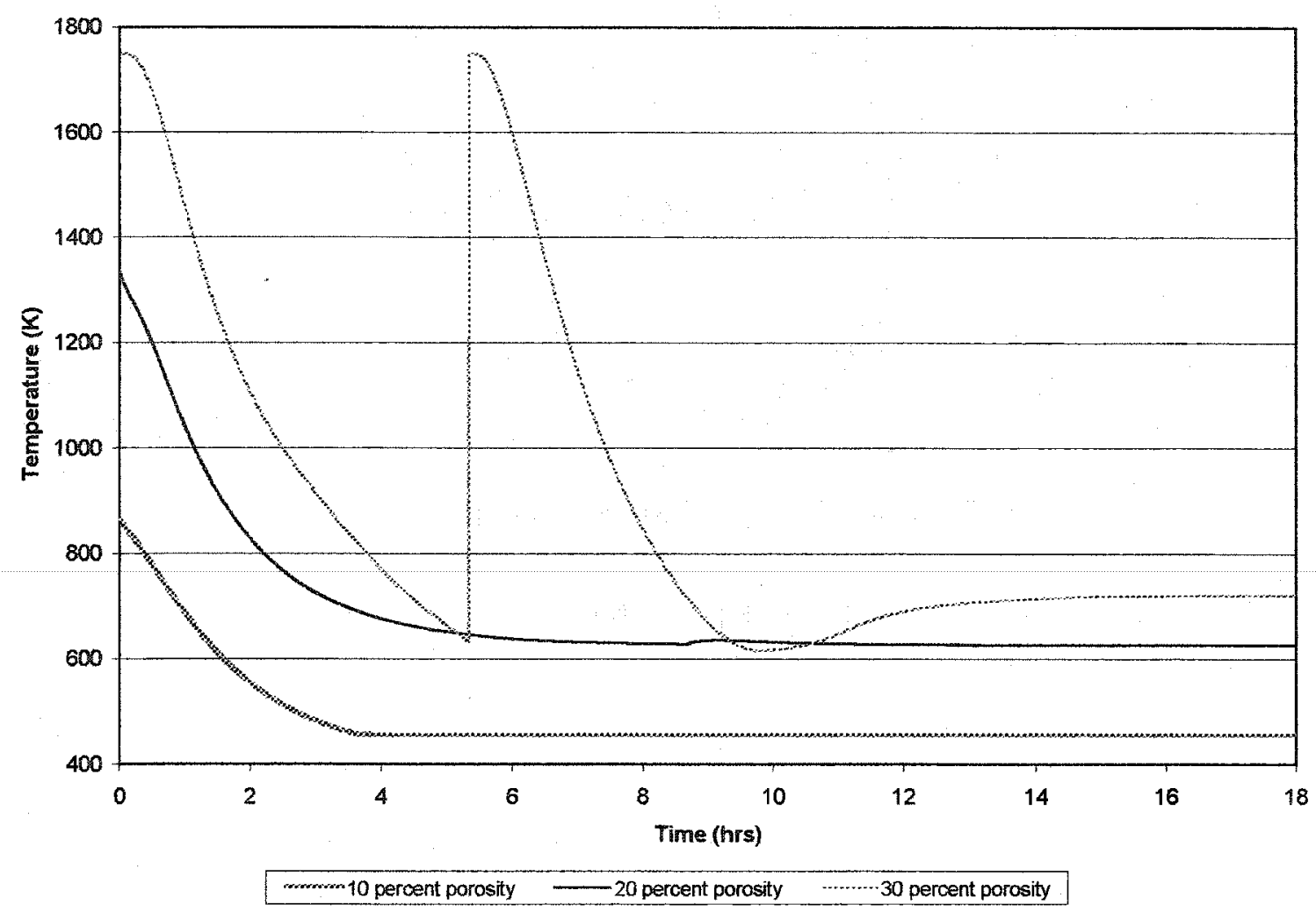

Figure 8.5 Temperatures for 30 Percent Concentration at the core and 5 Percent in Surrounding Areas of $\mathrm{UO}_{2}$ for varying Sandstone Porosity for the Center of the Reactor

The following graphs are snapshots of stream function, temperature, neutron flux and pressure at intervals of 20,000 seconds, ranging in times from 20,000 to 100,000 seconds. The two of plots for the stream function show a distinct bifurcating flow from 20,000 to 40,000 seconds. After 40,000 seconds, the stream function tends to stabilize and only minor changes occur. This is due to more stable conditions for temperature, producing less convective flow. The temperature plots change only slightly over the 80,000 second time change from the first to the last plot. The peak temperatures occur mostly around the center-line of the $y$ axis $(y=0.5 \mathrm{~m})$. Neutron flux plots show sharp spikes for values around certain areas of the reactor. A close comparison of the neutron flux and temperature plots over the 80,000 second interval reveals minor changes in the 
temperature with change in flux. This behavior is not consistently witnessed throughout the entire simulation; as a sharp increase in temperatures in earlier times prior to temperature stabilization may be observed. The flux and temperatures are affected by adjacent volumes with smaller or greater amounts of fissionable material, and can produce unstructured neutron flux value spikes due to the effect temperature has on reducing the fissionable cross section. Lastly, the pressure surface plots also show large spikes in value. The pressure is backed out of the stream functions and may vary greatly in different locations of the reactor. The coupling of the neutron diffusion, heat transfer and fluid movement equations are all dependent on the thermal properties of water, and thus highly nonlinear.

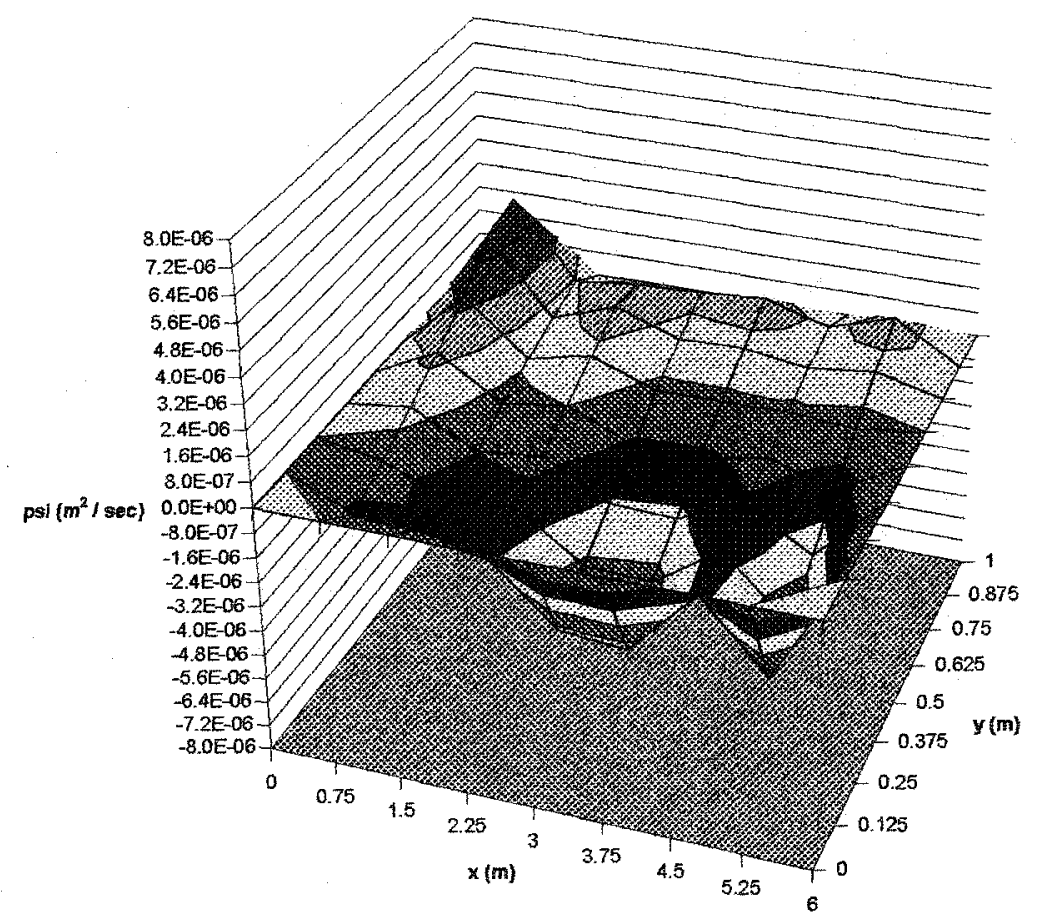

Figure 8.6 Stream Function Surface Plot for 20,000 seconds $15 \% \mathrm{UO}_{2}$ - core, $5 \% \mathrm{UO}_{2}$ surrounding and $20 \%$ porosity 


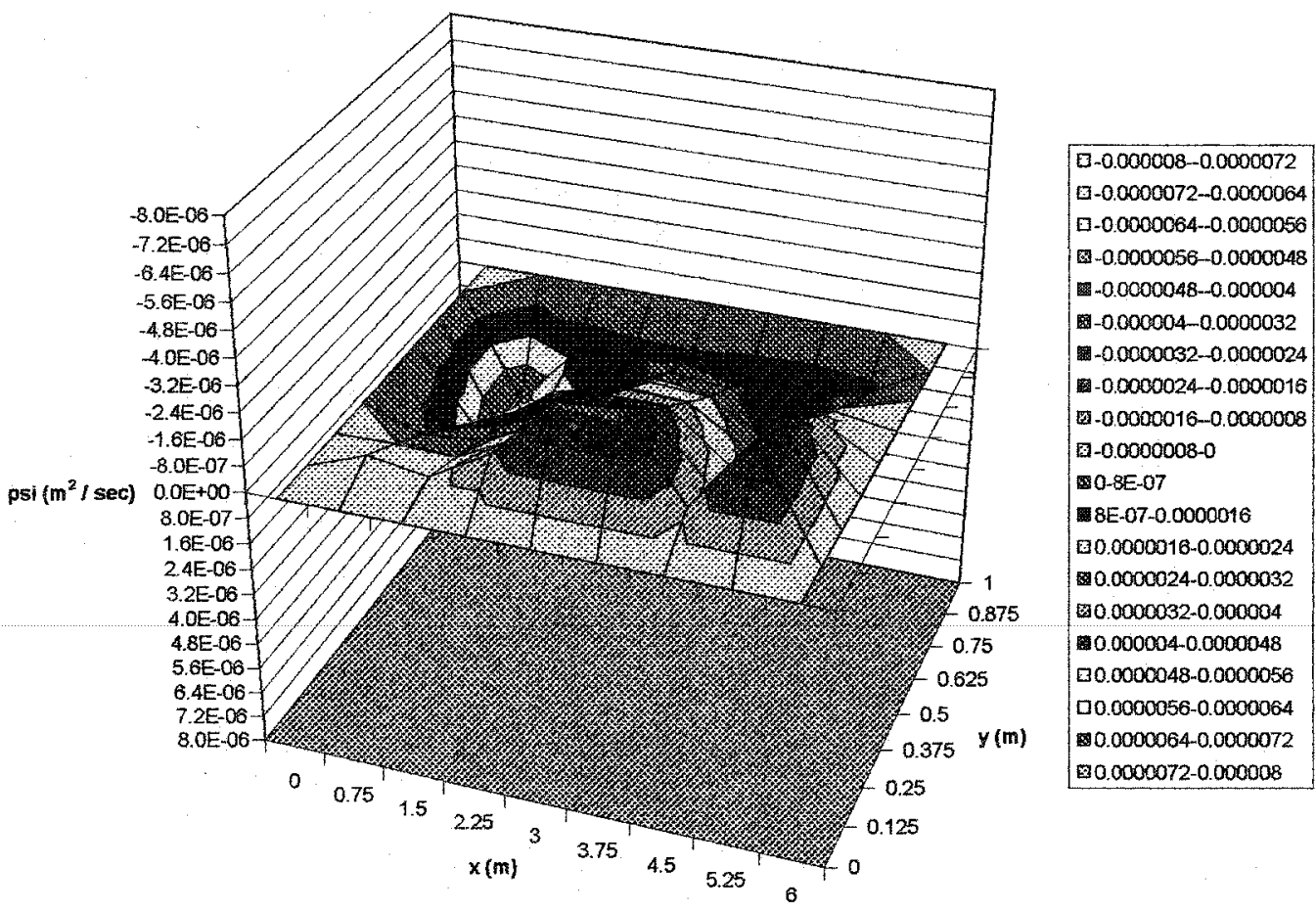

Figure 8.7 Stream Function Surface Plot for 40,000 seconds $15 \% \mathrm{UO}_{2}$ - core, $5 \% \mathrm{UO}_{2}$ surrounding and $20 \%$ porosity

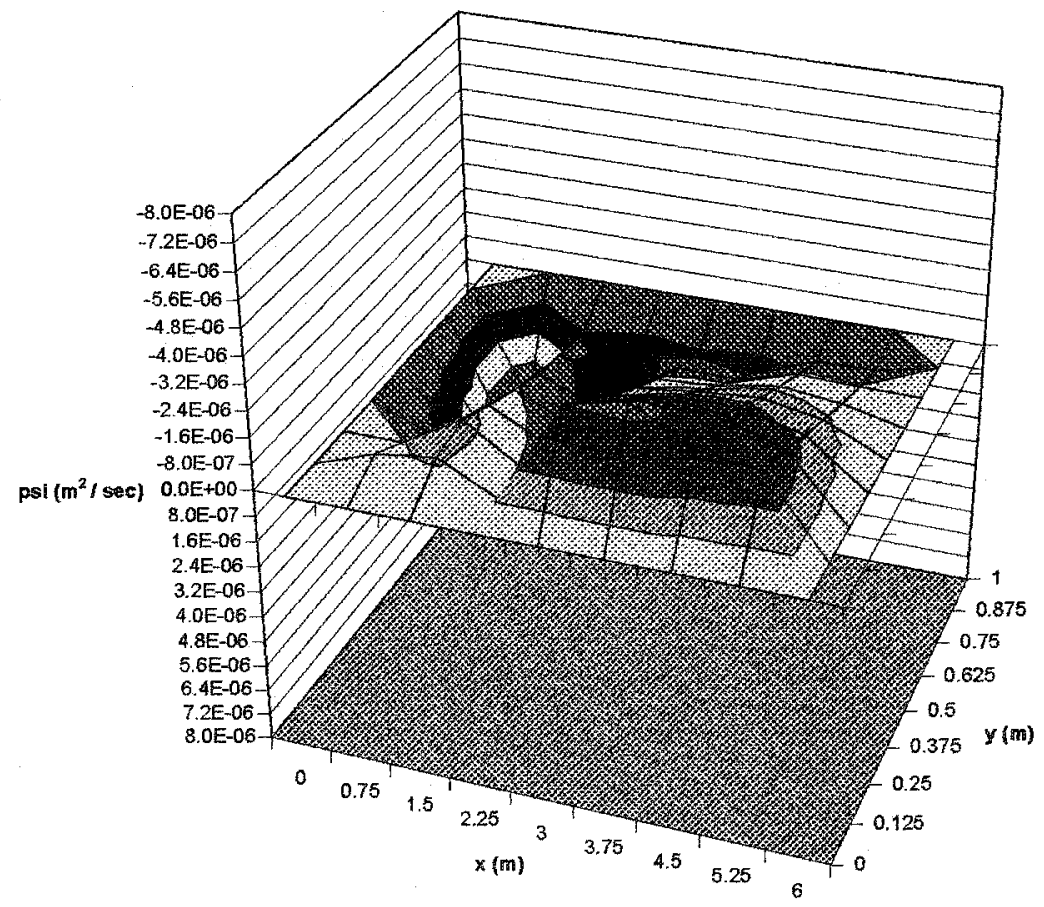

$[-0.000008-0.0000072$ $0-0.0000072-0.0000064$ 口-0.0000064-0.0000056 20.0000056-0.0000048 橉-0.0000048-0.000004 \$1-0.000004-0.0000032 - $-0.0000032-0.0000024$ $0.0000024-0.0000016$ 85-0.0000016-0.0000008 a $0.0000008-0$ 0-8E-07 1. $8 \mathrm{E}-07-0.0000016$ $00.0000016-0.0000024$ $0.0000024-0.0000032$ ga.0.000032-0.000004 $0.000004-0.0000048$ $\square 0.0000048-0.0000056$ 口0.0000056-0.0000064 0.0000064-0.0000072 Đ0.0000072-0.000008

Figure 8.8 Stream Function Surface Plot for 60,000 seconds $15 \%$ UO2 - core, $5 \%$ UO2 surrounding and $20 \%$ porosity 

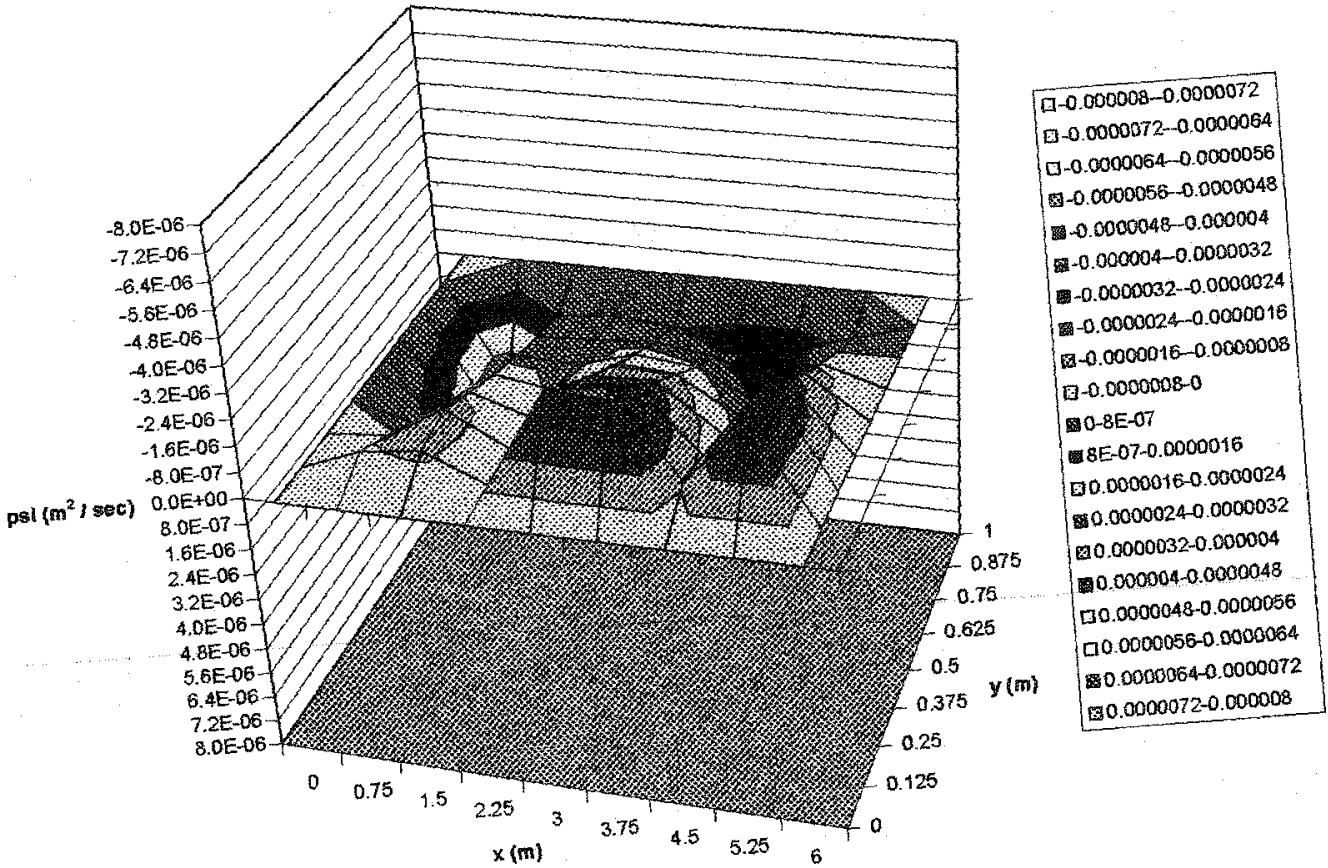

Figure 8.9 Stream Function Surface Plot for 80,000 seconds
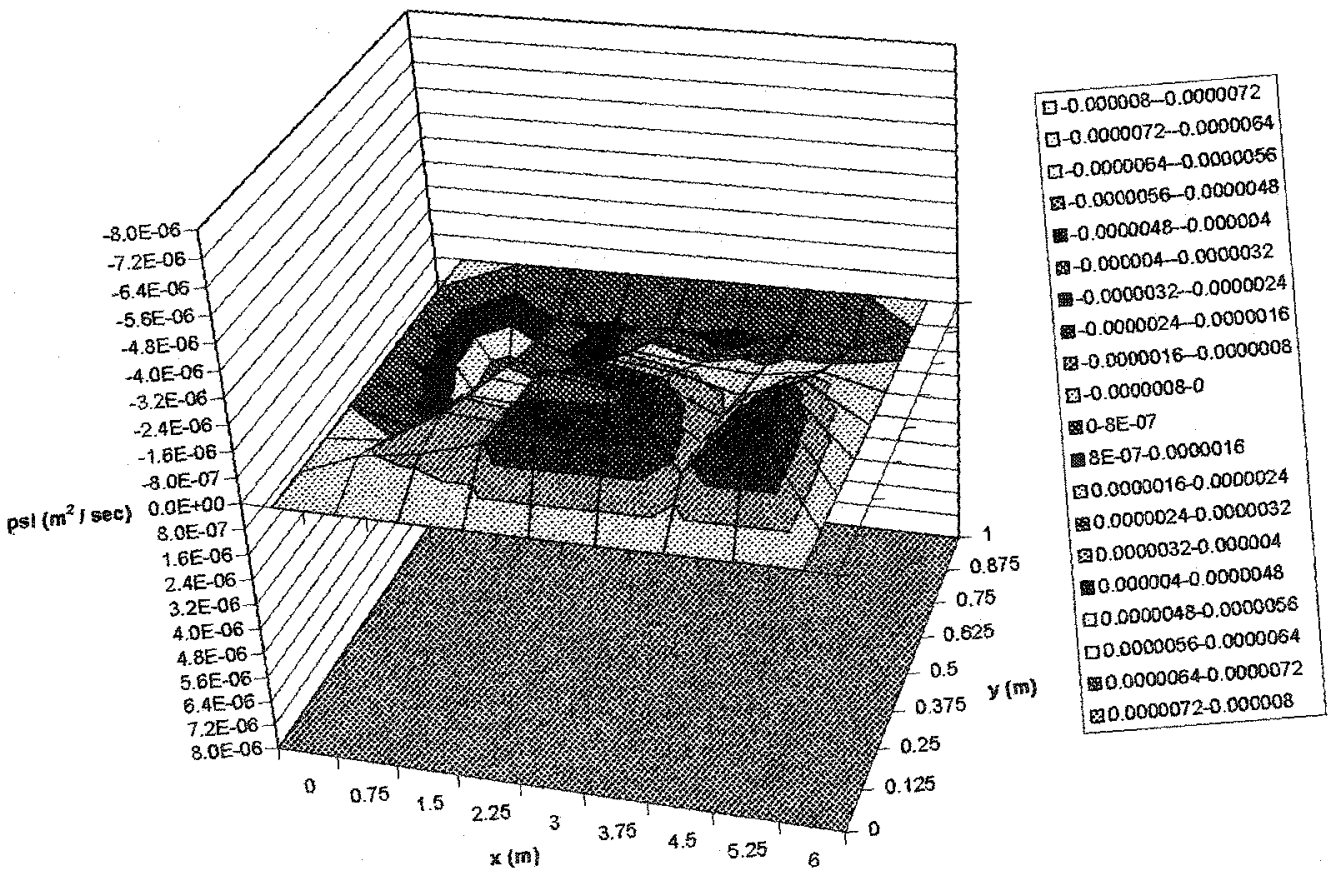

Figure 8.10 Stream Function Surface Plot for 100,000 seconds $15 \% \mathrm{UO}_{2}-\mathrm{core}, 5 \%$
\[ \mathrm{UO}_{2} \text { - surrounding and } 20 \% \text { porosity } \]

Reproduced with permission of the copyright owner. Further reproduction prohibited without permission. 


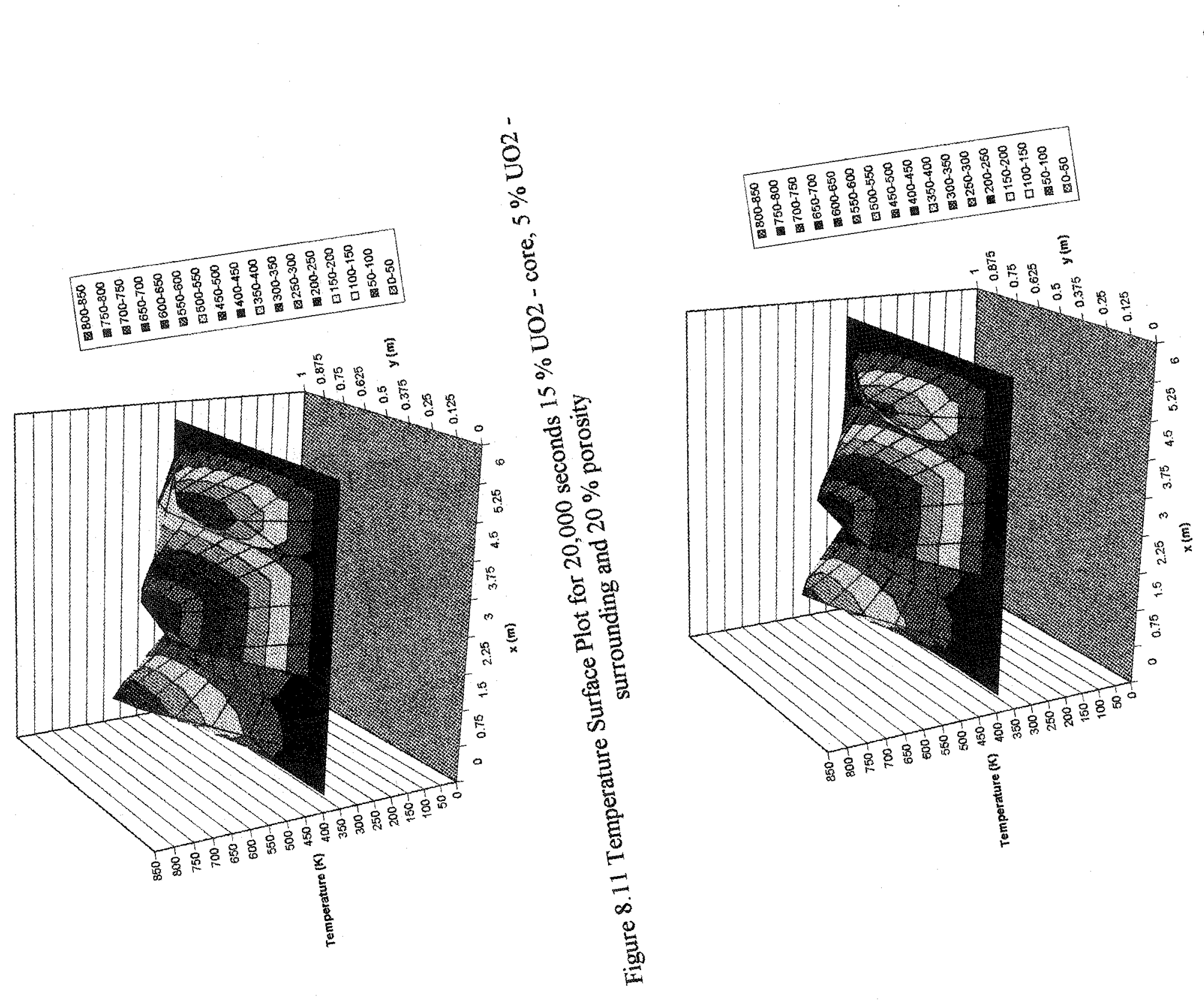

8

5
5
8
8
8
0
0

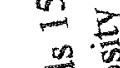

总

88

8 요

8요의

을

送

8 它

蛋

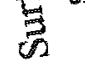

롤

莺

I

惡

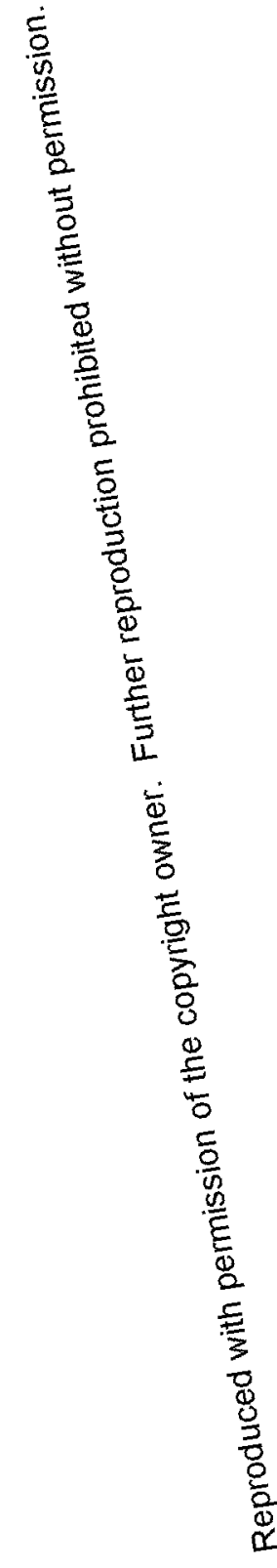




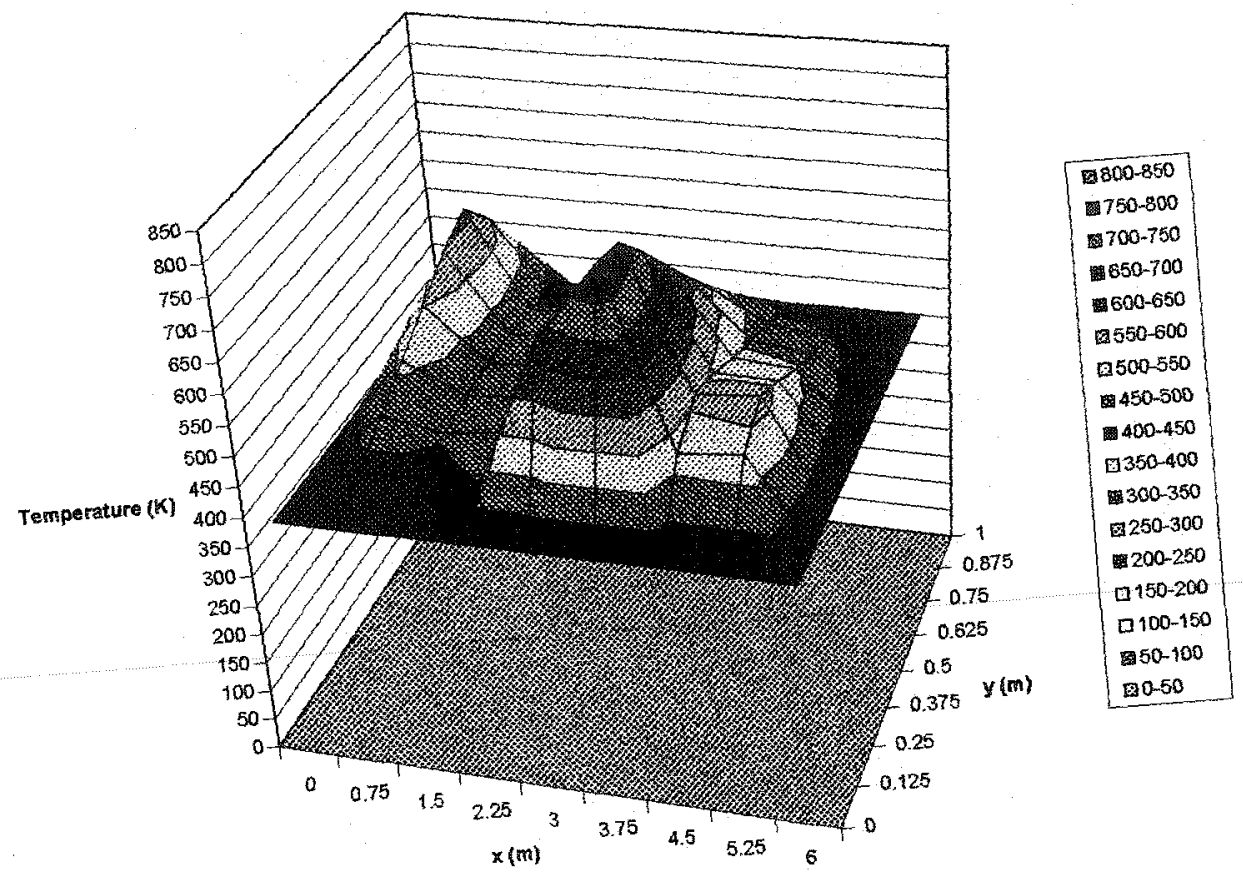

Figure 8.13 Temperature Surface Plot for 60,000 seconds $15 \%$
surrounding and $20 \%$ porosity

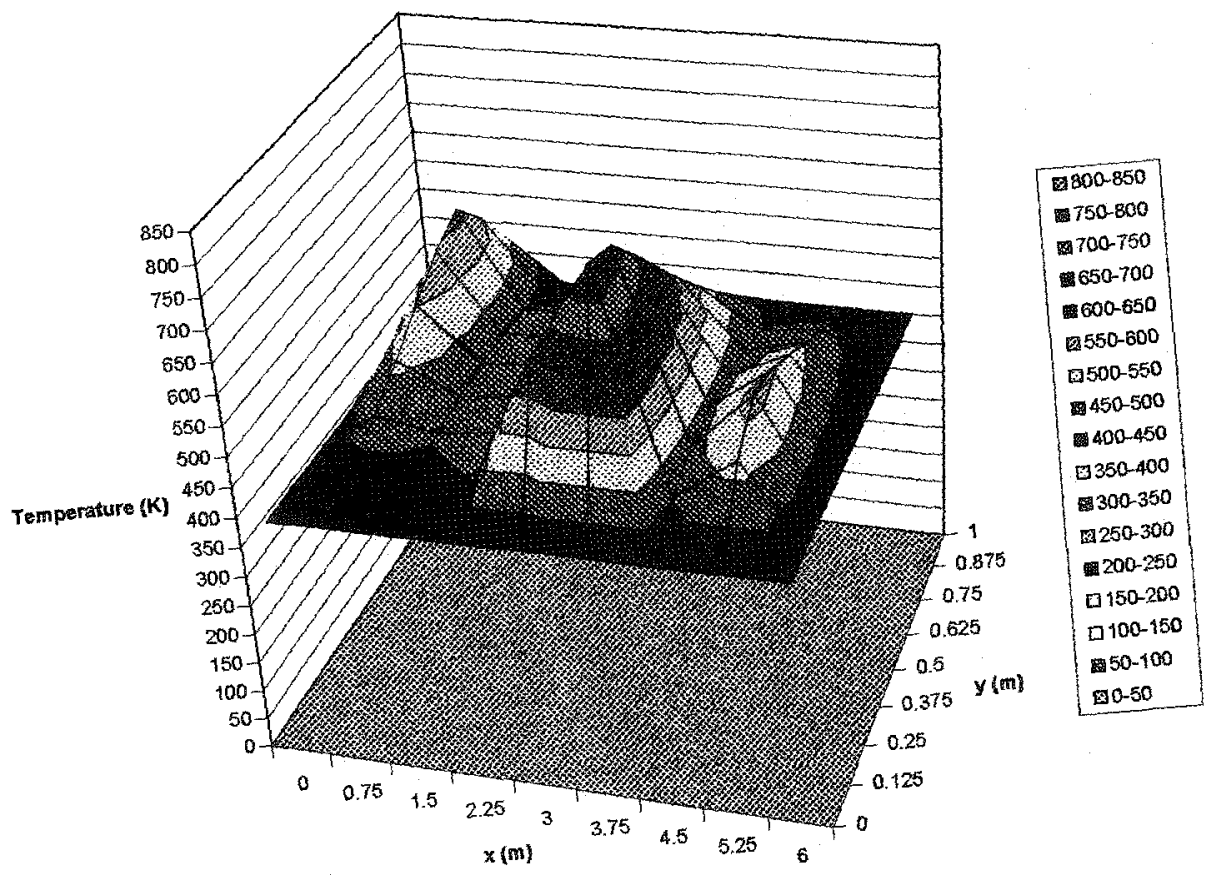

Figure 8.14 Temperature Surface Plot for 80,000 seconds $15 \%$ UO2 - core, $5 \%$ UO2 surrounding and $20 \%$ porosity

Reproduced with permission of the copyright owner. Further reproduction prohibited without permission. 

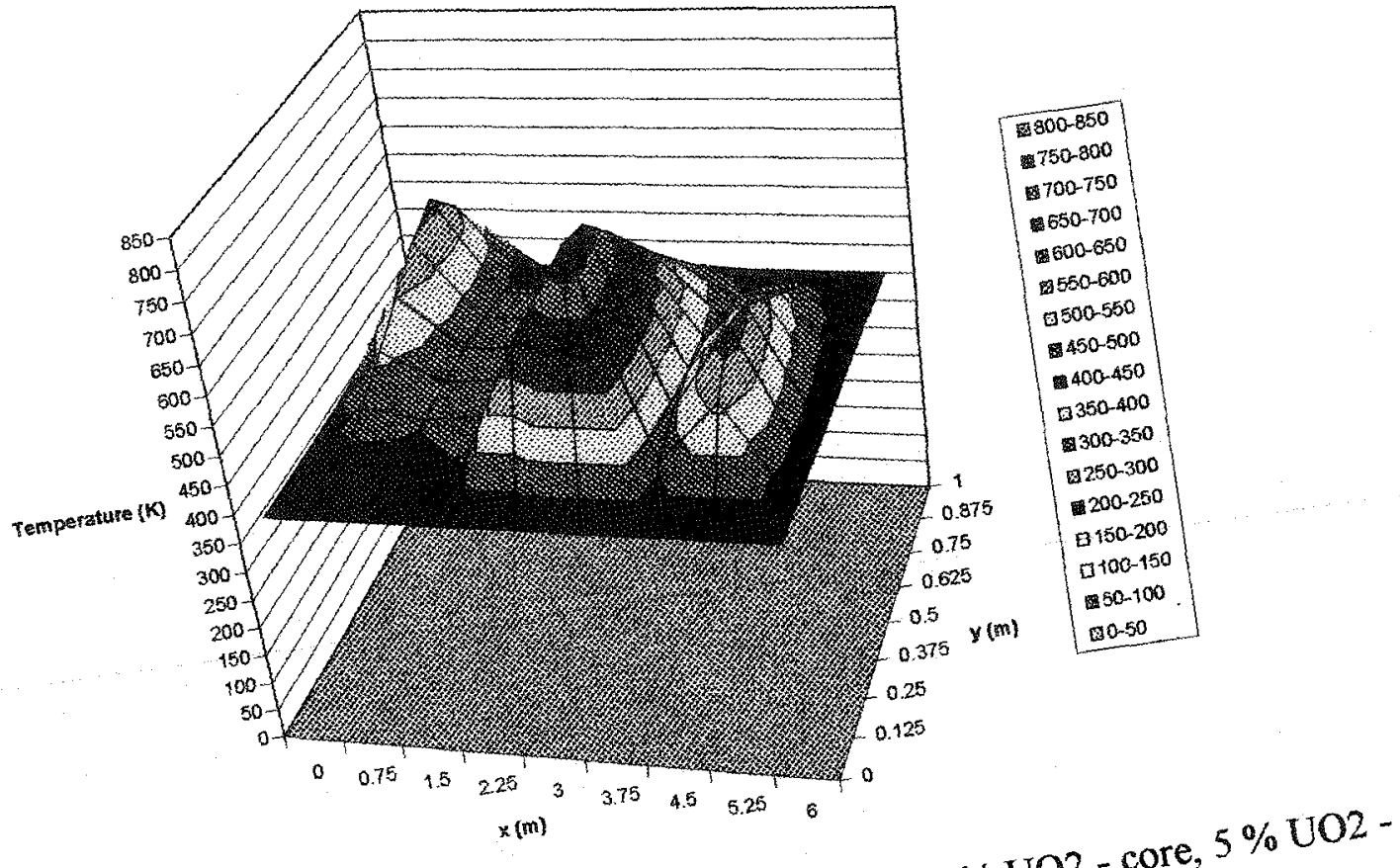

Figure 8.15 Temperature Surface Plot for 100,000 seconds 15
surtounding and $20 \%$ porosity
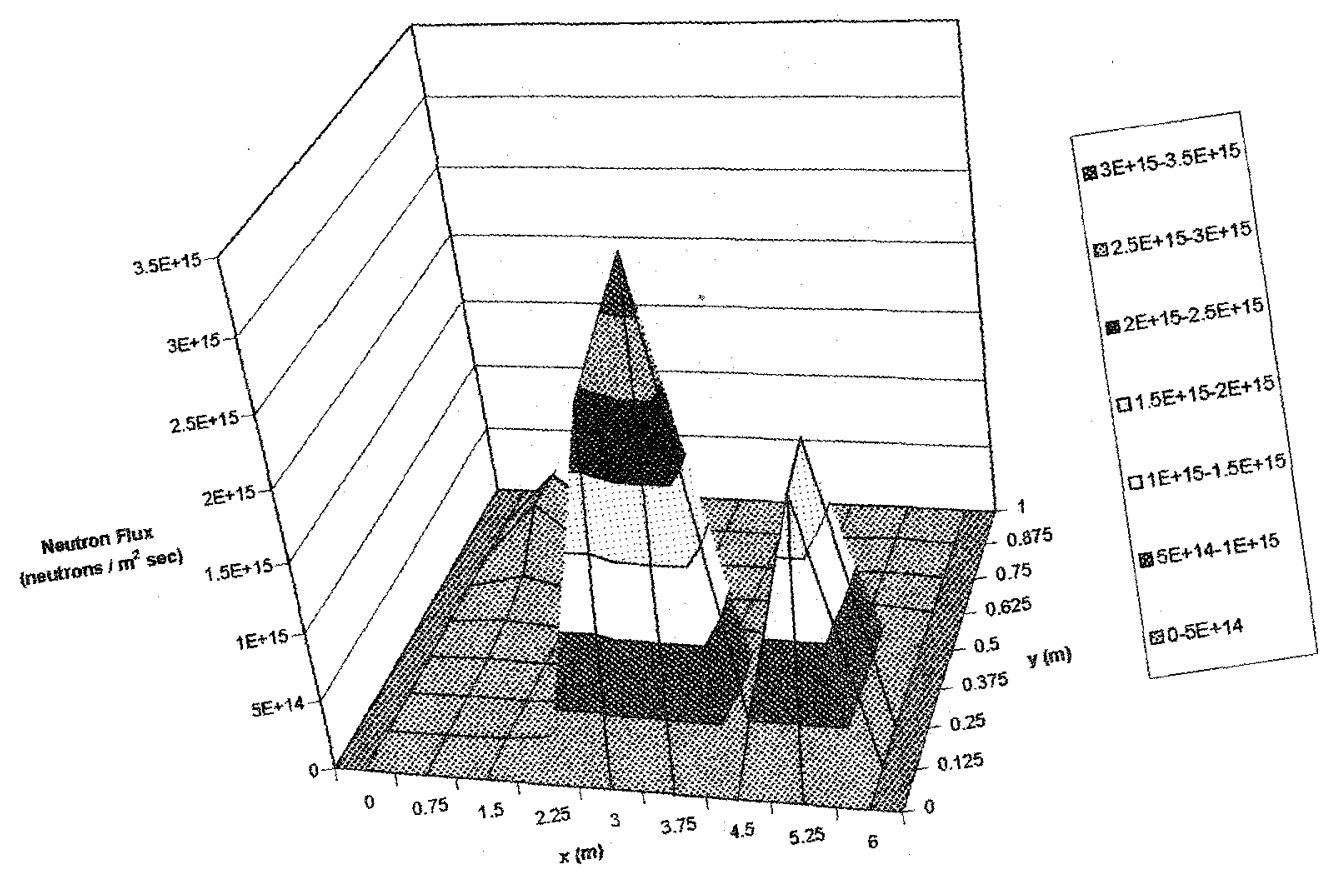

Figure 8.16 Neutron Flux Surface Plot for 20,000 seconds $15 \%$ porosity
surrounding and $20 \%$ por 


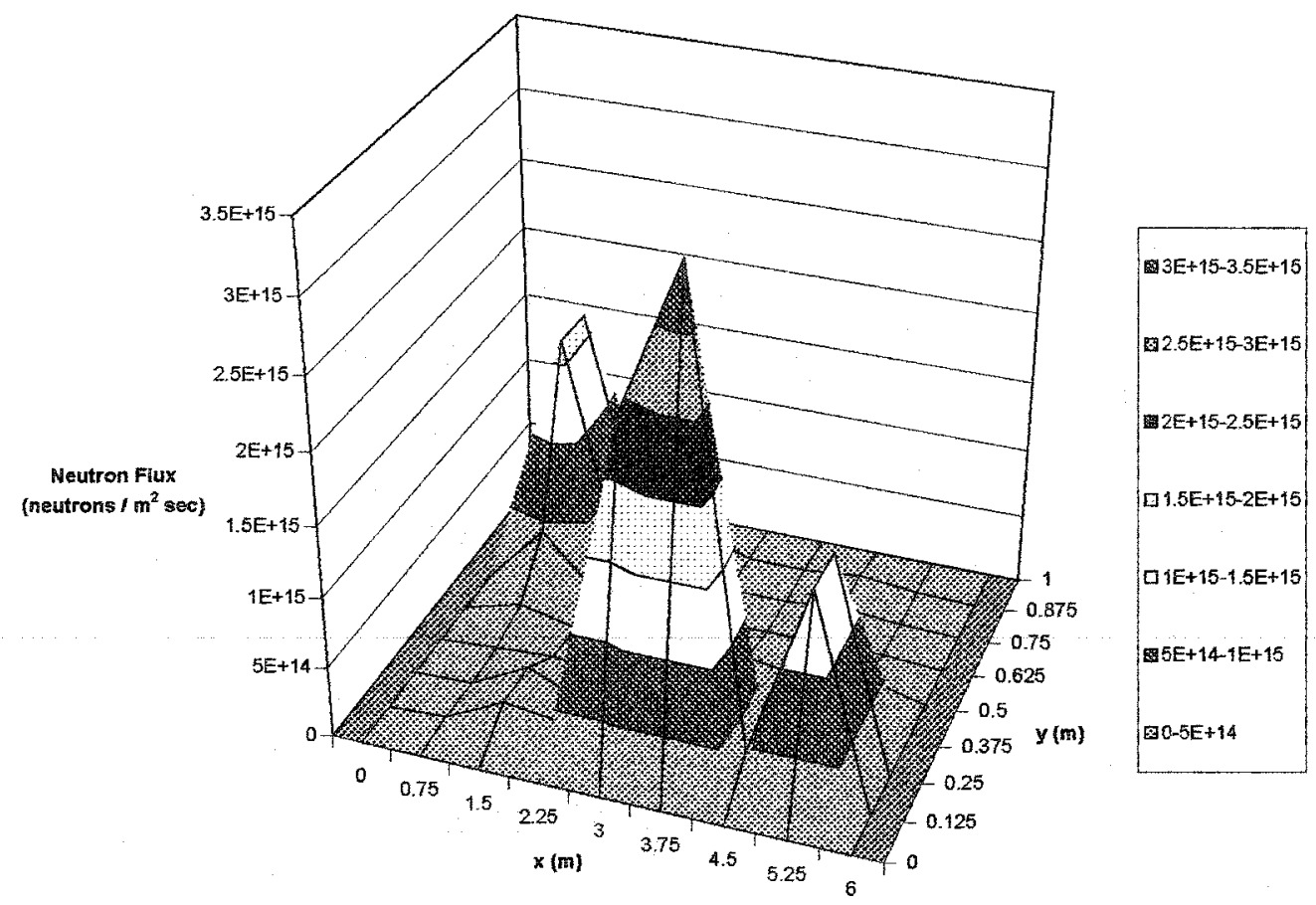

Figure 8.17 Neutron Flux Surface Plot for 40,000 seconds $15 \%$ UO2 - core, $5 \%$ UO2 surrounding and $20 \%$ porosity

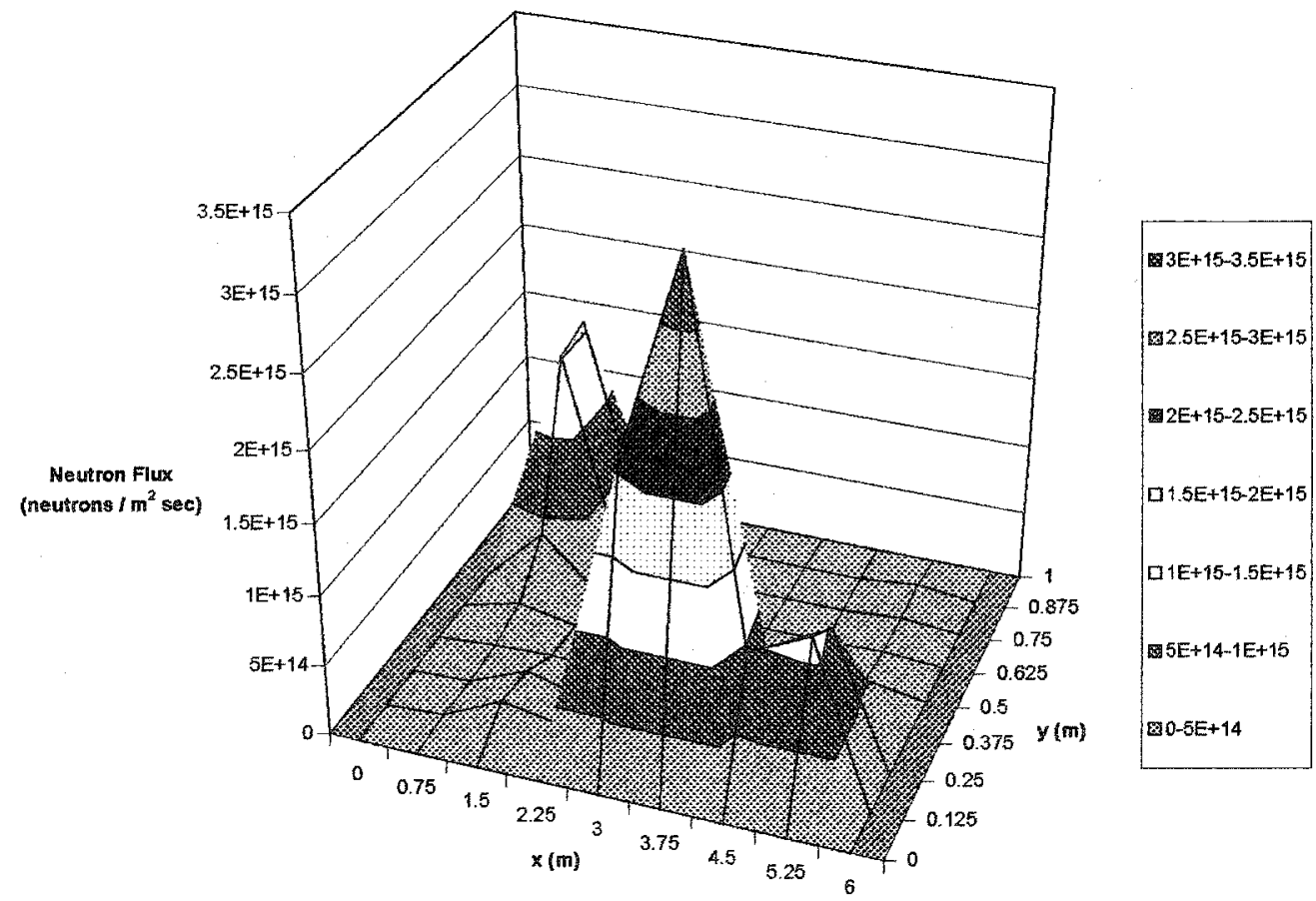

Figure 8.18 Neutron Flux Surface Plot for 60,000 seconds $15 \%$ UO2 - core, $5 \%$ UO2 surrounding and $20 \%$ porosity 


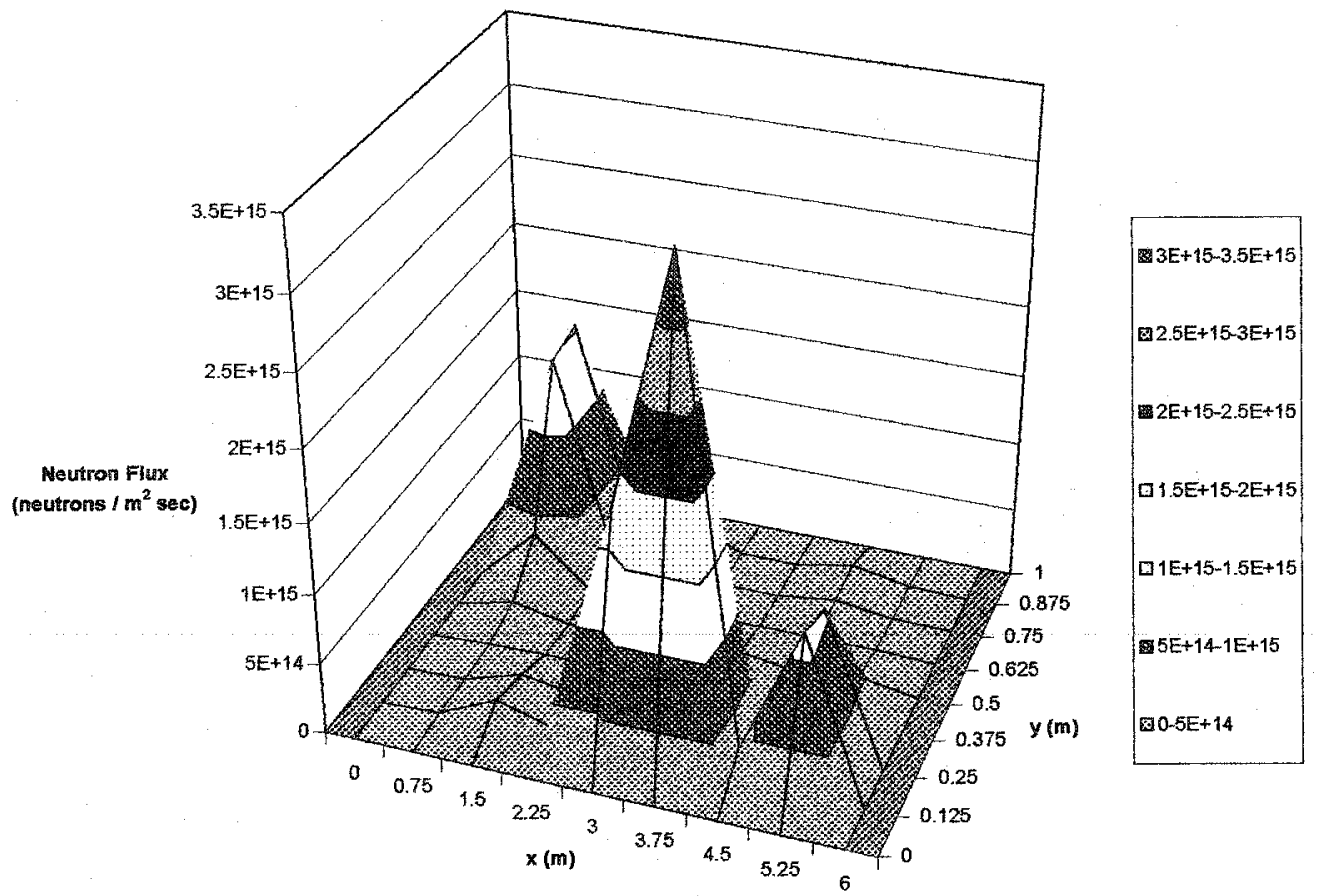

Figure 8.19 Neutron Flux Surface Plot for 80,000 seconds $15 \%$ UO2 - core, $5 \%$ UO2 surrounding and $20 \%$ porosity

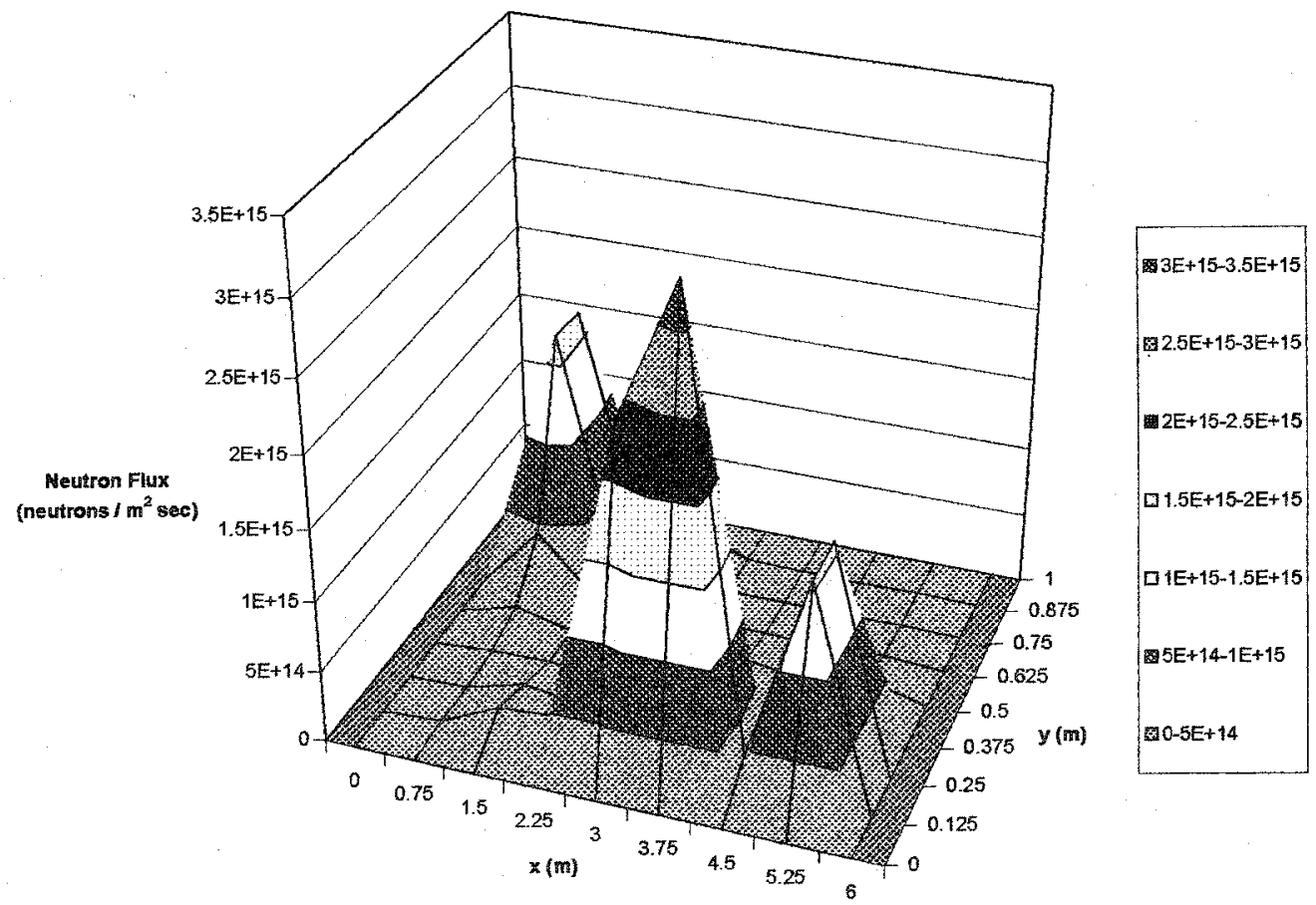

Figure 8.20 Neutron Flux Surface Plot for 100,000 seconds $15 \%$ UO2 - core, $5 \%$ UO2 surrounding and $20 \%$ porosity 


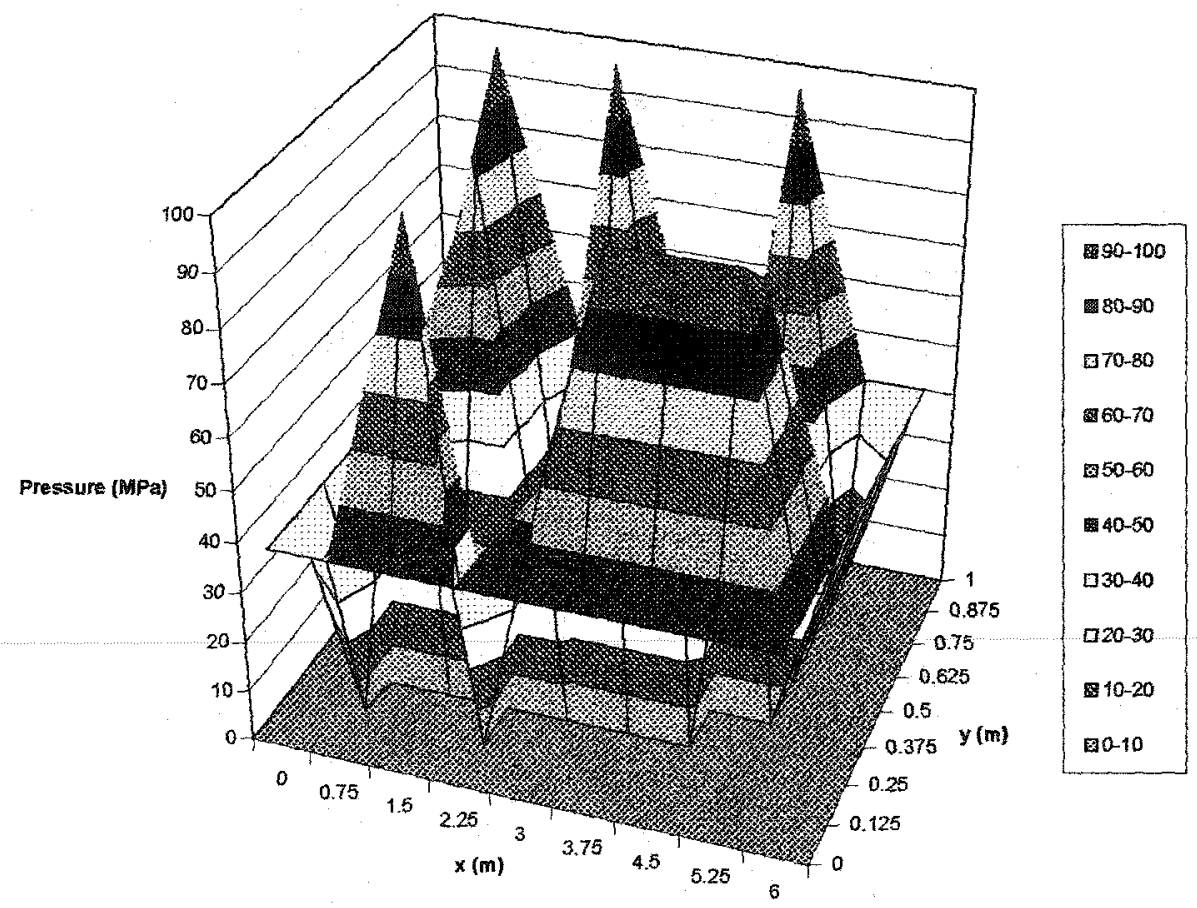

Figure 8.21 Pressure Surface Plot for 20,000 seconds $15 \%$ UO2 - core, $5 \%$ UO2 surrounding and $20 \%$ porosity

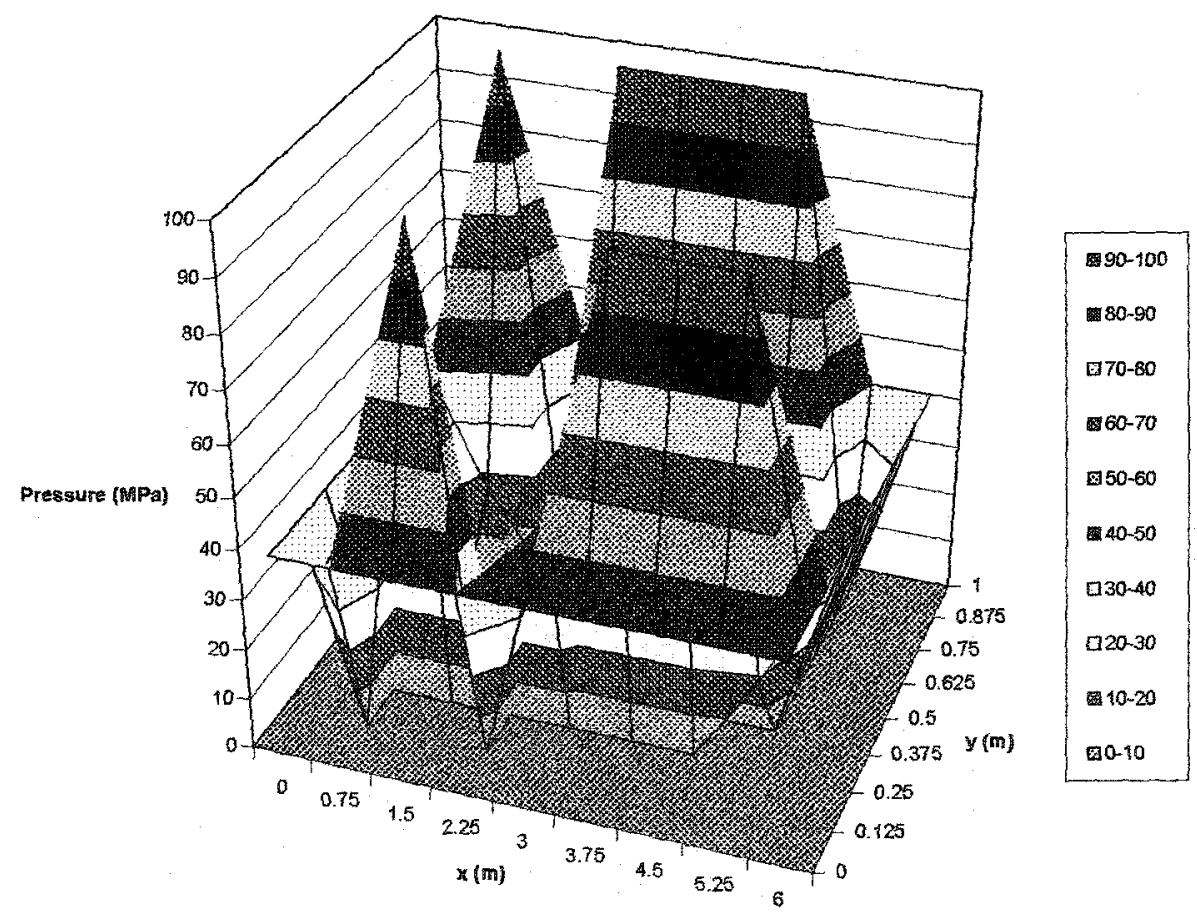

Figure 8.22 Pressure Surface Plot for 40,000 seconds $15 \%$ UO2 - core, $5 \%$ UO2 surrounding and $20 \%$ porosity 


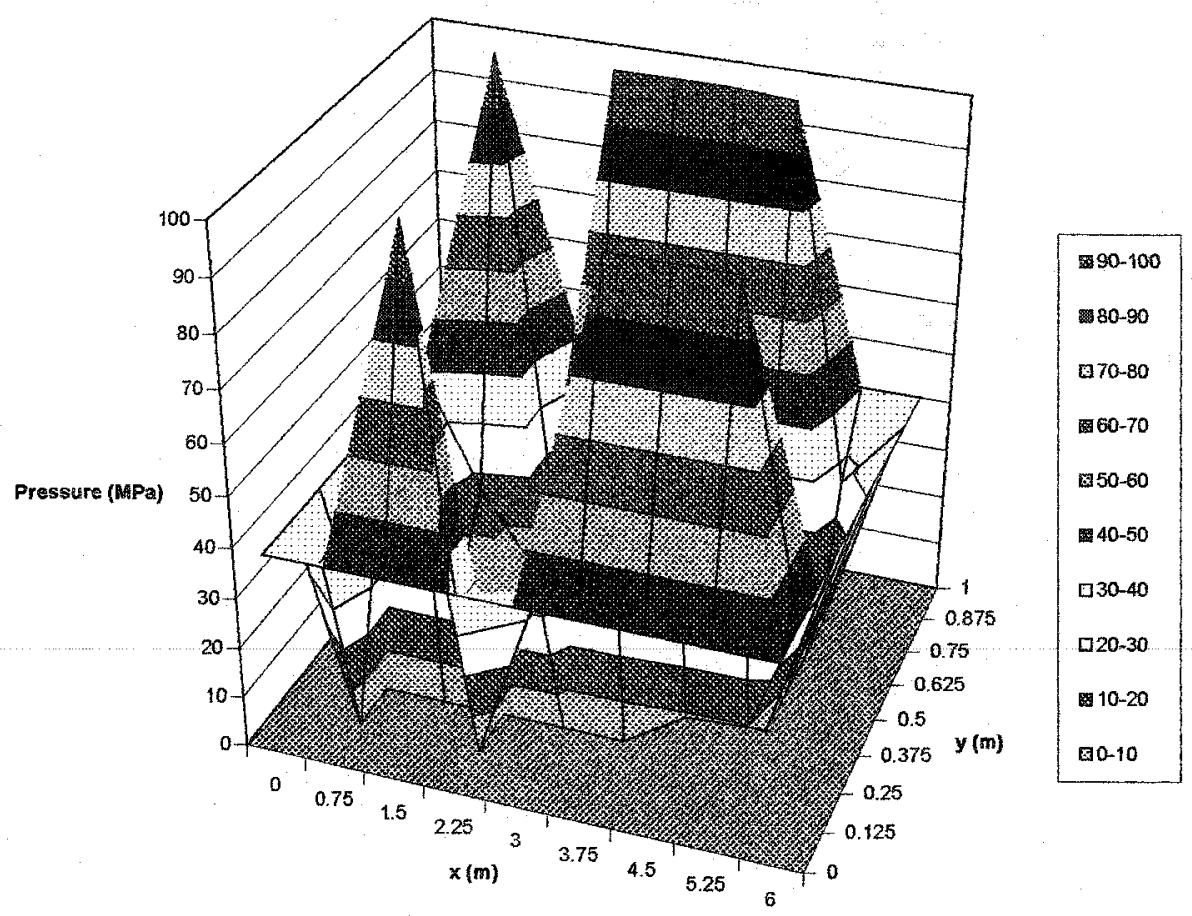

Figure 8.23 Pressure Surface Plot for 60,000 seconds $15 \%$ UO2 - core, $5 \%$ UO2 surrounding and $20 \%$ porosity

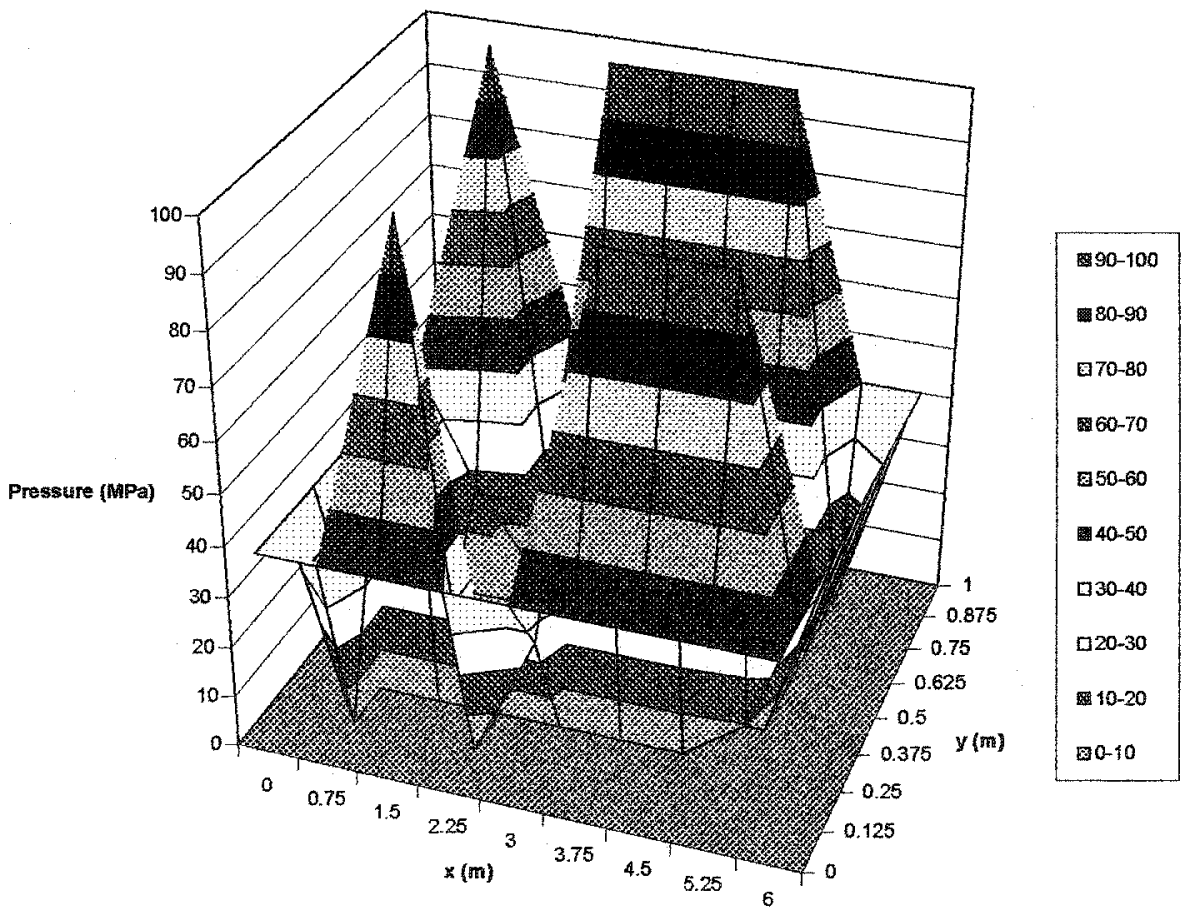

Figure 8.24 Pressure Surface Plot for 80,000 seconds $15 \%$ UO2 - core, $5 \%$ UO2 surrounding and $20 \%$ porosity 


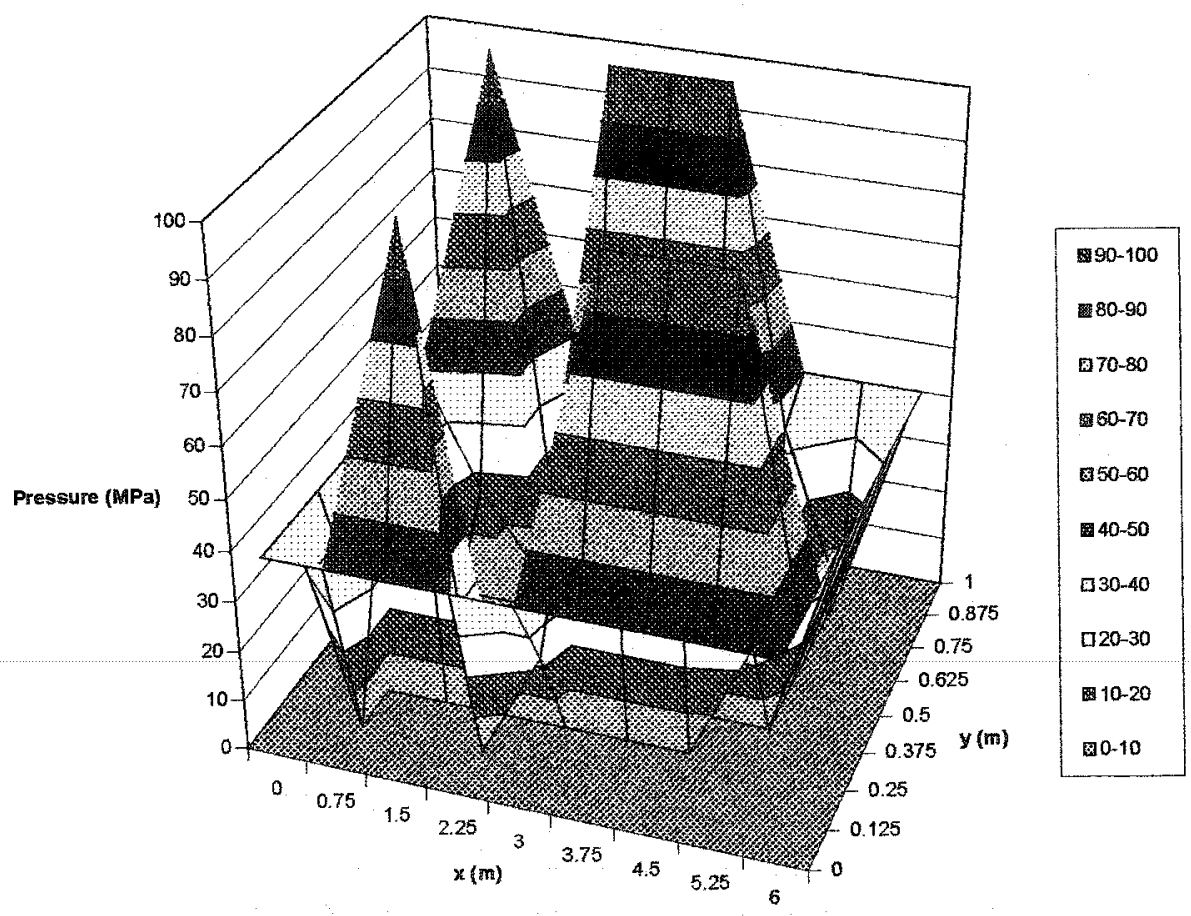

Figure 8.25 Pressure Surface Plot for 100,000 seconds $15 \%$ UO2 - core, $5 \%$ UO2 surrounding and $20 \%$ porosity 


\section{CHAPTER 9}

\section{CONCLUSIONS}

A two-dimensional numerical model that incorporates modeling of fluid flow, temperatures, and nuclear fission was developed for the Oklo natural reactors. Various combinations of $\mathrm{UO}_{2}$ in the reactor core and porosity were study to determine the effect both have on the operating temperatures, neutron flux behavior, flow characteristics and operating modes of the reactor such as the possibility of periodic heat generation.

Temperature profiles were shown to have a large spike in the initial start up of the reactor and then decay of to a steady state temperature for all cases except that of 30 percent $\mathrm{UO}_{2}$ concentration at the reactor core with 30 percent porosity. The operating temperatures ranged from about $456 \mathrm{~K}$ to about $721 \mathrm{~K}$. These temperature ranges agree exactly with Kuroda's predicted ranges and the upper limit agrees with Curtis and Gancarz's predicted lower limit of $723 \mathrm{~K}$ as seen in Figure 9.1.

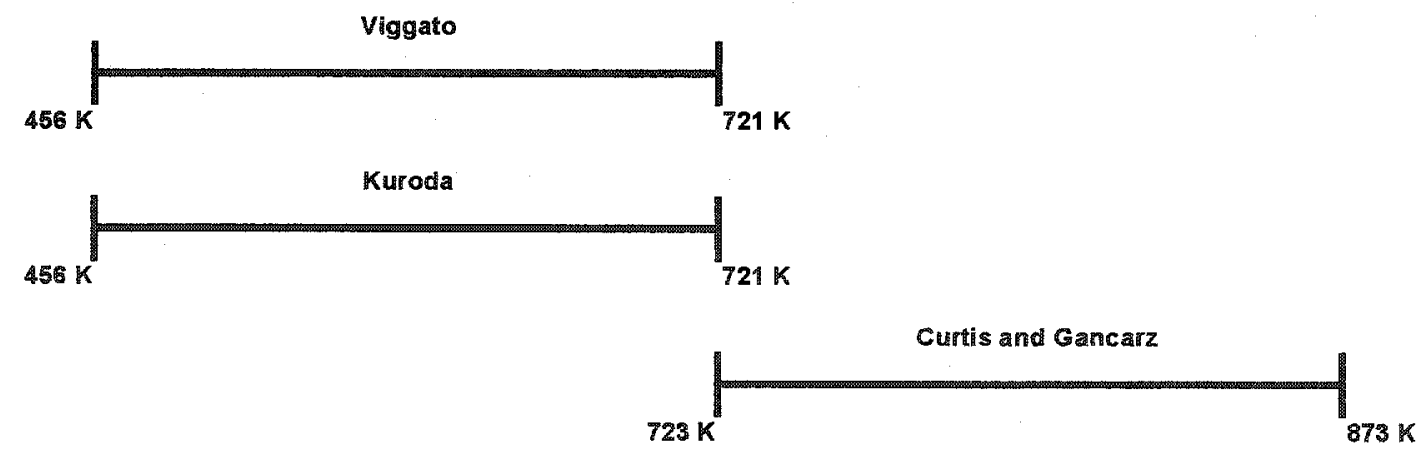

Figure 9.1 Operating Temperature Range Comparison to Previous Studies 
Critical reactions were observed for a wide range of concentrations and porosity values ( 9 to 30 percent $\mathrm{UO}_{2}$ and 10 to 20 percent porosity). The lower limit of fissionable material concentration was 9 percent for the Oklo_transient code which coincided with Naudet's prediction of 10 percent concentration of highly enriched material.

The period of operation that Kuroda predicted, occurred in the Oklo_transient prediction with concentrations of 30 and 5 percent $\mathrm{UO}_{2}$ in the reactor core and surrounding material respectively, and 30 percent concentration of water ( 30 percent porosity) which allowed a second super-critical spike in temperature. Kuroda predicted 3 to 4 hour durations while the Oklo_transient produced times of about 5 hours. The large instantaneous jumps in temperature could be an indication of the violent ejection of water that Kuroda predicted, resulting in ongoing geyser activity. Naudet indicated that the superheated hydrothermal flow of the water in the reactor could allow the leaching of uranium from the surrounding rock and transport this material back to the center, thus sustaining the reaction. The basis of this conclusion was the lack of high concentrations of uranium rich material surrounding the core. The stream function plots presented previous show bifurcating flow that could allow redistribution of uranium material back into the center of the reactor core as Naudet suggested.

The Oklo_transient code was validated through changing the number of nodes and time step for consitency of the solution. Very little change in the temperature history at the center of the reactor was witnessed through use of these variations. The model was further validated through comparisons to known analytical solutions and behavior for temperature, stream function and neutron flux. All of these verification tests agreed 
nicely with the corresponding analytical solution and/or behavior for the given geometry. Kuroda investigates a calculation of the period of free decays of the isotopes of Xenon and witnessed an upward shift of data points. "This means that here we have a powerful experimental tool with which to determine the time periods of the Oklo reactors, which have been operating intermittently nearly two billion years ago." (Kuroda, 1990) With this statement, it is confident to say that the similarity of temperatures and period shows the model developed accurately replicates the conditions under which the Oklo reactors operated.

Kuroda predicted the existence of natural fission reactors in 1956 and received criticism. In 1972, French scientists vindicated his predictions through the discovery of the Oklo Reactor Sites. Now, in 2004, a computer model that couples thermal fluid dynamics, heat transfer and nuclear reactor physics has demonstrated Kuroda's prediction of periodicity, temperature range and the potential for violent ejection of water in the form of a geyser are all reasonable.

Further work to more accurately model the reactor operation may be conducted. The addition of neutron poisons such as xenon and samarium would be one possible modification. Concentrations of $\mathrm{UO}_{2}$ in the reactor may have actually been as high as 90 percent. Modification of the source to allow extremely high concentrations along with the dissolution of surrounding rock to increase reactor concentrations would also be desirable. Fission products, their decay and transport and parallel implementation of source code could be integrated in to the current source. Modeling of future criticality events in geologic repositories with or without the above listed improvements could also be pursued. 


\section{BIBLIOGRAPHY}

Al-Khafaji, A.W. and Tooley, J.R., Numerical Methods in Engineering Practice. New York: Holt, Rinehart and Winston. 1986.

Abott, M.M. and Van Ness, H.C., Schaum's Outline of Thermodynamics, $2^{\text {nd }}$ edition. New York: McGraw-Hill. 1991.

Batchelor, G.K., An Introduction to Fluid Dynamics. New York: Cambridge University Press. 1970.

Bejan, A., Convection Heat Transfer. New York: Wiley. pp. 515-526. 1995.

Bilanovic, Z., and Harms, A., 1985, "The Nonlinear Dynamics of the Oklo Natural Reactor", Nuclear Science and Engineering, Vol. 91, pp. 286-292.

Bonilla, C.F., Nuclear Engineering. New York: McGraw-Hill. 1957.

Brookins, D.G., 1978, "Thermodynamic Considerations Underlying the Migration of Radionuclides in Geomedia: Oklo and Other Examples", Scientific Basis for Nuclear Waste Management, Vol. 1, pp. 355-366.

Brookins, D.G., "The Oklo Natural Reactor, Gabon: Analog for High Level Radioactive Waste Disposal", pp. 781-788.

Brookins, D.G., 1990, "Radionuclide Behavior at the Oklo Nuclear Reactor, Gabon", Waste Management, Vol. 10, pp. 285-296.

Bird, R.B. and Stewart, W.E., Transport Phenomena. New York: Wiley. 1960.

Burmeister, L.C., Convective Heat Transfer, $2^{\text {nd }}$ edition. New York: Wiley. 1993.

Callen, H.B., Thermodynamics and an Introduction to Thermostatistics, $2^{\text {nd }}$ edition. New York: Wiley. 1985.

Chapra, C.C. and Canale, R.P., Numerical Methods for Engineers, $2^{\text {nd }}$ edition. New York: McGraw-Hill. 1988. 
Conca, I., and Apted, M., 1993, "Aqueous Diffusion in Repository and Backfill Environments", Materials Research Society Symposium, Vol. 294, Materials Research Society, pp. 396-403.

Cowan, G.A., 1976, “A Natural Fission Reactor”, Scientific American, July, pp. 36-47.

Cramer, J., 1995, "Cigar Lake: A Natural Example of Long-Term Isolation of Uranium", Radwaste Magazine, Vol. 2, No. 3, May 1995, pp. 36-40.

Culbreth, W.G., and Zielinski, P.R., "Long-Term Effects of Neutron Absorber and Fuel Matrix Corrosion on Criticality"

Culbreth, W.G. and Steeps, L.E., 1996, "A Program for the Criticality Analysis of the Oklo Natural Fission Reactors," UNLV/WPP 96.01.

Culbreth, W.G., 1996, "Nuclear Criticality Analysis of the Oklo Natural Reactors," UNLV/WPP96.02 Report, June 25.

Culbreth, W.G. and Steeps, L.E., 1998, "Nuclear Criticality Studies of the Oklo Nuclear Reactors," Proc. of the $6^{\text {th }}$ International Conference on Nuclear Engineering, \#6131.

Culbreth, W.G. and Viggato, J.C., 2000, "Determination of the Depth and Pressure within the Oklo Natural Reactors", RPS 2000, Spokane, Washington.

Currie, I.G., Fundamental Mechanics of Fluids, $2^{\text {nd }}$ edition. New York: McGraw-Hill. 1993.

Curtis, D.B. and Gancarz, A.J., 1983, "Radiolysis in Nature: Evidence from the Oklo Natural Reactors", New Mexico, USA.

Curtis, D.B., 1985, "The Chemical Coherence of Natural Spent Fuel at the Oklo Nuclear Reactors", New Mexico, USA.

Dixon, C., Applied Mathematics of Science and Engineering. New York: Wiley. 1971.

Duderstadt, J.J. and Hamilton, L.J., Nuclear Reactor Analysis. New York: Wiley. 1976.

El-Wakil, M.M., Nuclear Power Engineering. New York: McGraw-Hill. 1962.

Ewing, R.C., and Jercinovic, M.J., 1987, "Natural Analogues: Their Application to the Prediction of the Long-Term Behavior of Nuclear Waste Forms", Materials Research Society Symposium, Vol. 84, Materials Research Society, pp. 67-83.

Foster, A.R. and Wright, R.L., Jr., Basic Nuclear Engineering, $4^{\text {th }}$ edition. Boston: Allyn and Bacon. 1983. 
Gauthier-Lafaye, F. and Weber, F., 1989, "Natural Fission Reactors at Oklo," Economic Geology, Vol. 84, pp. 2286-2295.

Gebhart, B., and Jaluria, Y., Buoyancy Induced Flows and Transport. New York: Hemisphere Publishing. 1988.

Giles, R.V., Evett, J.B. and Liu, C., Schaum's Outline of Theory and Problems of Fluid Mechanics and Hydraulics, $2^{\text {nd }}$ edition. New York: McGraw-Hill. 1992

Haar L., Gallagher, J.S. and Kell, G.S., NBS/NRC Steam Tables- Thermodynamic and Transport Properties and Computer Programs for Vapor and Liquid States of Water in SI Units. New York: Wiley. 1984.

Harms, A.A., Principles of Nuclear Science and Engineering. New York: Wiley. 1987.

Hidaka, H., 1998, "Isotopic Analyses by Using a Sensitive High Resolution Ion MicroProbe (SHRIMP) for Natural Analogue Study of Oklo and Bangombe' Natural Fission Reactors", Radiochim. Acta., Vol. 82, pp. 327-330.

Holliger, P., Devillers, C. and Retali, G., "Evalation des Temperatures Neutroniques Dans Les Zones de Reaction d'Oklo par L'etude des Rapports Isotopiques $\mathrm{Lu}^{176} / \mathrm{Lu}^{175}$ et $\mathrm{Gd}^{156} / \mathrm{Gd}^{155}$ " Les Reacteurs de Fission Naturels, Vienna, International Atomic Energy Agency (1978).

Howard, R., Cardle, J. and Culbreth, W.G., 1998, "Hydrothermal Modeling of the Oklo Natural Reactors", The Proceedings of 1998 International High Level Radioactive Waste Management Conference, American Nuclear Society.

Hughes, W.F. and Brighton, J.A., Schaum's Outline of Theory and Problems of Fluid Dynamics, $2^{\text {nd }}$ edition. New York: McGraw-Hill. 1991.

Incropera, F.P. and DeWitt, D.P., Fundamentals of Heat Transfer. New York: Wiley. 1981.

Incropera, F.P. and DeWitt, D.P., Introduction to Heat Transfer, $2^{\text {nd }}$ edition. New York: Wiley. 1992.

Isobe, H., Ohnuki, T., Murakami, T, and Gauthier-Lafaye, F., 1995, "Uranium Redistribution under Oxidizing Conditions in Oklo Natural Reactor Zone 2, Gabon", Materials Research Society Symposium, Materials Research Society, Vol. 294, pp. 396403.

Jakeman, D., Physics of Nuclear Reactors. New York: American Elsevier Publishing. 1966. 
Kakac, S. and Yener, Y., Heat Conduction, $3^{\text {rd }}$ edition. Washington, D.C.: Taylor and Francis. 1993.

Karam, A., "The Natural Nuclear Reactor at the Oklo: A Comparison with Modern Nuclear Reactors". Retrieved from the Idaho State University, Radiation Information Network's Radioactivity in Nature Web site: http://www.physics.isu.edu/radinf/oklo.htm.

Kastenberg, K. E., P. F. Peterson, J. Ahn, J. Burch, G. Casher, P. L. Chambré, E. Greenspan, D. R. Olander, J. L. Vujic, B. Bessinger, N. G. W. Cook, F. M. Doyle, and L. Brun Hilbert, Considerations of Autocatalytic Criticality of Fissile Materials in Geologic Repositories, Nuclear Tchnology, 115(3), 298-310, 1996.

Kneif, R.A., Nuclear Engineering Technology. New York: McGraw-Hill. 1981.

Kreith, F., Principles of Heat Transfer, $3^{\text {rd }}$ edition. New York: Harper and Row. 1973.

Kuroda, P.K., The Origin of the Chemical Elements and the Oklo Phenomenon. New York: Springer-Verlag. 1982.

Kuroda, P.K., 1990, "The Pre-Fermi Natural Reactor: A Note on the Periodic Mode of Operation", Journal of Radioanalytical and Nuclear Chemistry, January, No. 1, Vol. 142, pp. 101-112.

Kuroda, P.K., 1990, “The Pre-Fermi Natural Reactor", Journal of Radioanalytical and Nuclear Chemistry, January, Vol. 142, January, No. 1, Vol. 142, pp. 113-118.

LaFaye-Gauthier, F. and Weber, F., 1989, "Natural Fission Reactors of Oklo", Economic Geology, Vol. 84, pp. 2286-2295.

Lamarsh, J.R., Introduction to Nuclear Engineering, $2^{\text {nd }}$ edition. New York: AddisonWesley. 1983.

Loss, R.D. and Rosman, K.J.R. et al, 1989, "Fission-Product Retentivity in Peripheral Rocks at the Oklo Natural Fission Reactors, Gabon," Chemical Geology, Vol. 76, pp. 7184.

Meyer, C.A., McClintock, R.B., Silvestri, G.J. and Spencer, R.C. JR. ASME Steam Tables- Thermodynamic and Transport Properties of Steam, $6^{\text {th }}$ edition. New York: ASME Press. 1993.

Menet, C., Menager, M.T. and Petit, J.C., 1992, "Migration of Radioelements Around the New Nuclear Reactors at Oklo: Analogies with a High-Level Waste Repository," Radiochimica Acta, Vol. 58/59, pp. 395-400.

Mooney, D.A., Introduction to Thermodynamics and Heat Transfer. Englewood Cliff: Prentice Hall. 1953. 
Moran, M.J. and Shapiro, H.N., Fundamentals of Engineering Thermodynamics, $2^{\text {nd }}$ edition. New York: Wiley. 1992.

Munsen, B.R., Young, D.F. and Okiishi, T.H., Fundamentals of Fluid Mechanics, $2^{\text {nd }}$ edition. New York: Wiley. 1990.

Murray, R.L., Introduction to Nuclear Engineering, $2^{\text {nd }}$ edition. Englewood Cliffs: Prentice-Hall. 1961.

Murray, R.L., Nuclear Energy, $4^{\text {th }}$ edition. New York: Pergamon Press. 1993.

Murray, R.L., Understanding Radioactive Waste, $4^{\text {th }}$ edition. Columbus: Battelle Press. 1994.

Nagy, B., 1999, “Gabon's Natural Reactors”, Waste Management, February, Vol. 39, pp. 30-31.

R. Naudet, R., 1976, "Etude Parametrique de la Criticite des Reacteurs Naturels," IAEATC-119/22, pp. 589-599.

Naudet, R., 1976, "Prise en Compte des Effets Thermiques Dans L'Etude du Controle et de la Propagation des Reactions Nucleaires," IAEA-TC-119/23, pp. 601-618. Oversby, V.M., 1998, "Criticality in a Repository for Spent Fuel: Lessons from Oklo", Materials Research Society Symposium, Vol. 294, Materials Research Society, pp. 781-788.

Oosthuizen, P.H. and Naylor, D., Introduction to Convective Heat Transfer Analysis. New York: McGraw-Hill. 1999.

Patankar, S.V., Numerical Heat Transfer and Fluid Flow. New York: McGraw-Hill. 1994.

Pitts, D.R. and Sissom, L.E., Schaum's Outline of Theory and Problems of Heat Transfer. New York: McGraw-Hill. 1977.

Ram, K.S., Basic Nuclear Engineering. New York: Wiley. 1977.

Roberson, J.A. and Cassidy, J.J., Hydraulic Engineering, $2^{\text {nd }}$ edition. New York: Wiley. 1998.

Rodney, V.M., 1998, "Criticality in a Repository for Spent Fuel: Lessons from Oklo", Materials Research Society Symposium, Vol. 294, Materials Research Society, pp. 781788. 
Ruffenach, J.C. et al., 1980, "Isotopic Abundances Measurements a Key to Understanding the Oklo Phenomenon", Division de Chimie Centre d'Etudes Nucléaires de Saclay, France, Vol. 35a, pp. 171-179.

Stephenson, R., Introduction to Nuclear Engineering, $2^{\text {nd }}$ edition. New York: McGrawHill. 1958.

Szabo', Gyula et al., "Illite in the Oklo Natural Fission Reactors in Gabon: Considerations for Cs Containment", Materials Research Society Symposium, Vol. 353, Materials Research Society, pp. 1203-1211.

Viggato, J.C., A Study of the Influence of Physical Parameters on the Drying of Porous Media, M.S. Thesis, Mechanical Engineering, University of Nevada, Las Vegas, 1998.

Viessman, W.V., Jr. and Lewis, G.L., Introduction to Hydrology, $4^{\text {th }}$ edition. New York: Harper Collins College. 1996.

Wachspress, E.L., Iterative Solution of Elliptic Systems and Applications to the Neutron Diffusion Equations of Reactor Physics. Englewood Cliffs: Prentice-Hall. 1966.

Warner, C.F., Thermodynamic Fundamentals for Engineers. Patterson: Littlefield, Adams and Co. 1960.

Zumdahl, S.S., Chemistry, $2^{\text {nd }}$ edition. Lexington: Heath. 1989. 


\section{APPENDIX I}

\section{VERIFICATION DATA}

Analytical - Steady State Temperature

\begin{tabular}{llllllllllll}
$\mathrm{x}$ & & & \multicolumn{1}{c}{$\mathrm{y}$} & & & & & & & & \\
& 0 & 0.1 & 0.2 & 0.3 & 0.4 & 0.5 & 0.6 & 0.7 & 0.8 & 0.9 & 1 \\
0 & 0.000 & 0.000 & 0.000 & 0.000 & 0.000 & 0.000 & 0.000 & 0.000 & 0.000 & 0.000 & 100.000 \\
0.1 & 0.000 & 1.094 & 2.302 & 3.755 & 5.623 & 8.159 & 11.802 & 17.452 & 27.395 & 48.906 & 100.000 \\
0.2 & 0.000 & 2.077 & 4.366 & 7.108 & 10.604 & 15.275 & 21.776 & 31.220 & 45.634 & 68.226 & 100.000 \\
0.3 & 0.000 & 2.851 & 5.987 & 9.725 & 14.444 & 20.634 & 28.950 & 40.275 & 55.685 & 75.942 & 100.000 \\
0.4 & 0.000 & 3.344 & 7.017 & 11.378 & 16.841 & 23.906 & 33.159 & 45.228 & 60.604 & 79.232 & 100.000 \\
0.5 & 0.000 & 3.513 & 7.370 & 11.942 & 17.653 & 25.000 & 34.535 & 46.790 & 62.079 & 80.169 & 100.000 \\
0.6 & 0.000 & 3.344 & 7.017 & 11.378 & 16.841 & 23.906 & 33.159 & 45.228 & 60.604 & 79.232 & 100.000 \\
0.7 & 0.000 & 2.851 & 5.987 & 9.725 & 14.444 & 20.634 & 28.950 & 40.275 & 55.685 & 75.942 & 100.000 \\
0.8 & 0.000 & 2.077 & 4.366 & 7.108 & 10.604 & 15.275 & 21.776 & 31.220 & 45.634 & 68.226 & 100.000 \\
0.9 & 0.000 & 1.094 & 2.302 & 3.755 & 5.623 & 8.159 & 11.802 & 17.452 & 27.395 & 48.906 & 100.000 \\
1 & 0.000 & 0.000 & 0.000 & 0.000 & 0.000 & 0.000 & 0.000 & 0.000 & 0.000 & 0.000 & 100.000
\end{tabular}

Oklo_transient - Steady State Temperature

\begin{tabular}{|c|c|c|c|c|c|c|c|c|c|c|c|}
\hline r & & & & & & $y$ & & & & & \\
\hline & 0 & 0.1 & 0.2 & 0.3 & 0.4 & 0.5 & 0.6 & 0.7 & 0.8 & 0.9 & 1 \\
\hline 0 & 0.000 & 0.000 & 0.000 & 0.000 & 0.000 & 0.000 & 0.000 & 0.000 & 0.000 & 0.000 & 100.0 \\
\hline 0.1 & 0.000 & 1.108 & 2.331 & 3.803 & 5.700 & 8.289 & 12.034 & 17.884 & 28.091 & 48.893 & 100.0 \\
\hline 0.2 & 0.000 & 2.099 & 4.412 & 7.180 & 10.708 & 15.420 & 21.965 & 31.410 & 45.588 & 67.479 & 100.0 \\
\hline 0.3 & 0.000 & 2.878 & 6.039 & 9.798 & 14.532 & 20.720 & 28.996 & 40.202 & 55.371 & 75.436 & 100.0 \\
\hline 0.4 & 0.000 & 3.372 & 7.068 & 11.442 & 16.901 & 23.930 & 33.099 & 45.030 & 60.259 & 78.894 & 100.0 \\
\hline 0.5 & 0.000 & 3.541 & 7.420 & 12.001 & 17.701 & 25.000 & 34.439 & 46.560 & 61.740 & 79.882 & 100. \\
\hline 0.6 & 0.000 & 3.372 & 7.068 & 11.442 & 16.901 & 23.930 & 33.099 & 45.030 & 60.259 & 78.894 & \\
\hline 0.7 & 0.000 & 2.878 & 6.039 & 9.798 & 14.532 & 20.720 & 28.996 & 40.202 & 55.371 & 75.436 & \\
\hline 0.8 & 0.000 & 2.099 & 4.412 & 7.180 & 10.708 & 15.420 & 21.965 & 31.410 & 45.588 & 67.479 & 100 \\
\hline 0.9 & 0.000 & 1.108 & 2.331 & 3.803 & 5.700 & 8.289 & 12.034 & 17.884 & 28.091 & 48.893 & \\
\hline 1 & 0.000 & 0.000 & 0.000 & 0.000 & 0.000 & 0.000 & 0.000 & 0.000 & 0.000 & 0.000 & \\
\hline & & & & & & & & & & & \\
\hline$x$ & & & & & & $y$ & & & & & \\
\hline & 0 & 0.1 & 0.2 & 0.3 & 0.4 & 0.5 & 0.6 & 0.7 & 0.8 & 0.9 & 1 \\
\hline 0 & 0.00 & 0.00 & 0.00 & 0.00 & 0.00 & 0.00 & 0.00 & 0.00 & 0.00 & 0.00 & 0.00 \\
\hline 0.1 & 0.00 & 1.23 & 1.25 & 1.27 & 1.37 & 1.59 & 1.97 & 2.47 & 2.54 & 0.03 & 0.00 \\
\hline 0.2 & 0.00 & 1.08 & 1.06 & 1.02 & 0.98 & 0.95 & 0.87 & 0.61 & 0.10 & 1.09 & 0.00 \\
\hline 0.3 & 0.00 & 0.93 & 0.87 & 0.76 & 0.61 & 0.42 & 0.16 & 0.18 & 0.56 & 0.67 & 0.00 \\
\hline 0.4 & 0.00 & 0.82 & 0.73 & 0.56 & 0.36 & 0.10 & 0.18 & 0.44 & 0.57 & 0.43 & 0.00 \\
\hline 0.5 & 0.00 & 0.79 & 0.67 & 0.50 & 0.27 & 0.00 & 0.28 & 0.49 & 0.55 & 0.36 & 0.00 \\
\hline 0.6 & 0.00 & 0.82 & 0.73 & 0.56 & 0.36 & 0.10 & 0.18 & 0.44 & 0.57 & 0.43 & 0.00 \\
\hline 0.7 & 0.00 & 0.93 & 0.87 & 0.76 & 0.61 & 0.42 & 0.16 & 0.18 & 0.56 & 0.67 & 0.00 \\
\hline 08 & 0.00 & 1.08 & 1.06 & 102 & 0.98 & 0.95 & 0.87 & 0.61 & 0.10 & 1.09 & 0.00 \\
\hline 0.9 & 0.00 & 1.23 & 1.25 & 1.27 & 1.37 & 1.59 & 1.97 & 2.47 & 2.54 & 0.03 & 0.00 \\
\hline 1 & 0.00 & 0.00 & 0.00 & 0.00 & 0.00 & 0.00 & 0.00 & 0.00 & 0.00 & 0.00 & 0.00 \\
\hline
\end{tabular}


2-d Analytic $10 \mathrm{sec}$ - Transient Neutron Flux

$\begin{array}{llllllllllll}x & 0.0 & 0.1 & 0.2 & 0.3 & 0.4 & 0.5 & 0.6 & 0.7 & 0.8 & 0.9 & 1.0 \\ 0.0 & 0.000 & 0.000 & 0.000 & 0.000 & 0.000 & 0.000 & 0.000 & 0.000 & 0.000 & 0.000 & 0.000 \\ 0.1 & 0.000 & 27.092 & 43.863 & 50.286 & 51.805 & 52.008 & 51.805 & 50.286 & 43.863 & 27.092 & 0.000 \\ 0.2 & 0.000 & 43.863 & 71.014 & 81.414 & 83.874 & 84.201 & 83.874 & 81.414 & 71.014 & 43.863 & 0.000 \\ 0.3 & 0.000 & 50.286 & 81.414 & 93.336 & 96.156 & 96.532 & 96.156 & 93.336 & 81.414 & 50.286 & 0.000 \\ 0.4 & 0.000 & 51.805 & 83.874 & 96.156 & 99.062 & 99.449 & 99.062 & 96.156 & 83.874 & 51.805 & 0.000 \\ 0.5 & 0.000 & 52.008 & 84.201 & 96.532 & 99.449 & 99.837 & 99.449 & 96.532 & 84.201 & 52.008 & 0.000 \\ 0.6 & 0.000 & 51.805 & 83.874 & 96.156 & 99.062 & 99.449 & 99.062 & 96.156 & 83.874 & 51.805 & 0.000 \\ 0.7 & 0.000 & 50.286 & 81.414 & 93.336 & 96.156 & 96.532 & 96.156 & 93.336 & 81.414 & 50.286 & 0.000 \\ 0.8 & 0.000 & 43.863 & 71.014 & 81.414 & 83.874 & 84.201 & 83.874 & 81.414 & 71.014 & 43.863 & 0.000 \\ 0.9 & 0.000 & 27.092 & 43.863 & 50.286 & 51.805 & 52.008 & 51.805 & 50.286 & 43.863 & 27.092 & 0.000 \\ 1.0 & 0.000 & 0.000 & 0.000 & 0.000 & 0.000 & 0.000 & 0.000 & 0.000 & 0.000 & 0.000 & 0.000\end{array}$

\begin{tabular}{|c|c|c|c|c|c|c|c|c|c|c|c|}
\hline & & & & & & & & & & & \\
\hline & 0.0 & 0.1 & 0.2 & 0.3 & 0.4 & 0.5 & 0.6 & 0.7 & 0.8 & 0.9 & 1.0 \\
\hline 0.0 & 0.000 & 0.000 & 0.000 & 0.000 & 0.000 & 0.000 & 0.000 & 0.000 & 0.000 & 0.000 & 0.000 \\
\hline 0.1 & 0.000 & 29.220 & 45.207 & 51.254 & 53.029 & 53.379 & 53.032 & 51.258 & 45.207 & 29.213 & 0.000 \\
\hline 0.2 & 0.000 & 45.207 & 70.211 & 79.794 & 82.643 & 83.210 & 82.647 & 79.802 & 70.214 & 45.200 & 0.00 \\
\hline 0.3 & 0.000 & 51.254 & 79.794 & 90.825 & 94.133 & 94.796 & 94.139 & 90.835 & 79.801 & 51.250 & 0.0 \\
\hline 0.4 & 0.000 & 53.029 & 82.643 & 94.133 & 97.592 & 98.289 & 97.599 & 94.145 & 82.651 & 53.026 & 0.00 \\
\hline 0.5 & 0.000 & 53.379 & 83.210 & 94.796 & 98.289 & 98.992 & 98.296 & 94.808 & 83.219 & 53.377 & 0.00 \\
\hline 0.6 & 0.000 & 53.032 & 82.647 & 94.139 & 97.599 & 98.296 & 97.606 & 94.150 & 82.656 & 53.029 & 0.00 \\
\hline 0.7 & 0.000 & 51.258 & 79.802 & 90.835 & 94.145 & 94.808 & 94.150 & & & 51.252 & \\
\hline 0.8 & 0.000 & 45.207 & 70.214 & 79.801 & 82.651 & 83.219 & 82.656 & 79.807 & 70.216 & 45.199 & 0.00 \\
\hline 0.9 & 0.000 & 29.213 & 45.200 & 51.250 & 53.026 & 53.377 & 53.029 & 51.252 & 45.199 & 29.207 & \\
\hline. & 0.000 & 0.000 & 0.000 & 0.000 & 0.000 & 0.000 & 0.000 & 0.000 & 0.000 & 0.000 & 0.00 \\
\hline
\end{tabular}

01

$\%$ Error - $10 \mathrm{sec}$

\begin{tabular}{|c|c|c|c|c|c|c|c|c|c|c|c|}
\hline$x$ & \multicolumn{6}{|c|}{$y$} & & & & & \\
\hline & 0.0 & 0.1 & 0.2 & 0.3 & 0.4 & 0.5 & 0.6 & 0.7 & 0.8 & 0.9 & 1.0 \\
\hline 0.0 & 0.000 & 0.000 & 0.000 & 0.000 & 0.000 & 0.000 & 0.000 & 0.000 & 0.000 & 0.000 & 0.000 \\
\hline 0.1 & 0.000 & 7.856 & 3.064 & 1.925 & 2.363 & 2.637 & 2.368 & 1.933 & 3.064 & 7.830 & 0.000 \\
\hline 0.2 & 0.000 & 3.064 & 1.130 & 1.990 & 1.468 & 1.177 & 1.462 & 1.981 & 1.126 & 3.048 & 0.000 \\
\hline 0.3 & 0.000 & 1.925 & 1.990 & 2.690 & 2.104 & 1.798 & 2.098 & 2.679 & 1.982 & 1.916 & 0.000 \\
\hline 0.4 & 0.000 & 2.363 & 1.468 & 2.104 & 1.484 & 1.167 & 1.477 & 2.092 & 1.458 & 2.358 & 0.000 \\
\hline 0.5 & 0.000 & 2.637 & 1.177 & 1.798 & 1.167 & 0.846 & 1.160 & 1.786 & 1.166 & 2.632 & 0.000 \\
\hline 0.6 & 0.000 & 2.368 & 1.462 & 2.098 & 1.477 & 1.160 & 1.470 & 2.086 & 1.453 & 2.362 & 0.000 \\
\hline 0.7 & 0.000 & 1.933 & 1.981 & 2.679 & 2.092 & 1.786 & 2.086 & 2.669 & 1.974 & 1.922 & 0.000 \\
\hline 0.8 & 0.000 & 3.064 & 1.126 & 1.982 & 1.458 & 1.166 & 1.453 & 1.974 & 1.124 & 3.046 & 0.000 \\
\hline 0.9 & 0.000 & 7.830 & 3.048 & 1.916 & 2.358 & 2.632 & 2.362 & 1.922 & 3.046 & 7.806 & 0.000 \\
\hline 1.0 & 0.000 & 0.000 & 0.000 & 0.000 & 0.000 & 0.000 & 0.000 & 0.000 & 0.000 & 0.000 & 0.000 \\
\hline
\end{tabular}


VITA

\author{
Graduate College \\ University of Nevada, Las Vegas \\ Jason Charles Viggato
}

Local Address:

University of Nevada, Las Vegas

Department of Mechanical Engineering

4505 Maryland Parkway

Las Vegas, NV 89154

\title{
Degrees:
}

Bachelor's Degree, Mechanical Engineering, 1996

State University of New York College at Buffalo

Master of Science, Mechanical Engineering, 1998

University of Nevada, Las Vegas

Publications:

Determination of the Depth and Pressure Within the Oklo Natural Reactors.

Thesis Title: A Study of the Influence of Physical Parameters on the Drying of Porous Media

Dissertation Title: Thermohydraulic Modeling of Natural Fission Reactors

Dissertation Committee:

Chairperson, Dr. William Culbreth, Ph.D.

Committee Member, Dr. Robert Boehm, Ph.D.

Committee Member, Dr. Yi-Tung Chen, Ph.D.

Committee Member, Dr. George Miel, Ph.D.

Committee Member, Dr. Darrell Pepper, Ph.D. 